El jurado asignado por la División de Ciencias Biológicas y de la Salud de la Unidad Iztapalapa aprobó la tesis:

\title{
DEFENSA ANTIOXIDANTE DURANTE LA REMOCIÓN DE UNA MEZCLA DE HIDROCARBUROS POR LA ASOCIACIÓN INDUCIDA ENTRE Festuca arundinacea Y Lewia sp.
}

\author{
Que presentó la estudiante
}

M en B. CALIOPE MENDARTE ALQUISIRA

Comité tutorial

Directora: Dra. Tania L. Volke Sepúlveda

Asesor interno: Dr. Mariano Gutiérrez Rojas

Asesor externo: Dr. Humberto González Márquez

Jurado

Presidente: Dr. Mariano Gutiérrez Rojas

Secretario: Humberto González Márquez

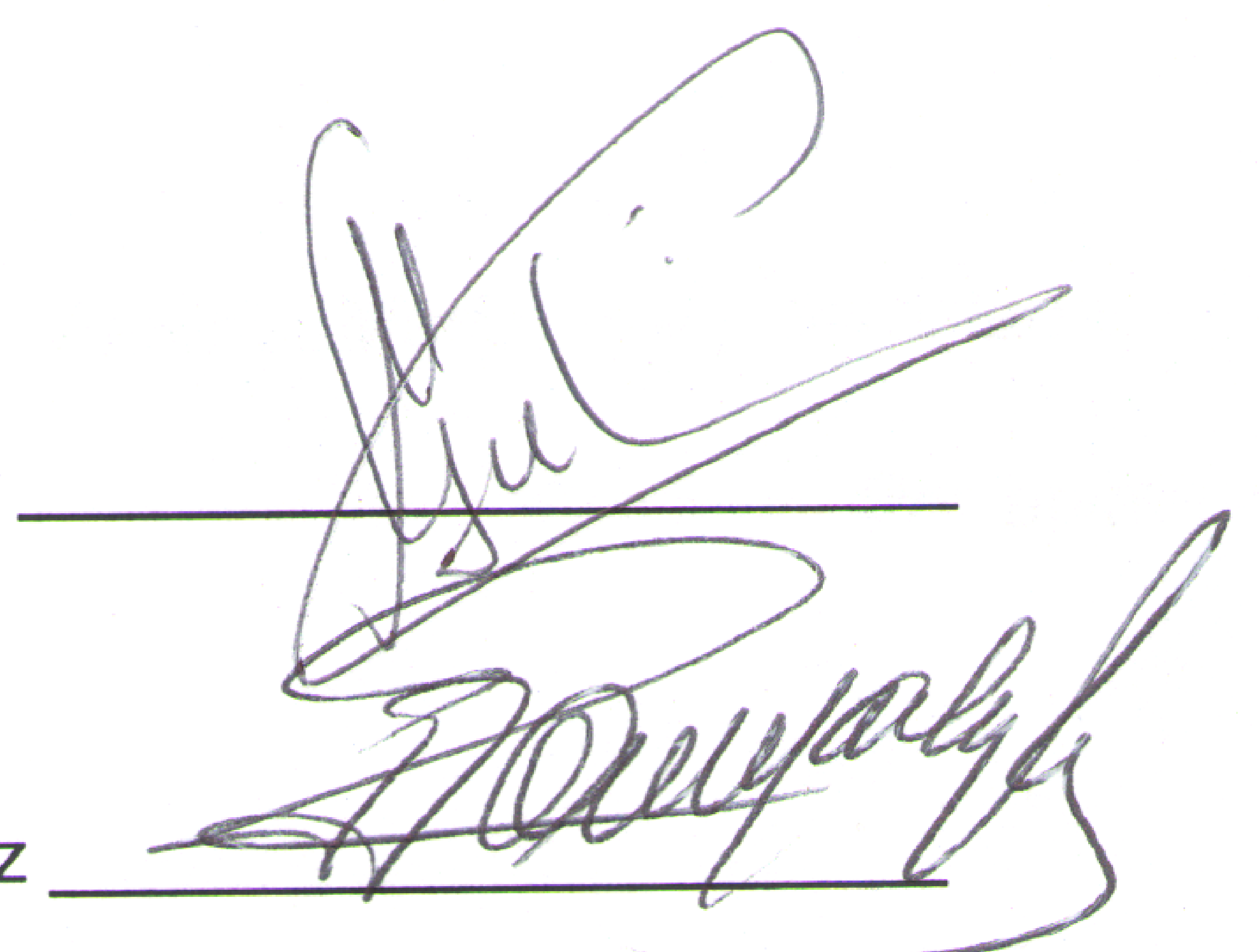

Vocal: Erika Escalante Buendía

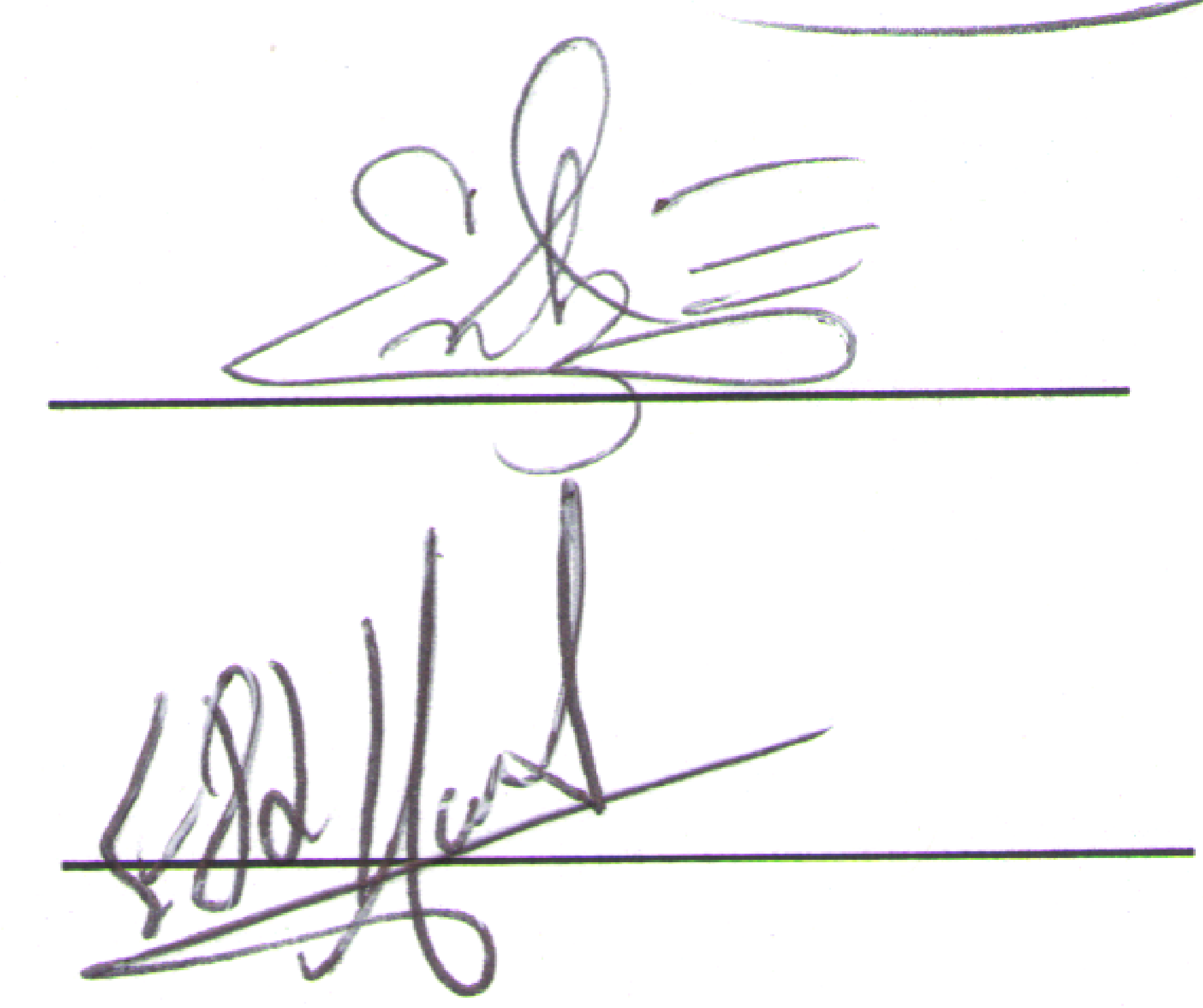

Vocal: Fernando Díaz de León Sánchez 


\title{
UNIVERSIDAD AUTÓNOMA METROPOLITANA
}

\section{IZTAPALAPA}

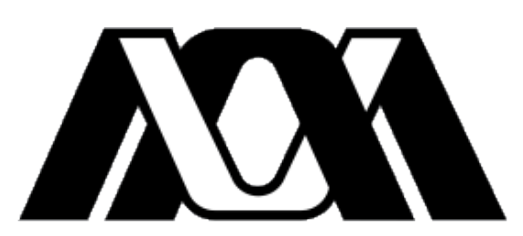

Casa abierta al tiempo

DIVISIÓN DE CIENCIAS BIOLÓGICAS Y DE LA SALUD

Departamento de Biotecnología

DEFENSA ANTIOXIDANTE DURANTE LA REMOCIÓN DE UNA MEZCLA DE HIDROCARBUROS POR LA ASOCIACIÓN INDUCIDA ENTRE

Festuca arundinacea Y Lewia sp.

\author{
TESIS \\ Para obtener el grado de \\ DOCTORA EN BIOTECNOLOGÍA \\ Presenta: \\ CALIOPE MENDARTE ALQUISIRA \\ Directora \\ Asesor \\ Asesor
}

Comité tutorial:

Dra. Tania L. Volke Sepúlveda

Dr. Mariano Gutiérrez Rojas

Dr. Humberto González Márquez 
El Doctorado en Biotecnología de la Universidad Autónoma Metropolitana Unidad Iztapalapa está incluida en el Padrón Nacional de Posgrados (PNPC) del CONACYT en el nivel de Competencia Internacional, y además cuenta con el apoyo del mismo consejo con el No. de referencia 001466. 
El jurado asignado por la División de Ciencias Biológicas y de la Salud de la Unidad Iztapalapa aprobó la tesis:

\title{
DEFENSA ANTIOXIDANTE DURANTE LA REMOCIÓN DE UNA MEZCLA DE HIDROCARBUROS POR LA ASOCIACIÓN INDUCIDA ENTRE \\ Festuca arundinacea Y Lewia sp.
}

\author{
Que presentó la estudiante \\ M en B. CALIOPE MENDARTE ALQUISIRA
}

Comité tutorial

Directora: Dra. Tania L. Volke Sepúlveda

Asesor interno: Dr. Mariano Gutiérrez Rojas

Asesor externo: Dr. Humberto González Márquez

Jurado

Presidente: Dr. Mariano Gutiérrez Rojas

Secretario: Humberto González Márquez

Vocal: Erika Escalante Buendía

Vocal: Fernando Díaz de León Sánchez 


\section{DEDICATORIA}

A Dios todopoderoso:

Quien nos muestras su amor en la naturaleza y me ciñe de conocimiento

A mi madre:

\section{Olga Lidia}

Por su amor incondicional

A mis hermanas:

$$
\text { Danae y Calipso }
$$

Por su inmenso amor y vivencias

A mis sobrinos:

$$
\text { Osmara, Yael y Alcides }
$$

Por sus enseñanzas

A mis abuelitos:

$$
\text { Celsa y Everardo }
$$

Por su ternura y cariño

A mis tíos y primos:

Elvira, Mario, Fabiola, Alberto, Mario, Isaí y Miroslaba

Por animarme a continuar

Al resto de mi familia:

Por estar ahí 


\section{AGRADECIMIENTOS}

A la Dra. Tania L. Volke, por dirigir este proyecto.

Especialmente a los doctores Mariano Gutiérrez Rojas y Humberto González Márquez por su gran apoyo y consejos para mi crecimiento personal y profesional.

A todos los compañeros de los laboratorios W-103 y W-108.

A las amigas y amigos que siempre me escucharon: Lizbeth Morales, Leisy Mariela, Esperanza Jazmín, Tania Anayansi, Fabiola y Luis Daniel.

Especialmente al doctor César C. Rojas Loria, por ser un hombre extraordinario y estar siempre.

A Carlos Francisco Millán Medina, por ser mi amigo incondicional.

A Beatriz Salazar la secretaria del laboratorio, por sus consejos y apoyo administrativo. 


\section{RESUMEN}

La fitorremediación asistida por microorganismos endófitos es una tecnología que permite la recuperación de sitios contaminados con compuestos orgánicos. La eficiencia de esta tecnología puede mejorarse a través del establecimiento de asociaciones endófitas entre plantas y microorganismos tolerantes que degraden o estabilicen contaminantes particulares. Para lo anterior, es posible inducir la asociación en condiciones in vitro, permitiendo su establecimiento antes de su uso en sitios contaminados. El objetivo de este trabajo fue evaluar el efecto de Lewia sp., un ascomiceto, en la asociación endófita inducida con Festuca arundinacea sobre el control del estrés oxidante durante la remoción de una mezcla de hidrocarburos (MHC) en un suelo modelo. Para lo anterior, primero se establecieron las condiciones para inducir la asociación endófita y determinar la tolerancia de los organismos a concentraciones crecientes de la MHC, compuesta por hexadecano, fenantreno y pireno, en un suelo modelo. Posteriormente, plantas solas y asociadas se expusieron a una concentración fija de la MHC $\left(800 \mathrm{mg} \mathrm{kg}^{-1}\right)$ durante 45 días, para cuantificar el daño oxidante, la defensa antioxidante y la remoción de la MHC. El medio de cultivo que permitió el mejor desarrollo de plantas, fue el medio con sales completas de Murashige y Skoog adicionado con $10 \mathrm{~g} \mathrm{~L}^{-1}$ de sacarosa. En este mismo medio, fue posible inducir la asociación endófita planta-hongo en 15 días, obteniendo plantas visiblemente sanas. Al término del periodo de inducción de la asociación en condiciones in vitro (15 días), el hongo incrementó significativamente el crecimiento vegetal, la concentración de $\mathrm{H}_{2} \mathrm{O}_{2}$ y de malondialdehído, y causó la disminución de la actividad glutatión S-transferasa (GST). Estas respuestas permitieron que Lewia sp. mejorara la tolerancia de las plantas a la MHC en un suelo modelo. La asociación de $F$. arundinacea con Lewia sp. incrementó el crecimiento y la remoción de hexadecano y pireno en el suelo modelo contaminado a través de una disminución en el estrés oxidante en las plantas expuestas a la MHC.

Palabras clave: asociación endófita · Festuca arundinacea · hidrocarburos · Lewia sp. · estrés oxidante $\cdot$ defensa antioxidante. 


\begin{abstract}
Endophyte-assisted phytoremediation is a technology that allows the recovery of sites contaminated with organic compounds. The efficiency of this technology can be improved through the establishment of endophytic associations between tolerant plants and microorganisms that degrade or stabilize particular contaminants. For this, it is possible to induce the association under in vitro conditions, allowing its establishment before its use in contaminated sites. The aim of this work was to evaluate the effect of Lewia sp., an ascomycete, on the endophytic association induced with Festuca arundinacea on the control of oxidative stress during the removal of a hydrocarbon mixture (HCM) in a model soil. Thus, we first established the conditions to induce the endophytic association and to determine the tolerance of organisms to different concentrations of HCM, which was composed of hexadecane, phenanthrene and pyrene, in a model soil. Subsequently, endophyte-free and endophyte-associated plants were exposed to $800 \mathrm{mg} \mathrm{kg}^{-1}$ of HCM for 45 days, allowing to quantify oxidant damage, antioxidant defense and HCM removal. The culture medium that allowed obtaining healthy plants was the Murashige and Skoog medium with complete salts and $10 \mathrm{~g} \mathrm{~L}^{-1}$ of sucrose added. With this same medium, it was possible to induce the plantfungus endophytic association in 15 days, obtaining visibly healthy plants. After the induction period under in vitro conditions (15 days), the fungus significantly increased plant growth, as well as $\mathrm{H}_{2} \mathrm{O}_{2}$ and malondialdehyde concentration and, caused a decrease in glutathione S-transferase (GST) activity. These responses led to an improvement in plant tolerance to the HCM in a model soil by fungus effect. The association of $F$. arundinacea with Lewia sp. increased the growth and the removal of hexadecane and pyrene in the model soil through of a decrease in the oxidative stress in plants exposed to HCM.
\end{abstract}

Key words: endophytic association - Festuca arundinacea - hydrocarbons · Lewia sp. . oxidative stress $\cdot$ antioxidant defense. 


\section{LISTA DE ABREVIATURAS}

APX: Ascorbato peroxidasa

ASC: Ascorbato

CAT: Catalasa

$\mathrm{Cl}_{50}$ : Concentración inhibitoria media

DHA: Dehidroascorbato

DHAR: Dehidroascorbato reductasa

EPA: Environmental Protection Agency

ERO: Especies reactivas de oxígeno

FE: Factor de estabilización

FT: Factor de translocación

Grupos CO: Grupos carbonilo

GR: Glutatión reductasa

GSSG: Glutatión disulfuro

GSH: Glutatión

GST: Glutatión S-transferasa

HAP: Hidrocarburos aromáticos policíclicos

$\mathrm{H}_{2} \mathrm{O}_{2}$ : Peróxido de hidrógeno

HXD: Hexadecano

IT: Índice de tolerancia
MDHA: Mono-dehidroascorbato

MDHAR: Mono-dehidroascorbato reductasa

\section{NADPH-oxidasas:}

${ }^{1} \mathrm{O}_{2}$ : Oxígeno singulete

$\cdot \mathrm{O}_{2}{ }^{-}$: Radical superóxido

•OH: Radical hidroxilo

PEMEX: Petróleos Mexicanos

PF: Peso fresco

PHE: Fenantreno

PS: Peso seco

POD: Peroxidasas no específicas

PPO: Polifenol oxidasas

PROFEPA: Procuraduría Federal de

Protección Ambiental

PYR: Pireno

RP: Residuo peligroso

SEMARNAT: Secretaría de Medio Ambiente y Recursos Naturales

SOD: Superóxido dismutasa 


\section{ÍNDICE GENERAL}

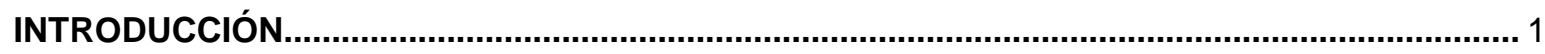

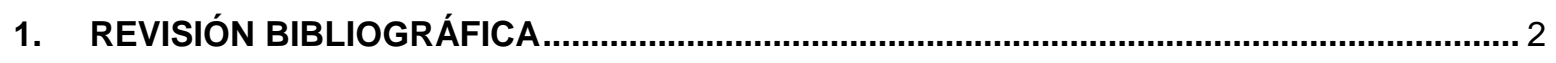

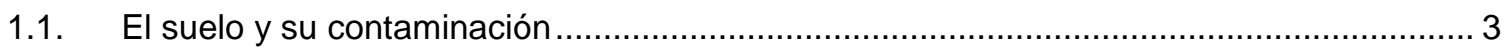

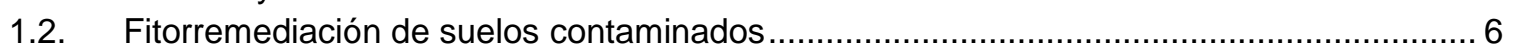

1.3. Producción de especies reactivas de oxígeno (ERO) y estrés oxidante ........................... 9

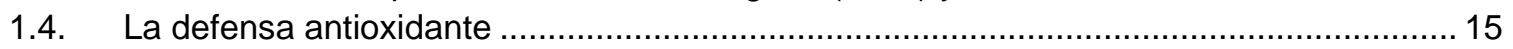

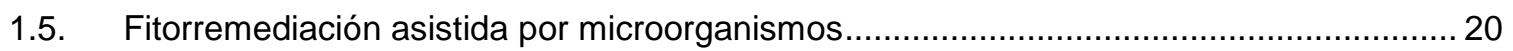

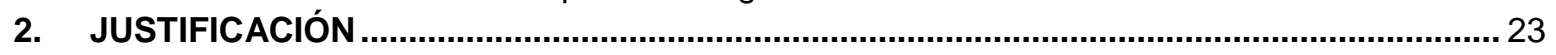

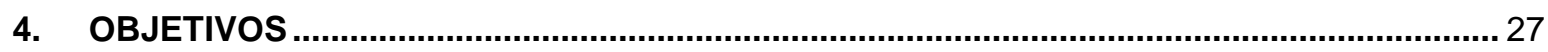

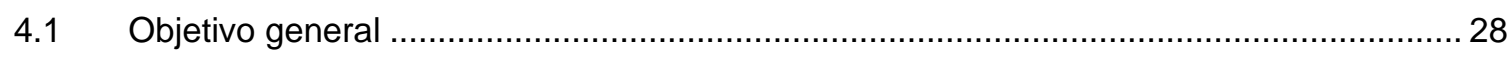

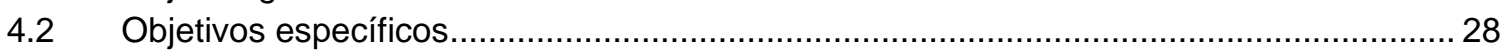

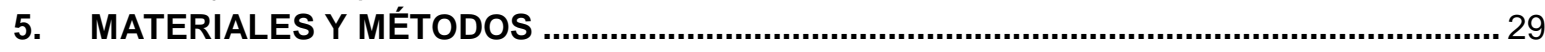

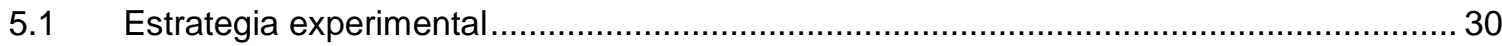

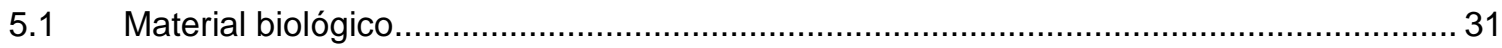

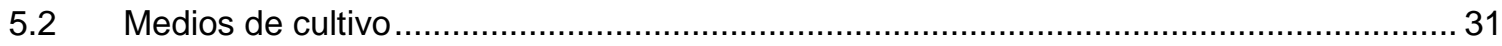

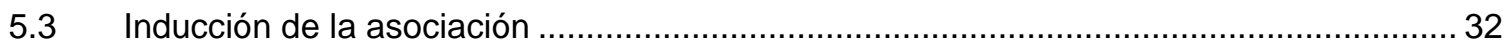

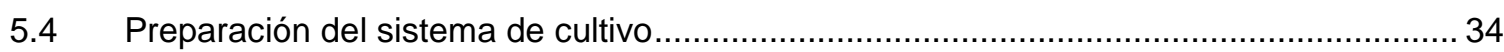

5.5 Determinación de la tolerancia a una mezcla de hidrocarburos ...................................... 34

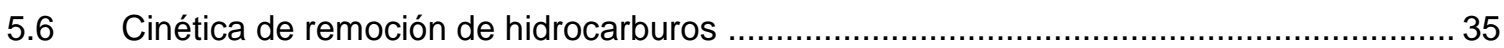

5.7 Determinación de la supervivencia y el crecimiento ..................................................... 36

5.8 Preparación de extractos crudos libres de células.......................................................... 37

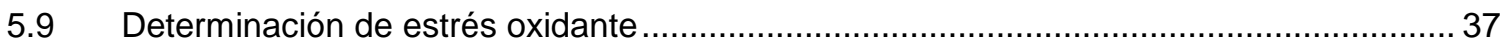

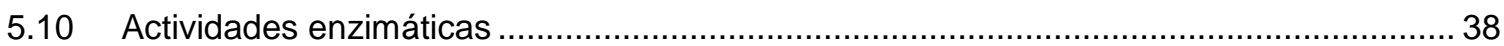

5.10.4 Estimación de índices relativos de actividad enzimática .............................................. 39

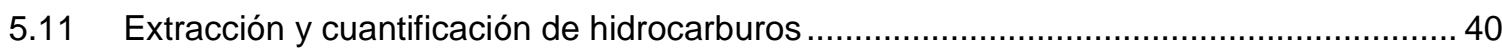

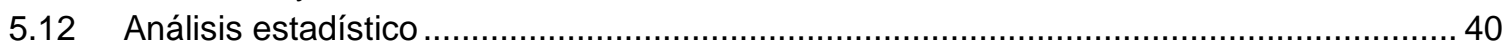

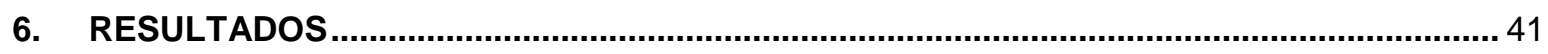

6.1 Establecimiento de la asociación F. arundinacea-Lewia sp. ....................................... 42

6.2 Efecto de la asociación endófita sobre F. arundinacea ................................................. 45

6.3 Evaluación de la tolerancia a hidrocarburos en un suelo modelo..................................... 49

6.4 Efecto de una mezcla de hidrocarburos sobre $F$. arundinacea y la asociación endófita.. 61

6.5 Influencia de Lewia sp. sobre plantas de $F$. arundinacea expuestas a hidrocarburos .... 70

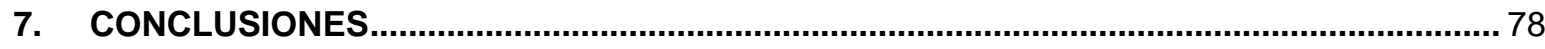

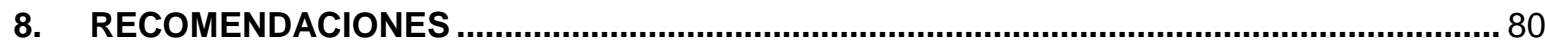

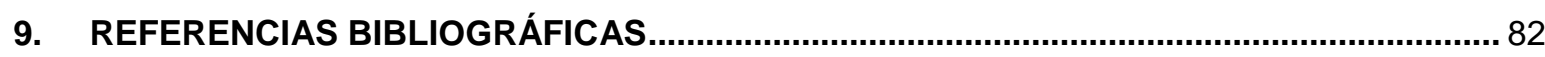

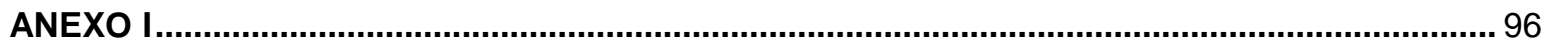

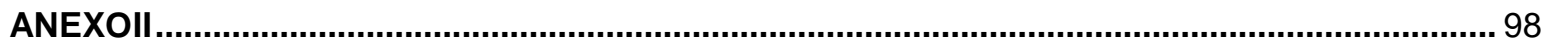

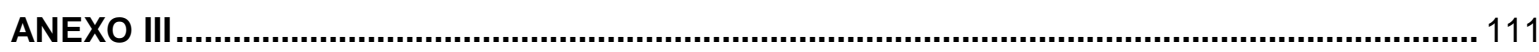




\section{ÍNDICE DE TABLAS}

Tabla 1. Estructura molecular, nombre, masa molecular y solubilidad en agua a $25^{\circ} \mathrm{C}$ de los $16 \mathrm{HAP}$ considerados contaminantes prioritarios por la EPA.

Tabla 2. Concentración de sacarosa y de nutrientes, y relación carbono/nitrógeno $(\mathrm{C} / \mathrm{N})$ resultante para los medios de cultivo en los tratamientos. .....

Tabla 3. Concentraciones iniciales teóricas y disponibles de la mezcla de hidrocarburos (MHC) añadida al suelo modelo para la evaluación de la tolerancia.

Tabla 4. Efecto de la inducción de la asociación endófita entre F. arundinacea y Lewia sp. sobre la acumulación de $\mathrm{H}_{2} \mathrm{O}_{2}$ y el daño oxidante (MDA y CO), después de 15 días de contacto.

Tabla 5. Efecto de la inducción de la asociación endófita entre $F$. arundinacea y Lewia sp. sobre la defensa antioxidante (SOD, POD y GST).

Tabla 6. Correlación entre la remoción de hexadecano (HXD), fenantreno (PHE) y pireno (PYR) y los diferentes parámetros determinados.

Tabla 7. Contenido de $\mathrm{H}_{2} \mathrm{O}_{2}$ en $F$. arundinacea y la asociación endófita $F$. arundinacea-Lewia sp. creciendo con y sin $800 \mathrm{mg} \mathrm{kg}^{-1}$ de la MHC en suelo modelo.

Tabla 8. Daño oxidante medido como contenido de malondialdehído (MDA) y proteínas oxidadas (grupos $\mathrm{CO}$ ) en $F$. arundinacea y la asociación endófita $F$. arundinacea-Lewia sp. creciendo con y $\sin 800 \mathrm{mg} \mathrm{kg}^{-1}$ de la MHC en suelo modelo. 


\section{ÍNDICE DE FIGURAS}

Figura 1. Formas de reducción del oxígeno en sistemas biológicos (Li y Moore 2007)................ 10

Figura 2. Radical libre del carbono centrado en una cadena lateral de ácidos grasos poliinsaturados

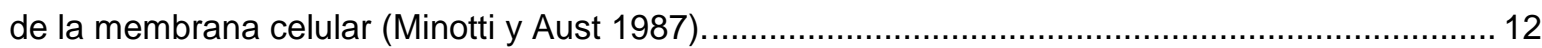

Figura 3. Representación del ciclo ASC-GSH o de Halliwell-Asada (Singh y col. 2012)................ 18

Figura 4. Reciclaje de glutatión (Almroth y col. 2008) ............................................................ 19

Figura 5. Estrategia experimental general utilizada para cumplir los objetivos del proyecto. ......... 30

Figura 6. Criterios para la división de las raíces y tallos para verificar la endofiticidad de Lewia sp.

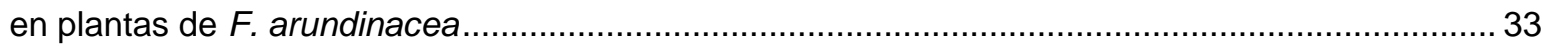

Figura 7. Criterios considerados para cuantificar la longitud de las raíces y tallos. ...................... 36

Figura 8. Índice de germinación acumulado de semillas de $F$. arundinacea. ................................. 43

Figura 9. Tiempo de formación de la asociación F. arundinacea-Lewia sp.................................... 44

Figura 10. Efecto de la asociación entre $F$. arundinacea y Lewia sp. sobre la producción de biomasa

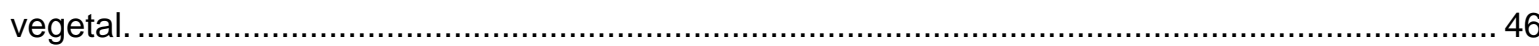

Figura 11. Supervivencia de $F$ arundinacea y la asociación $F$. arundinacea-Lewia sp. expuestas a diferentes concentraciones de la MHC.

Figura 12. Elongación de raíces y tallos de $F$ arundinacea y la asociación $F$. arundinacea-Lewia sp.después de la exposición a diferentes concentraciones de la MHC. 52 Figura 13. Producción de biomasa de raíces y tallos de $F$ arundinacea y la asociación $F$. arundinacea-Lewia sp. expuestas a diferentes concentraciones de la MHC. 55

Figura 14. Concentración de clorofila a y clorofila $b$ en $F$ arundinacea y la asociación $F$. arundinaceaLewia sp. después de la exposición a diferentes concentraciones de la MHC. 56 Figura 15. Índices de tolerancia de F. arundinacea y la asociación F. arundinacea-Lewia sp.

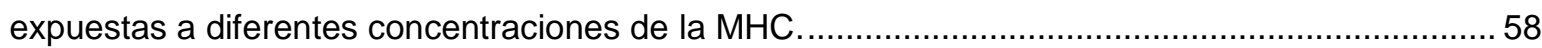

Figura 16. Supervivencia e incidencia de clorosis de $F$. arundinacea en medios de cultivo concentrados $3,4,5$ y 6 veces. 59

Figura 17. Elongación y producción de biomasa de raíces y tallos de $F$. arundinacea en medio de cultivo MS con las sales concentradas 3, 4, 5 y 6 veces.

Figura 18. Producción de biomasa en raíces y tallos de $F$. arundinacea y la asociación entre $F$. arundinacea y Lewia sp. expuestas a $800 \mathrm{mg} \mathrm{kg}^{-1}$ de la MHC en el suelo modelo. 61

Figura 19. Efecto del tiempo de exposición a $800 \mathrm{mg} \mathrm{kg}^{-1}$ de la $\mathrm{MHC}$ sobre el contenido de malondialdehído de $F$. arundinacea y la asociación $F$. arundinacea-Lewia sp. 63

Figura 20. Efecto del tiempo de exposición a $800 \mathrm{mg} \mathrm{kg}^{-1}$ de la $\mathrm{MHC}$ sobre las actividades SOD y POD de $F$. arundinacea y la asociación $F$. arundinacea-Lewia sp. 64

Figura 21. Efecto del tiempo de exposición a $800 \mathrm{mg} \mathrm{kg}^{-1}$ de la MHC sobre la actividad GST de $F$. arundinacea y la asociación $F$. arundinacea-Lewia sp. 66 
Figura 22. Remoción de hexadecano (HXD), fenantreno (PHE) y pireno (PYR) por F. arundinacea y F. arundinacea asociada con Lewia sp......

Figura 23. Producción de biomasa de $F$. arundinacea y $F$. arundinacea asociada con Lewia sp. expuesta o no a $800 \mathrm{mg} \mathrm{kg}^{-1}$ de hidrocarburos (MHC).

Figura 24. Actividades SOD y POD de F. arundinacea creciendo asociada o no con Lewia sp. en un suelo modelo conteniendo o no $800 \mathrm{mg} \mathrm{kg}^{-1}$ de una MHC. 74

Figura 25. Actividad enzimática relativa de SOD y POD de $F$. arundinacea creciendo no asociada 0 asociada con Lewia sp. en un suelo modelo contaminado con una MHC. ....................................... 75 Figura 26. Actividad GST de F. arundinacea creciendo no asociadas o asociadas con Lewia sp. en un suelo modelo conteniendo o no $800 \mathrm{mg} \mathrm{kg}^{-1}$ de una MHC. ..................................................... 76

Figura 27. Actividad enzimática relativa GST de $F$. arundinacea creciendo no asociada o asociada con Lewia sp. en un suelo modelo contaminado con una MHC 


\section{INTRODUCCIÓN}

El asentamiento de las poblaciones ha provocado el aumento de la contaminación y en especial, la debida a hidrocarburos, como los alifáticos, aromáticos policíclicos (HAP) y otros hidrocarburos derivados del petróleo. Estos compuestos poseen características tóxicas para los organismos, ya que tienen propiedades mutagénicas y carcinogénicas. Lo anterior ha conducido a las autoridades ambientales a promover el desarrollo de tecnologías eficientes y económicamente factibles que permitan su eliminación del ambiente. De hecho, se ha demostrado que la remoción de HAP es más rápida en suelos con vegetación en crecimiento, comparado con suelos sin vegetación. La fitorremediación es una alternativa tecnológica, en la que se aprovecha la capacidad de las plantas para extraer, degradar, volatilizar y/o estabilizar contaminantes del aire, agua y suelo. Durante las últimas décadas, se han encontrado varias especies de gramíneas (Poaceae) eficaces para la fitorremediación de suelos contaminados con hidrocarburos alifáticos y HAP. Una de las más estudiadas y utilizadas para tal fin es Festuca arundinacea. Recientemente, se demostró que la asociación de esta planta con el hongo endófito Lewia sp. mejora la eficiencia de la fitorremediación. Sin embargo, aún no se conoce el papel de Lewia sp. en el aumento de la tolerancia a HAP en $F$. arundinacea.

En este trabajo se evaluaron varias condiciones para la producción de plantas de $F$. arundinacea y para inducir su asociación endófita con Lewia sp. en un medio semisólido, seleccionando las mejores condiciones para el establecimiento de la asociación en un periodo de 15 días. Posteriormente se evaluó la tolerancia de la planta y la asociación planta-hongo a una mezcla definida de hidrocarburos en un suelo modelo. Asimismo, se determinó la influencia del endófito sobre el estrés oxidante y la defensa antioxidante de la planta al final del periodo de infección ( 15 días), así como durante 45 días de exposición a una mezcla de hidrocarburos.

En el primer capítulo de este documento se presenta una revisión bibliográfica que, de manera general, aborda el tema de la contaminación de suelos por hidrocarburos, la fitorremediación como una alternativa para su remediación. Se presentan también los aspectos más relevantes acerca del daño oxidante causado por los contaminantes y la defensa antioxidante involucrada en la detoxificación. En seguida, se bosqueja el problema a partir del cual se plantea la hipótesis a demostrar y los objetivos a cumplir. En el capítulo cinco se presenta la estrategia experimental general y se detallan los materiales y métodos utilizados para alcanzar los objetivos. En el capítulo seis se presentan y discuten los resultados obtenidos. Finalmente se exponen las conclusiones del trabajo y las recomendaciones para futuros estudios. 


\section{REVISIÓN BIBLIOGRÁFICA}




\subsection{El suelo y su contaminación}

El suelo (del latín "solum" que significa piso) es definido como la capa superior de la Tierra que se distingue de la roca sólida y es el sitio donde las plantas se establecen. Los suelos son formaciones geológicas naturales y desarrolladas bajo condiciones diversas de clima y materiales de origen, y están en constante evolución, lo que justifica su gran variedad (Navarro 2003).

Independientemente de su origen, el suelo tiene la función de soportar vegetales y poblaciones de organismos (macro y micro) y, por ello, el suelo debe tener las condiciones necesarias para su desarrollo. Con este enfoque, el suelo puede definirse como la mezcla de partículas sólidas pulverulentas, de agua y de aire. El suelo puede, entonces, considerarse como un sistema disperso, constituido por tres fases (sólida, líquida y gaseosa), siendo posible distinguir cuatro componentes: compuestos minerales, orgánicos, agua y aire, íntimamente ligados, mezclados entre sí y originando un medio ideal para el desarrollo de los organismos y el crecimiento de las plantas (Navarro 2003).

\subsubsection{Contaminación del suelo}

La contaminación es un cambio dañino en las características químicas, físicas y biológicas del agua, aire y suelo, comúnmente conducen al detrimento en el desarrollo de los organismos que habitan esos sitios (Lucho-Constantino y col. 2005). En particular, la contaminación del suelo aumenta como resultado de su explotación, el asentamiento de poblaciones y las actividades antropogénicas, lo que ha provocado el aumento de residuos que llegan al agua, aire y suelo. Particularmente en México, como consecuencia de años de actividad minera y, posteriormente, debido a las actividades industriales (farmacéutica, química básica y petrolera) se han producido grandes cantidades de residuos peligrosos (RP) (Lucho-Constantino y col. 2005). La generación de RP se ha incrementado en los últimos años. Tan sólo en el periodo del 2004 al 2011 se reportaron 1.92 millones de toneladas de RP resultantes de 68,733 empresas en toda la República Mexicana (SEMARNAT 2013). Además, el manejo inadecuado de los RP, el uso industrial de suelo y las emergencias ambientales afectan de manera inmediata la salud humana. De acuerdo con datos de la Procuraduría Federal de Protección al Ambiente (PROFEPA), en el 2015 se presentaron 1,562 emergencias ambientales, de las cuales el $85.2 \%$ fueron provocadas por derrames de hidrocarburos.

\subsubsection{Contaminación de suelos por hidrocarburos}

Hasta 2016, en México, Petróleos Mexicanos (PEMEX) ha sido el monopolio a cargo de las actividades de exploración, transformación almacenamiento y distribución de petróleo crudo y sus derivados. La mala disposición o manejo de petróleo crudo y de sus derivados impacta negativamente sobre la calidad del ambiente, provocando contaminación en el aire, agua y suelo. 
En el país, tan sólo en 2015, se tenían identificadas 1162 hectáreas de suelo contaminado con petróleo y sus derivados (PEMEX 2016).

El petróleo está formado principalmente por hidrocarburos, que están constituidos esencialmente por átomos de carbono (76 a 86\%) e hidrógeno (10 a 14\%). Se conoce una gran diversidad de hidrocarburos alifáticos y aromáticos policíclicos (Lee y col. 2008). Los hidrocarburos alifáticos son cadenas sencillas de carbono e hidrógeno y también se conocen como hidrocarburos saturados, ya que sólo presentan un enlace entre carbono e hidrógeno. Los hidrocarburos aromáticos policíclicos (HAP) se encuentran compuestos por dos o más anillos de benceno fusionados que comparten dos átomos de carbono. Los HAP se encuentran distribuidos en el suelo porque, además de que provienen de fuentes pirogénicas, por su estructura, pueden quedar retenidos durante años en los suelos (Lee y col. 2008).

Uno de los hidrocarburos alifáticos en los residuos de diésel es el hexadecano $\left(\mathrm{C}_{16} \mathrm{H}_{34} ; 226.4 \mathrm{~g} \mathrm{~mol}^{-}\right.$ 1; solubilidad en agua a $25^{\circ} \mathrm{C}$ : $\left.9 \times 10^{-4} \mathrm{mg} \mathrm{L}^{-1}\right)$ (Krummenacher y col. 2003). Éstos han sido señalados por las normas mexicanas como peligrosos (Ferrera-Cerrato y col. 2007). Por otra parte, los efectos de los HAP sobre los organismos están relacionados con su tamaño y estructura. De acuerdo a la Agencia de Protección Ambiental de los Estados Unidos (EPA, por sus siglas en inglés), se ha reportado el potencial mutagénico y carcinogénico de 16 HAP sobre los seres humanos (Lee y col. 2008) (Tabla 1). El comportamiento de los HAP en el suelo depende de sus propiedades físicas y químicas, además de las características del suelo donde se encuentran. Todas las propiedades antes mencionadas son el conjunto que define el tamaño y la distribución de la contaminación en una zona específica cuando existen derrames de petróleo.

El derrame del petróleo y sus derivados produce una contaminación constante de suelos que son utilizados para el cultivo de productos agrícolas de consumo humano, representando un gran peligro para la salud pública, ya que los HAP pueden introducirse en estos productos (Lee y col. 2008). Debido a los daños que los HAP pueden causar a la salud, en México se han tomado medidas de saneamiento en los sitios contaminados; para tal propósito, por varias décadas, se han investigado diversas técnicas (Ferrera-Cerrato y col. 2007).

El saneamiento o detoxificación de los sitios contaminados requiere de investigación, innovación y/o adaptación de tecnologías que sean amigables con el ambiente y de bajo costo. El uso de procesos biológicos cumple con esos requisitos, sin embargo, existen algunas limitantes que dificultan su aplicabilidad, como la disponibilidad de nutrientes, el alto contenido de arcillas, la aireación, disponibilidad y tiempo de contaminación. 
Tabla 1. Estructura molecular, nombre, masa molecular y solubilidad en agua a $25^{\circ} \mathrm{C}$ de los 16 HAP considerados contaminantes prioritarios por la EPA.*

\begin{tabular}{|c|c|c|c|}
\hline $\begin{array}{l}\text { Estructura } \\
\text { molecular }\end{array}$ & Nombre & $\begin{array}{l}\text { Masa molecular } \\
\qquad\left(\mathrm{g} \mathrm{mol}^{-1}\right)\end{array}$ & $\begin{array}{c}\text { Solubilidad }\left(\mathrm{mg} \mathrm{L}^{-1}\right) \\
\text { en agua }\end{array}$ \\
\hline & Naftaleno & 128.17 & 31.60 \\
\hline & Acenafteno & 154.21 & 1.91 \\
\hline & Acenaftileno & 152.20 & 3.93 \\
\hline & Fluoreno & 166.20 & 1.98 \\
\hline & Antraceno & 178.20 & 0.76 \\
\hline & Fenantreno & 178.20 & 1.20 \\
\hline & Pireno & 202.30 & $7.7 \times 10^{-2}$ \\
\hline & Fluoranteno & 202.26 & 0.26 \\
\hline & Benzo[a]antraceno & 228.29 & $1.0 \times 10^{-2}$ \\
\hline & Criseno & 228.30 & $2.8 \times 10^{-3}$ \\
\hline & Benzo[b]fluoranteno & 252.30 & $1.2 \times 10^{-3}$ \\
\hline & Benzo[a]pireno & 252.30 & $2.3 \times 10^{-3}$ \\
\hline & Benzo[g, h, i]perileno & 276.34 & $2.6 \times 10^{-4}$ \\
\hline & Dibenzo[a, h]antraceno & 278.35 & $5.0 \times 10^{-4}$ \\
\hline & $\begin{array}{l}\text { Indeno[1, 2, 3,-c, } \\
\text { d]pireno }\end{array}$ & 276.30 & $6.2 \times 10^{-2}$ \\
\hline & Benzo[e]pireno & 252.30 & $6.3 \times 10^{-3}$ \\
\hline
\end{tabular}

${ }^{\star}$ Modificado de Lee y col. (2008). 
Como parte de los esfuerzos para mejorar o acelerar la detoxificación de los sitios contaminados, se han estudiado plantas tolerantes a los contaminantes, con el fin de favorecer su oxidación y degradación en el suelo (Ferrera-Cerrato y col. 2007). A continuación, se esbozan algunas de las razones por las que las plantas han sido seleccionadas para el saneamiento de los suelos contaminados con hidrocarburos.

\subsection{Fitorremediación de suelos contaminados}

La fitorremediación es una alternativa tecnológica en la que se aprovecha la capacidad de las plantas para extraer, degradar, volatilizar y/o estabilizar contaminantes del aire, agua y suelo. Esta tecnología se ha aprovechado para remediar suelos con contaminantes como metales pesados, residuos radiactivos y compuestos orgánicos, como hidrocarburos alifáticos y HAP derivados del petróleo (Lee y col. 2008).

Varias especies de plantas exhiben una tolerancia alta a los contaminantes; entre estas, una de las familias más estudiadas es la de las gramíneas (Poaceae) (Aprill y Sims 1990). Durante las últimas décadas, se han sugerido varias especies de gramíneas como plantas eficaces para la fitorremediación de suelos contaminados con hidrocarburos alifáticos y HAP (Parrish y col. 2004). Lo anterior se debe a que poseen sistemas radiculares fibrosos, por lo que la superficie de contacto con el suelo es mayor, de este modo, también se amplía la superficie de colonización de los microorganismos del suelo en la rizósfera, lo que permite incrementar la interacción entre la comunidad microbiana de la rizósfera y el contaminante (Aprill y Sims 1990). Por ejemplo, Parrish y col. (2004) reportaron que después de 12 meses, aumentaba (24\%) la remoción de HAP en un suelo contaminado utilizando Festuca arundinacea (Schreb.) comparado con un suelo sin plantas.

F. arundinacea (Schreb.) es una gramínea originaria de Europa y ampliamente distribuida en América, de acuerdo a la base de datos Tropicos del Missouri Botanical Garden, esta especie pertenece a la clase Equisetopsida, con subclase Magnoliidae, superorden Lilianae, orden Poales, familia Poaceae y subfamilia Pooideae (http://www.tropicos.org/Name/25509613). F. arundinacea (Schreb) es una gramínea perenne amacollada con un tamaño variable $(0.5 \mathrm{~cm}-2 \mathrm{~m}$ de alto); tiene tallos no ramificados, con nodos de color oscuro; con hojas alternas y dispuestas en dos hileras sobre el tallo, divididas en dos porciones, la anterior (vaina) envuelve al tallo, la parte superior de la hoja (lámina) es muy larga, angosta, plana o a veces plegada y en su unión con la vaina se prolonga en dos lóbulos, entre la vaina y la lámina, por la cara interna, presenta una prolongación membranácea de ápice truncado, llamada lígula; su inflorescencia es panícula, generalmente angosta y densa, de hasta $40 \mathrm{~cm}$ de largo, ubicada en la punta del tallo, compuesta de varias ramitas ascendentes en las que se disponen varias espiguillas sobre pedicelos muy cortos, el eje y las ramas 
de la inflorescencia son angulosas y ásperas al tacto; sus flores son muy pequeñas y se encuentran cubiertas por una serie de brácteas puntiagudas pero sin aristas evidentes; producen una sola semilla fusionada a la pared del fruto; y su raíz es fibrosa y con tallos subterráneos (rizomas) cortos (Walsh 1995). Por sus propiedades nutrimentales $F$. arundinacea ha sido considerada una gramínea forrajera importante en la producción extensiva de ganado y en algunos países se le cultiva con ese fin (Cuyeu y col. 2013). Es una planta que una vez establecida proporciona cobertura efectiva del suelo y controla la erosión, mejora la estructura del suelo y retrasa o previene la invasión de la maleza (Walsh 1995).

Una de las razones por las que $F$. arundinacea se ha seleccionado como una planta con gran potencial fitorremediador es porque se ha demostrado que tolera condiciones de estrés tanto bióticas (patógenos, herbívoros), como abióticas (salinidad, sequía, contaminantes orgánicos y metales pesados, entre otros). Además, F. arundinacea puede coexistir con microorganismos endófitos de manera natural e inducida, permitiendo mayor tolerancia a las condiciones de estrés. Los mecanismos de fitorremediación han podido ser caracterizados utilizando plantas como $F$. arundinacea (Pilon-Smits 2005).

\subsubsection{Mecanismos de fitorremediación}

Dependiendo del tipo de contaminante, las condiciones climatológicas del sitio y el nivel de limpieza requerido, la fitorremediación se puede utilizar ya sea como un medio de contención (rizofiltración, fitoestabilización) o de remoción (fitoextracción, fitodegradación, fitovolatilización, fitoestimulación y fitorremediación asistida con microorganismos) de los contaminantes (Pilon-Smits 2005). A continuación, se detallan cada los mecanismos de acuerdo con Pilon-Smits (2005).

La rizofiltración es el uso de las plantas para adsorber y absorber los contaminantes, principalmente metales, del suelo o del agua a través de las raíces. Cuando el sistema radicular de las plantas está bien desarrollado, éstas se introducen en el sitio contaminado. A medida que las raíces se van saturando del contaminante, las plantas se cosechan y se disponen de manera segura.

La fitoestabilización permite inmovilizar el contaminante en el suelo a través de su absorción y acumulación en las raíces, o bien, por su precipitación en la zona de la rizósfera. Este mecanismo reduce la biodisponibilidad y movilidad de los contaminantes evitando su migración a las aguas subterráneas o al aire.

La fitoextracción se basa en la absorción de los contaminantes a través de las raíces, para ser translocados y acumulados en altas concentraciones en los tejidos aéreos de las plantas. Así se logra extraer los contaminantes del suelo para concentrarlos y disponerlos de forma segura. 
En la fitovolatilización, las plantas pueden convertir los contaminantes en formas volátiles que son, generalmente, menos tóxicas y liberarlas hacia la atmósfera, a través de la evapo-transpiración.

Durante la fitodegradación, las plantas y los microorganismos asociados degradan los contaminantes orgánicos en productos menos tóxicos, o bien, los mineralizan hasta $\mathrm{CO}_{2}$ y $\mathrm{H}_{2} \mathrm{O}$. En este mecanismo, los contaminantes son metabolizados y transformados dentro de los tejidos vegetales. La fitodegradación se ha utilizado para la remoción de diversos hidrocarburos, incluidos los HAP.

La fitoestimulación se lleva a cabo porque las raíces de las plantas exudan sustancias (azúcares, ácidos carboxílicos y aminoácidos, entre otros) que son aprovechadas por los microorganismos degradadores de contaminantes que se encuentran cercanos a la rizósfera y el contaminante puede ser degradado tanto por las plantas como por los microorganismos.

La fitorremediación asistida por microorganismos se basa en la asociación entre plantas y microorganismos como bacterias promotoras del crecimiento vegetal, los hongos microrrícicos arbursculares, bacterias $u$ hongos endófitos, que facilitan y pueden mejorar significativamente los mecanismos de fitorremediación antes descritos (Glick 2010).

Los mecanismos de fitorremediación mencionados pueden ocurrir de manera simultánea en una misma planta y, para saber qué tan eficiente es la fitorremediación, existen varios factores de medición; entre los más usados, se encuentra el factor de fitoestabilización (FE) y el factor de translocación (FT). Uno de los factores cuantitativos más utilizados para medir la eficiencia de fitorremediación de una planta, es el FT con el que se establece la capacidad de una planta para transportar los contaminantes, a través del xilema, desde la raíz hasta los tallos, y representa la concentración del compuesto en el tallo de la planta. Mientras que el FE, ayuda a determinar la cantidad del contaminante que es fijada o inmovilizada fuera de la planta. Los mecanismos de fitorremediación son el resultado de procesos bioquímicos que se llevan a cabo tanto dentro como fuera de las células vegetales, que llevan a la detoxificación de los contaminantes.

\subsubsection{Mecanismos de detoxificación de suelos contaminados con hidrocarburos}

Durante la fitorremediación de suelos contaminados con compuestos orgánicos, se busca reducir la concentración de los contaminantes, lo que puede ocurrir a través de la acción de al menos uno de los siguientes procesos de detoxificación: (i) bioquímicos: metabolismo en el interior y exterior (rizósfera) de la planta (excreción, conjugación); transformación y/o mineralización; y (ii) físico: absorción (extracción y compartimentación) (Kvesitadze y col. 2009). La detoxificación bioquímica puede llevarse a cabo mediante las siguientes etapas. 
Activación. Las moléculas orgánicas hidrofóbicas xenobióticas adquieren grupos funcionales hidrofílicos (hidroxilos, carboxilos y grupos amino, entre otros), como resultado de una oxidación, reducción o hidrólisis enzimática, entre otras. Debido a la adición del grupo funcional, las moléculas adquieren polaridad y su toxicidad se modifica. Esto promueve un incremento en la afinidad de las enzimas que catalizan sus modificaciones posteriormente (Mika y Lüthje 2002).

Conjugación. Ocurre como un mecanismo básico en la fitorremediación y consiste en la formación de complejos químicos entre los contaminantes y compuestos intracelulares (proteínas, péptidos, aminoácidos, ácidos orgánicos, mono, oligo, o poli-sacáridos, lignina), formando enlaces peptídicos, éter, éster, tio-éter u otro tipo de enlace covalente (Shahrtash 2013). A partir de aquí el conjugado puede ser secuestrado en un organelo celular o degradado a un compuesto menos tóxico para la planta.

Compartimentación o secuestro. Implica el almacenamiento (en la mayoría de los casos), en un compartimento celular, como la vacuola, de los productos resultantes de la conjugación. Los conjugados solubles de compuestos tóxicos, conjugados a péptidos, azúcares y aminoácidos, son acumulados en estructuras celulares como las vacuolas. Los conjugados insolubles, conjugados a lignina, almidón, pectina, celulosa y xilanos, son excretados de la célula vía exocitosis en el apoplasto para ser acumulados en la pared celular. Este proceso de excreción, ocurre mediante transporte activo facilitado, que es controlado por la bomba de ATP y depende de glutatión. E almacenaje de estos compuestos permite que la célula elabore las enzimas necesarias para la degradación de los compuestos (Chrikishvili y col. 2006).

Durante los procesos bioquímicos de detoxificación de compuestos orgánicos, participan muchas enzimas que, en condiciones naturales, intervienen en el metabolismo del ciclo celular de las plantas. Sin embargo, concentraciones altas de los contaminantes modifican la actividad de esas enzimas, llevando a la célula a sobre-producir especies reactivas de oxígeno (ERO) y, consecuentemente a una condición de estrés oxidante.

\subsection{Producción de especies reactivas de oxígeno (ERO) y estrés oxidante}

La producción de ERO es una consecuencia inevitable en la vida de los organismos aerobios, producidas continuamente como productos secundarios de varias vías metabólicas y también por algunos sistemas específicos bajo el control celular. Al mismo tiempo, las ERO son degradadas a través de varios mecanismos, tanto específicos como no específicos, además algunas ERO son utilizadas como moléculas de señalización en la célula (Cheeseman 2006). 
Tanto la generación como la degradación de ERO se encuentran bajo un control celular estricto, manteniendo concentraciones bajas $\left(<10^{-8} \mathrm{M}\right.$ ) en el interior de la célula (Li y Moore 2007). Más del $90 \%$ del oxígeno consumido por los organismos vivos se utiliza para producir energía mediante la fosforilación oxidativa, con la acción de la cadena de transporte de electrones, a través de un mecanismo que involucra la transferencia de cuatro electrones que conducen a la producción de ATP y agua. La adición consecutiva de electrones a la molécula de $\mathrm{O}_{2}$ también conduce a la producción de agua (pero no de ATP) a través de formas intermediarias del oxígeno, las ERO (Fig. 1). Entre las $E R O$ se incluyen radicales libres como el anión superóxido $\left(\cdot \mathrm{O}_{2}^{-}\right)$y el radical hidroxilo $(\cdot \mathrm{OH})$, y también especies no radicales, como el peróxido de hidrógeno $\left(\mathrm{H}_{2} \mathrm{O}_{2}\right)$ y el oxígeno singulete $\left({ }^{1} \mathrm{O}_{2}\right)$.

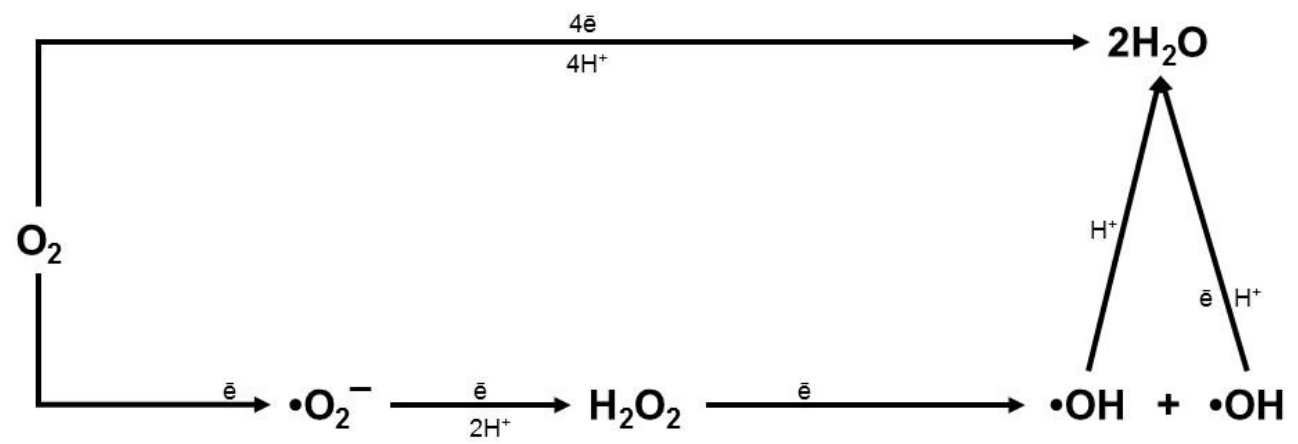

Figura 1. Formas de reducción del oxígeno en sistemas biológicos. La parte superior muestra los cuatro electrones $(\overline{\mathrm{e}})$ de la reducción del oxígeno molecular en la cadena del transporte de ē. La parte inferior muestra la adición consecutiva de un ē a una molécula de oxígeno con la formación de productos intermedios-ERO- anión superóxido $\left(\cdot \mathrm{O}_{2}{ }^{-}\right)$, peróxido de hidrógeno $\left(\mathrm{H}_{2} \mathrm{O}_{2}\right)$ y radical hidroxilo $(\cdot \mathrm{OH})$. Al final se aceptan los cuatro ē y protones para dar lugar a dos moléculas de agua. En ambos casos el máximo estado de reducción del oxígeno se alcanza en la molécula de agua (Li y Moore 2007).

La mayor parte de las ERO (>90\%) de los organismos son producidas por la cadena de transporte de electrones mitocondrial, del retículo endoplásmico, de la membrana plasmática nuclear y del sistema fotosintético (Starkov 2008). Además, cantidades menores de ERO se generan por algunas enzimas como las oxidasas, a través de la auto-oxidación de diferentes moléculas. Las oxidasas que producen ERO son NADPH-oxidasas, lipooxigenasas, ciclooxigenasas y xantinoxidasas (Møller y col. 2007). En presencia de luz, en los cloroplastos de las plantas se genera la mayor producción de ERO. Mientras que, en las partes que no son verdes y durante la oscuridad, las mitocondrias parecen ser los mayores productores de ERO. Las NADPH-oxidasas de la membrana plasmática producen $\mathrm{O}_{2}{ }^{-}$, los cloroplastos producen ${ }^{1} \mathrm{O}_{2}$ en el fotosistema $\mathrm{II}$ y $\bullet^{-\mathrm{O}_{2}}{ }^{-}$en los fotosistemas I y II. La mitocondria produce $\cdot \mathrm{O}_{2}^{-}$en dos complejos (I y III), mientras que los peroxisomas producen $\cdot \mathrm{O}_{2}{ }^{-}$ y $\mathrm{H}_{2} \mathrm{O}_{2}$ (Starkov 2008).

Cuando el balance entre la producción de ERO y su eliminación se altera a favor de las primeras, ocurre el llamado estrés oxidante (Almroth y col. 2008). El estrés oxidante es un evento común en 
muchos estados patológicos, incluyendo el envejecimiento, y este conduce a consecuencias adversas en la célula. Por lo anterior, la investigación sobre el estrés oxidante se ha hecho cada vez más importante, no sólo desde el punto de vista básico, sino también en aspectos aplicados como la medicina, el deporte, la ciencia, la toxicología y las ciencias ambientales.

\subsubsection{Consecuencias del estrés oxidante}

La interacción de las ERO con los componentes de la célula depende de muchas circunstancias, tales como su lugar de formación y su naturaleza. El efecto de las ERO en la célula depende de su actividad química, la que aumenta en el orden siguiente: ${ }^{1} \mathrm{O}_{2}<\cdot \mathrm{O}_{2}{ }^{-}<\mathrm{H}_{2} \mathrm{O}_{2}<\cdot \mathrm{OH}$. El radical ${ }^{1} \mathrm{O}_{2}$ puede oxidar ácidos grasos poliinsaturados, guanidina presente en el DNA, así como aminoácidos (histidina, tirosina, metionina y cisteína). Por su parte el radical $\cdot \mathrm{O}_{2}{ }^{-}$difícilmente oxida ácidos grasos poliinsaturados, pero sí reacciona fácilmente con los centros Fe-S de las proteínas. Mientras que el $\mathrm{H}_{2} \mathrm{O}_{2}$ reacciona poco con los ácidos grasos poliinsaturados, puede oxidar fácilmente la cisteína de las proteínas. El radical $\bullet \mathrm{OH}$ oxida rápidamente ácidos grasos poliinsaturados, DNA, carbohidratos y proteínas (Møller y col. 2007).

Los radicales libres pueden reaccionar químicamente con moléculas similares o con moléculas que no son radicales, de modo que la reacción entre un radical libre y una molécula no radical puede ser (Møller y col. 2007):

- La reacción convierte la molécula no radical en una molécula radical.

- Estas reacciones tienden a ser reacciones en cadena: un radical produce otro radical y así sucesivamente.

- La intensidad de la reactividad química es variable según el radical que intervenga.

Así, la toxicidad del radical $\cdot \mathrm{O}_{2}{ }^{-}$se atribuye a su interacción con el peróxido de hidrógeno con el que reacciona para formar el radical hidroxilo (Reacción 1).

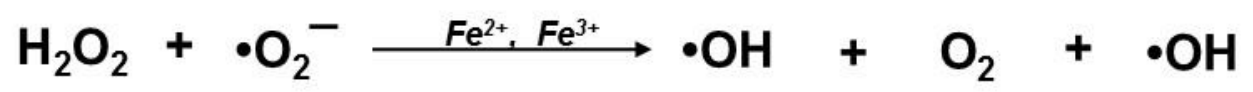

Reacción 1. Reacción entre el radical superóxido y el peróxido de hidrógeno en presencia de $\mathrm{Fe}^{2+}$, dando como productos $\mathrm{Fe}^{3+}$, el radical hidroxilo y oxígeno molecular (Minotti y Aust 1987).

$\mathrm{EI} \mathrm{H}_{2} \mathrm{O}_{2}$, es convertido en radical libre (radical hidroxilo, $\bullet \mathrm{OH}$ ) por medio de las reacciones de Fenton (Reacción 2) o de Haber-Weiss (Reacción 3), en presencia de $\mathrm{Fe}^{2+}$ o $\mathrm{Cu}^{2+}$ presentes en la célula. 


\section{$\mathrm{Fe}^{2+}+\mathrm{H}_{2} \mathrm{O}_{2} \longrightarrow \mathrm{Fe}^{3+}+\cdot \mathrm{OH}+\cdot \mathrm{OH}$}

Reacción 2. Reacción de Fenton. El Fe ${ }^{2+}$ es oxidado en presencia de peróxido de hidrógeno para dar como resultado $\mathrm{Fe}^{3+}$ y dos radicales hidroxilos (Minotti y Aust 1987).

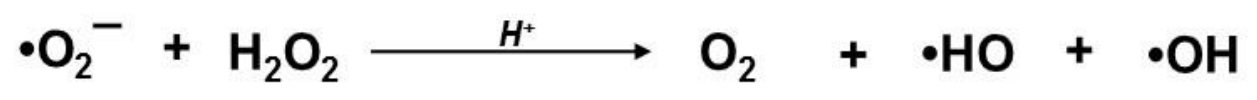

Reacción 3. Reacción de Haber-Weiss para la formación del radical hidroxilo (Minotti y Aust 1987).

El radical $\cdot \mathrm{OH}$ es conocido como la ERO más reactiva, puesto que ataca y daña casi todas las moléculas encontradas en las células y en su vecindad inmediata, conduciendo una reacción en cadena que implica daño celular. Dos ejemplos de oxidación por el radical • $\mathrm{OH}$ son:

- $\quad \mathrm{El} \cdot \mathrm{OH}$ puede atacar el DNA, originando reacciones en cadena que afectan las bases púricas y las pirimídicas, lo que a su vez, puede conducir a mutaciones.

- $\quad \mathrm{El} \cdot \mathrm{OH}$ destruye membranas en una reacción en cadena que se denomina peroxidación de lípidos o lipoperoxidación. Esto ocurre cuando el $\bullet \mathrm{OH}$ se genera cerca de las membranas y ataca las cadenas laterales de ácidos grasos poliinsaturados, dando como resultado un radical libre del carbono centrado (-C•-) (Fig. 2).

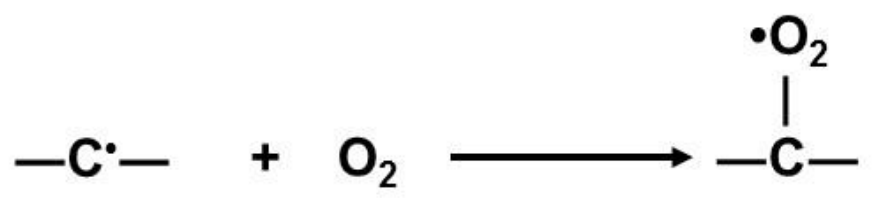

Figura 2. Radical libre del carbono centrado en una cadena lateral de ácidos grasos poliinsaturados de la membrana celular que reacciona con el oxígeno molecular formando así el peroxirradical (Minotti y Aust 1987).

El radical $\bullet \mathrm{OH}$ comúnmente se combina con oxígeno, generando un nuevo radical conocido como radical peroxilo o peroxirradical. El peroxirradical puede reaccionar con otras cadenas laterales de ácidos grasos poliinsaturados, continuando la reacción en cadena para originar hidroperóxidos lipídicos. Estos alteran la fluidez de la membrana y pueden conducir a su ruptura o generar productos citotóxicos que dañan las proteínas de las membranas, inactivan receptores, dañan mecanismos de transducción y proteínas de transporte (Starkov 2008).

El inicio de la peroxidación de los lípidos de membrana requiere de la presencia de hierro en la célula, por lo que, en condiciones sin estrés, se producen cantidades pequeñas de hidroperóxidos lipídicos o endoperóxidos lipídicos. Los endoperóxidos lipídicos contienen al menos 3 dobles enlaces de metilenos interrumpidos que pueden dirigir a la formación del malondialdehído (MDA) como 
producto final. El MDA es conocido como uno de los subproductos cuantificables de la oxidación de los ácidos grasos poliinsaturados de la membrana plasmática (Minotti y Aust 1987).

De igual manera que los lípidos de membrana, los carbohidratos, el DNA y las proteínas pueden ser modificadas por las ERO (Cvjetko y col. 2010). La modificación de las proteínas comienza con la oxidación de alguno de sus componentes. Dependiendo de la ERO, la oxidación de proteínas puede ser: (i) específica, como en el caso de la oxidación catalizada por un metal, que daña las proteínas con conjuntos Fe-S o con Fe libre por formación del radical hidroxilo; (ii) inespecífica, como ocurre en la oxidación por radicación en la que se produce ${ }^{1} \mathrm{O}_{2}$; (iii) reversible, como la glutationilación y Snitrosilación; (iv) irreversible, como la carbonilación, nitración, formación de enlaces proteínaproteína y ruptura de enlaces peptídicos. Las proteínas dañadas pueden ser reconocidas dentro de la célula para después ser reparadas; sin embargo, cuando su reparación es ineficiente las proteínas oxidadas comienzan a acumularse. La oxidación de proteínas puede considerarse como un biomarcador del estrés oxidante ya que se forman grupos carbonilo (cetonas y aldehídos) que permiten su detección (Juszczuk y col. 2008).

El estrés oxidante puede ser originado por la sobre-producción de ERO, pero también se puede originar durante el metabolismo de compuestos orgánicos reducidos como los HAP, ya que, cuando los HAP son activados pueden dar lugar a moléculas que podrían reaccionar con las biomoléculas de las plantas y producir compuestos oxidantes (Liu y col. 2009).

\subsubsection{Estrés oxidante provocado por hidrocarburos}

En las plantas, además de ser subproductos citotóxicos, las ERO funcionan como moléculas de señalización. En condiciones normales, se producen durante la fotosíntesis en la cadena de transporte de electrones en cloroplastos y mitocondrias, y son subproductos de la vía metabólica de los peroxisomas. Debido a que las ERO pueden atacar químicamente nucleótidos, proteínas, carbohidratos y ácidos grasos, las plantas poseen varios mecanismos para neutralizarlos. Bajo condiciones anormales, como el ataque de patógenos, las plantas utilizan niveles bajos de ERO como moléculas de señalización como respuesta defensiva. En tal caso, ocurre una acumulación de ERO en el apoplasto de la célula, seguido de la muerte programada del sitio del tejido infectado. Desde una perspectiva evolutiva, este tipo de respuesta surgió para restringir, espacialmente, un ataque microbiano. Las células detectan los niveles de ERO y transmiten las señales por mecanismos que incluyen cambios en el estado de oxidación y reducción de la cisteína contenida en varias proteínas (Tanaka y col. 2006).

La exposición a contaminantes puede modificar la producción de ERO dentro de la célula, debido a la acumulación de $\mathrm{H}_{2} \mathrm{O}_{2}$ por acción de la $\mathrm{NADPH}$-oxidasa, o por la inhibición en la fijación de $\mathrm{CO}_{2}$ 
en el ciclo de Calvin. Cuando esta vía metabólica es inhibida, la reserva disponible de $\mathrm{NADP}^{+}$se agota, permitiendo así que la cadena de transporte de electrones disminuya y, en última instancia, conduce a la formación de ERO en los cloroplastos. Otra posibilidad es la formación de subproductos químicos tóxicos durante el metabolismo de los contaminantes (Rodríguez y col. 2005; Liu y col. 2009).

La fitotoxicidad de muchos compuestos químicos orgánicos ha sido muy documentada. El interés de estos estudios se ha centrado en el efecto de los contaminantes sobre el estrés oxidante. El estudio de Alkio y col. (2005) muestra una clara correlación entre los cambios morfológicos de Arabidopsis thaliana y el estrés oxidante ocasionado por la exposición a fenantreno. También se ha reportado incremento en la actividad de enzimas antioxidantes y en los niveles de glutatión en Fontinalis antipiretica expuesta a benzo[a]antraceno y a una mezcla de HAP en un suelo contaminado (Roy y col. 1994; Roy y col. 1996). Badu y col. (2005) encontraron un efecto sinérgico de una mezcla de HAP y metales (dihidroxiantraquinona y cobre) sobre la inducción de estrés oxidante en plantas acuáticas de Lemna gibba. Por su parte, Martí y col. (2009), observaron inhibición en el crecimiento de alfalfa, junto con un aumento en la oxidación de proteínas y en la actividad de las enzimas involucradas en la detoxificación de HAP por efecto de los hidrocarburos. Liu y col. (2009) demostraron que la presencia de fenantreno incrementó la producción de ERO y la oxidación de los lípidos de membrana en A. thaliana. Por otro lado, Hernández-Ortega y col. (2013) observaron que la presencia de los hidrocarburos del diésel disminuyeron el crecimiento de plantas de Melilotus albus, e incrementaron la actividad de enzimas antioxidantes totales y el contenido de compuestos fenólicos. Liu y col. (2014) observaron que la presencia de una mezcla de HAP (fluoranteno, pireno, benzo[a]antraceno, criseno, benzo[b]fluoranteno, benzo[k]fluoranteno, benzo[a]pireno y dibenzo[a,h]antraceno) incrementó la actividad de las enzimas deshidrogenasa, peroxidasas y catalasas de plantas Phoenix sp. Wei y col. (2014) reportaron una disminución mayor al 50\% en la concentración de clorofilas $a$ y $b$ en plantas Triticum aestivum expuestas a $200 \mathrm{mg} \mathrm{kg}^{-1} \mathrm{de}$ fenantreno. Tomar y Jajoo (2015) demostraron que los HAP intactos y los HAP-fotomodificados inhiben la germinación, el crecimiento y el contenido de pigmentos, así como las actividades peroxidasa, superóxido dismutasa, catalasa y glutatión reductasa en plantas de T. aestivum.

El estrés oxidante, causado en plantas debido a la presencia de los contaminantes también ocurre en microorganismos. Sin embargo, el grado de estrés depende de la tolerancia de los organismos a los contaminantes, y la tolerancia de plantas y microorganismos a los contaminantes está relacionada con sus sistemas de defensa antioxidante (Yankova y col. 2002). 


\subsection{La defensa antioxidante}

La defensa antioxidante fue desarrollada en células aerobias para contrarrestar los daños causados por la producción de ERO durante la respiración. La defensa antioxidante puede ser enzimática y no enzimática. En la defensa no enzimática, se incluyen compuestos con propiedades intrínsecamente antioxidantes, tales como las vitaminas C y E, el glutatión (GSH) y el $\beta$-caroteno (Pannangpetch y col. 2007). El sistema enzimático, incluye un conjunto de enzimas entre las que están las superóxido dismutasas (SOD, E.C.1.15.1.1), catalasas (CAT, EC.1.11.1.6) y peroxidasas (POD, EC.1.11.1.7), que protegen directamente a la célula eliminando el radical superóxido y el peróxido de hidrógeno, respectivamente, para convertirlos en especies menos reactivas (Lee y col. 2007). Las SOD catalizan la dismutación del $\cdot \mathrm{O}_{2}{ }^{-}$a $\mathrm{H}_{2} \mathrm{O}_{2}$ (Reacción 4), mientras que las CAT y POD actúan reduciendo el $\mathrm{H}_{2} \mathrm{O}_{2}$ a $\mathrm{H}_{2} \mathrm{O}$. Por lo tanto, estas tres enzimas sirven como primera línea de defensa ante las ERO.

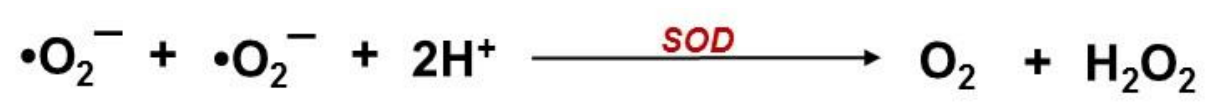

Reacción 4. Dismutación del $\bullet_{2}{ }^{-}$a $\mathrm{O}_{2}$ y $\mathrm{H}_{2} \mathrm{O}_{2}$ por la superóxido dismutasa (Dufernez y col. 2008).

La SOD presenta varias isoenzimas, han sido aisladas y caracterizadas en una gran variedad de organismos. Las isoenzimas cambian dependiendo del metal cofactor metálico que contengan. La isoforma citosólica, en células eucariotas, cloroplastos y algunos procariotas, contiene $\mathrm{Cu} / \mathrm{Zn}$ (Cu/Zn-SOD) en su sitio activo, igual que la forma extracelular (Lee y col. 2007). Existe una forma mitocondrial única de SOD que tiene $\mathrm{Mn}$ en su sitio activo (Mn-SOD), que también se puede encontrar en células procariotas. El tercer grupo, tiene Fe (III) (Fe-SOD) y constituye parte del sistema enzimático antioxidante de procariotas, algas y cloroplastos de algunas plantas. El cuarto grupo, tiene Ni (II/III) (Ni-SOD) y se ha encontrado en estreptomicetos (Dufernez y col. 2008).

A diferencia de otros organismos, que sólo tienen un tipo de SOD en varios compartimentos celulares, las plantas tienen muchas formas de SOD debido a que estas son codificadas por más de un gen, lo que indica que las plantas tienen defensas antioxidantes más complejas que otros organismos aerobios (Dufernez y col. 2008). La inactividad de las SOD en las plantas conduce a fenotipos dañados, incluyendo crecimiento retrasado, daño fotooxidante, daño en el DNA, peroxidación de lípidos, oxidación de proteínas y daño en los sistemas fotosintéticos.

La dismutación de $\cdot \mathrm{O}_{2}^{-}$a $\mathrm{O}_{2}$ y $\mathrm{H}_{2} \mathrm{O}_{2}$ por la SOD implica la formación de $\mathrm{H}_{2} \mathrm{O}_{2}$, que puede reaccionar con iones metálicos dando lugar al $\bullet \mathrm{OH}$. Sin embargo, la CAT interviene degradando el $\mathrm{H}_{2} \mathrm{O}_{2}$ a $\mathrm{O}_{2}$ y $\mathrm{H}_{2} \mathrm{O}$. La mayoría de los organismos aerobios, incluyendo mamíferos, poseen al menos una forma de CAT con un grupo hemo en su sitio activo (Yankova y col. 2002). 
La CAT es una enzima que descompone $\mathrm{H}_{2} \mathrm{O}_{2}$ a un ritmo extremadamente rápido dentro de las células mediante la reacción que se muestra abajo (Reacción 5). La CAT es una enzima homotetramérica que, en gran parte, se localiza en los peroxisomas de todos los organismos aerobios, donde hay muchas enzimas productoras de $\mathrm{H}_{2} \mathrm{O}_{2}$. La CAT exhibe una alta afinidad por el $\mathrm{H}_{2} \mathrm{O}_{2}$ y puede actuar sobre este antes de que se difunda a otras partes de la célula. Debido a su amplia distribución, conservación evolutiva y capacidad para degradar rápidamente el $\mathrm{H}_{2} \mathrm{O}_{2}$, se ha propuesto que la CAT desempeña un papel de suma importancia en los sistemas que permiten que los organismos vivan en ambientes aerobios. Como en el caso de la SOD, existen múltiples isoenzimas de CAT codificadas por genes específicos en plantas, mientras que los animales presentan sólo una forma (Yankova y col. 2002).

$$
\mathrm{H}_{2} \mathrm{O}_{2}+\mathrm{H}_{2} \mathrm{O}_{2} \longrightarrow 2 \mathrm{H}_{2} \mathrm{O}+\mathrm{O}_{2}
$$

Reacción 5. Formación de agua y oxígeno molecular a partir de peróxido de hidrógeno, en la reacción catalizada por la catalasa (Yankova y col. 2002)

Las POD catalizan la oxidación del $\mathrm{H}_{2} \mathrm{O}_{2}$ a $\mathrm{H}_{2} \mathrm{O}$ (Reacción 6), en presencia de un sustrato reducido. Pertenecen a un grupo extenso de enzimas ubicuas en hongos, plantas y vertebrados. Usualmente contienen un grupo prostético ferriprotoporfirínico y oxidan diversos sustratos en presencia de $\mathrm{H}_{2} \mathrm{O}_{2}$ (Mika y Lüthje 2002).

\section{$\mathrm{H}_{2} \mathrm{O}_{2}+\mathrm{R}(\mathrm{HO})_{2} \longrightarrow 2 \mathrm{POD}_{2} \mathrm{O}+\mathrm{R}(\mathrm{O})_{2}$}

Reacción 6. Oxidación de un compuesto con un grupo $\mathrm{OH}$ en presencia de peróxido de hidrógeno, reacción catalizada por una peroxidasa (Mika y Lüthje 2002).

Las POD catalizan reacciones con radicales libres y, en ocasiones, el compuesto oxidado resultante oxida a otros compuestos orgánicos (incluidos los hidrocarburos). De hecho, se ha encontrado que la mayoría de los contaminantes orgánicos son oxidados por POD en plantas (Stiborová y Anzenbachlr 1991). Lo anterior se basa en su distribución ubicua de estas enzimas en las plantas y en su alta inespecificidad por contaminantes como N,N-dimetilanilina, 3,4-benzopireno, 4-nitro-ofenilendiamina, 4-cloroanilina, fenol, aminofluoreno, acetaminofén e hidroxianisoles. En las plantas, las isoenzimas de POD se producen en las paredes celulares, plasmalema, tonoplasto, membranas del retículo endoplásmico, plástidos y citoplasma.

En plantas superiores, la actividad POD se incrementa en respuesta al estrés y participan en la fase I de detoxificación de contaminantes (activación). Entre las múltiples funciones de las POD en las plantas, se encuentra la protección de las células de las reacciones oxidantes que ocurren debido a 
la fotosíntesis. La gran versatilidad de las POD es su característica predominante y, por lo tanto, no existe una única función para estas enzimas multifuncionales (Stiborová y Anzenbachlr 1991).

Otro grupo de enzimas multifuncionales en la célula son las glutatión-S-transferasas (GST). Las GST (EC.2.5.1.18) de las plantas son enzimas codificadas por una súper-familia de genes y se dividen en cinco clases: fi: GSTF; tau: GSTU; teta: GSTT; zeta: GSTZ y lambda: GSTL. Las GST están involucradas en la detoxificación celular a través de la conjugación de compuestos endógenos o xenobióticos con el tripéptido glutatión (GSH) (Shahrtash 2013).

Las GST desempeñan un papel muy importante en la fase II de detoxificación (conjugación) de compuestos xenobióticos. En tal caso, las GST actúan después de que las enzimas de la fase I han introducido un grupo funcional en los compuestos xenobióticos (activación). Este grupo funcional ofrece un centro electrofílico que es atraído por el GSH, en una reacción catalizada por la GST. La adición de GSH a la molécula xenobiótica permite que el conjugado sea alojado en la vacuola durante la fase III de detoxificación (compartimentación) o excretado de la célula. Además de catalizar reacciones de conjugación con el GSH, las GST pueden funcionar como transportadoras de auxinas y fenil-propanoides, así como de antocianinas en la vacuola y en el catabolismo de tirosina. Pueden servir como moléculas de señalización, activando el metabolismo de fenilpropanoides después de la exposición a luz ultravioleta. Las GST inducibles por estrés también tienen actividad peroxidasa, protegiendo así a las células de la sobreproducción de ERO, a través de la detoxificación de hidroperóxidos orgánicos de ácidos grasos y nucleicos. Los hidroperóxidos orgánicos se generan en las plantas durante procesos como la fotosíntesis, ataque de patógenos, la detoxificación de toxinas y fitoalexinas producidas durante la respuesta hipersensible (Shahrtash 2013).

Se sabe que los compuestos intermediarios de las ERO funcionan como reguladores de la expresión génica de las GST (Moons 2005). El análisis de la expresión de GST de clase Lambda, particularmente durante el daño oxidante de la célula en arroz, sugiere que varios miembros de esta familia se expresan diferencialmente durante el crecimiento y desarrollo de las plantas, así como durante el estrés biótico y abiótico (Kumar y col. 2013). Se han encontrado varias isoenzimas de GST en muchos géneros de hongos de los filos Ascomycota y Basidiomycota, entre los cuales se ha demostrado una capacidad notable para degradar muchos compuestos orgánicos complejos como los HAP (Shahrtash 2013).

Aunado al sistema enzimático de defensa antioxidante, las plantas producen compuestos antioxidantes como defensas de segundo nivel que permiten mantener el estado redox de la célula en condiciones de estrés (Singh y col. 2012). Entre estos, el glutatión (GSH) y el ascorbato (ASC) son los más importantes, mantienen el balance de oxidación y reducción intracelular a través del 
ciclo ascorbato-glutatión (ASC-GSH) o de Halliwell-Asada (Fig. 3). Otras moléculas antioxidantes importantes son los tocoferoles, flavonoides, carotenoides y alcaloides, que actúan mitigando la acumulación de ERO (Singh y col. 2012). Todas las plantas y los animales, excepto los primates y los conejillos de indias, pueden sintetizar ácido ascórbico. En las plantas, el ASC, se puede acumular en concentraciones milimolares tanto en tejidos fotosintéticos como no fotosintéticos (Gao y col. 2012). De las muchas funciones atribuidas al ASC, la de antioxidante es la más importante, ya que, reacciona de manera directa con el oxígeno singulete y los radicales superóxido e hidroxilo.

El ciclo ASC-GSH es uno de los más eficientes sistemas de detoxificación de ERO y ayuda a mantener el balance de oxidación y reducción en la célula (Singh y col. 2012). El ciclo incluye enzimas de oxidación y reducción, entre las cuales la ascorbato peroxidasa (APX, EC.1.11.1.11) es la más abundante, y requiere ascorbato para reducir el $\mathrm{H}_{2} \mathrm{O}_{2}$ a $\mathrm{H}_{2} \mathrm{O}$. El monodehidroascorbato (MDHA) es reducido a dehidroascorbato por la monodehidroascorbato reductasa (MDHAR, EC.1.6.5.4), que requiere $\mathrm{NADH}$, o puede descomponerse en ascorbato y dehidroascorbato (DHA). En seguida, la dehidroascorbato reductasa (DHAR, EC.1.8.5.1) regenera el ascorbato a partir de DHA, utilizando GSH como reductor. El GSH oxidado, el glutatión disulfuro (GSSG), es regenerado por la glutatión reductasa (GR, EC1.6.4.2) en presencia de NADPH como poder reductor.

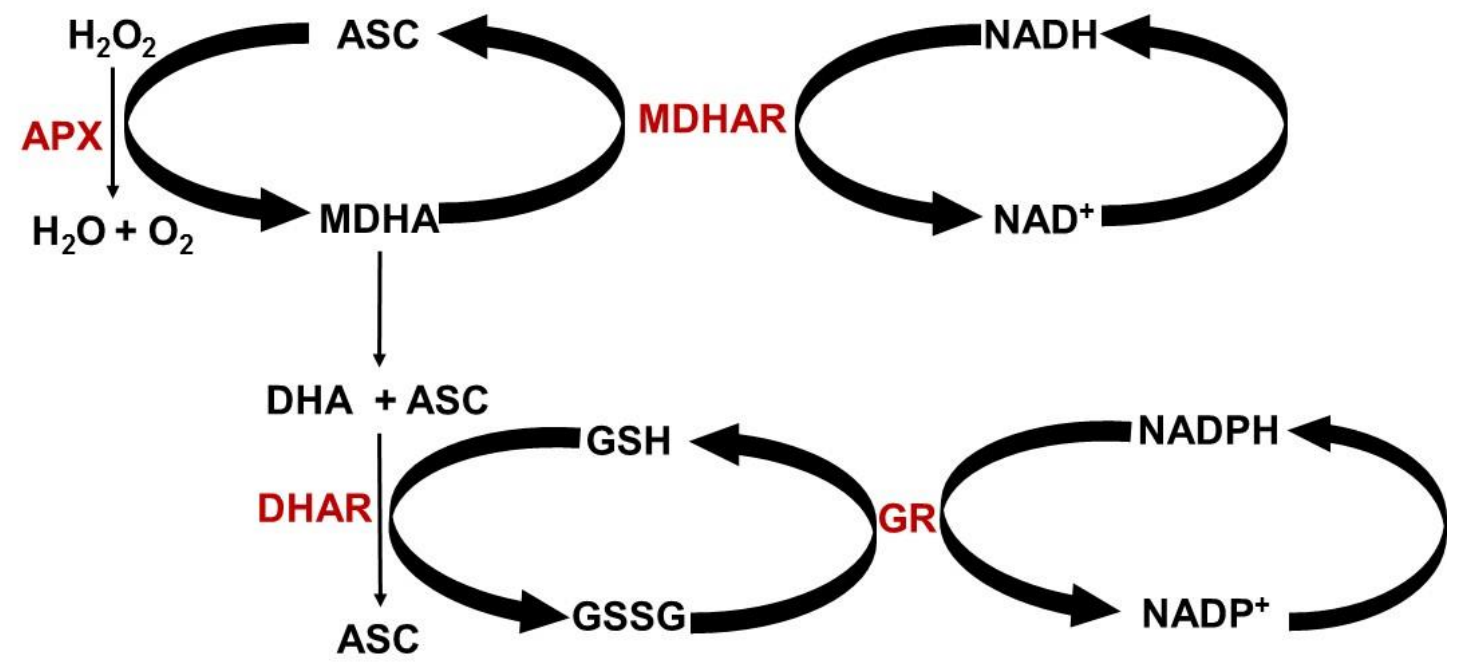

Figura 3. Representación del ciclo ASC-GSH o de Halliwell-Asada (Singh y col. 2012).

El ascorbato es la forma predominante a pH fisiológico. Su capacidad antioxidante le permite reaccionar directamente con ERO, oxidándose sucesivamente a MDHA y DHA. Además, el ascorbato es cofactor de las dioxigenasas y participa en la regulación del ciclo celular y en la organogénesis. La regeneración del ASC en el ciclo requiere de la participación de GSH, la coordinación de estos antioxidantes permite que la célula mantenga un estado de oxidación y reducción que le permita un buen funcionamiento. 
El GSH es un tripéptido ( $\gamma$-glu-cys-gly), cuya utilidad como agente antioxidante consiste en la actividad multifuncional del átomo de azufre en su residuo de cisteína. Se caracteriza por ser el compuesto tiólico no-proteico más abundante en las células. Presenta una capacidad alta para donar electrones y, en condiciones normales, el 90\% del GSH se encuentra en su estado reducido. Así, el GSH proporciona equivalentes reductores para enzimas como glutatión-S-transferasas (GST) y glutatión peroxidasas (G-POX), durante su función para reducir peróxidos lipídicos. La G-POX, que contiene selenio (Se) como cofactor metálico, utiliza los grupos sulfhidrilo (SH) del GSH como donadores de $\mathrm{H}^{+}$para producir el glutatión disulfuro (GSSG) (Almroth y col. 2008). El GSSG es regenerado por la enzima glutatión reductasa $(\mathrm{GR})$, que utiliza el $\mathrm{NADPH}^{+}$formado en la ruta de las pentosas fosfato como donador de $\mathrm{H}^{+}$(Fig. 4).

De este modo, el GSH puede reciclarse y participar en otras reacciones, como en la detoxificación de contaminantes o manteniendo la fuente de ácido ascórbico en su estado reducido (ciclo del ácido ascórbico). Durante la detoxificación de contaminantes, el GSH actúa como citoprotector a través de la formación de conjugados que conducen a un péptido polar no tóxico. Esta reacción (conjugación) es catalizada por la acción de las GST.

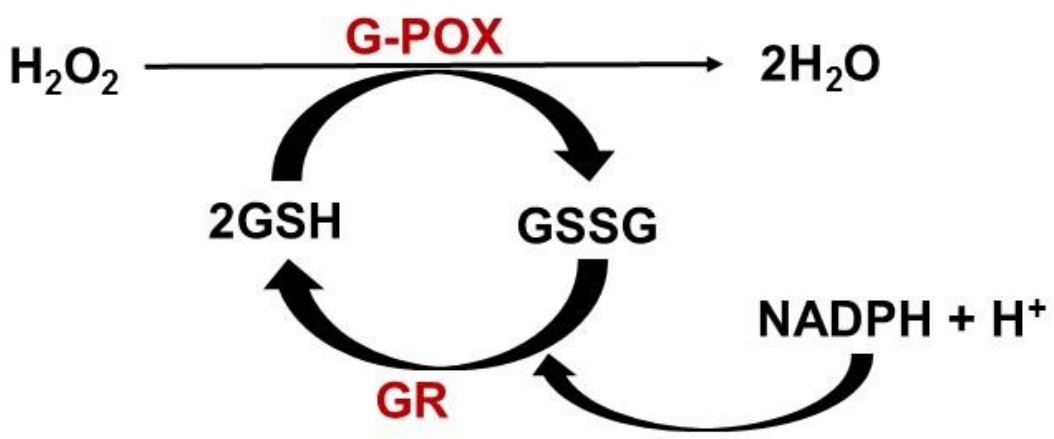

Figura 4. Reciclaje de glutatión en el ciclo de la enzima glutatión peroxidasa (Almroth y col. 2008).

Para mejorar la eficiencia de la defensa antioxidante tanto enzimática como no enzimática y con esto mejorar la fitorremediación, se han propuesto algunas estrategias: (i) selección de plantas con mayor tolerancia a contaminantes específicos; (ii) utilización de técnicas agronómicas (como el ajuste de $\mathrm{pH}$ ), adición de fertilizantes y quelantes; (iii) manipulación genética, como las técnicas de sobreexpresión de los genes responsables de la resistencia y/o tolerancia o degradación de contaminantes; (iv) la asociación de plantas con microorganismos que resisten, toleran y/o degradan contaminantes, al mismo tiempo que benefician a la planta (Ferrera-Cerrato y col. 2006; Gao y col. 2011). 


\subsection{Fitorremediación asistida por microorganismos}

La posibilidad de aumentar la tolerancia al estrés oxidante de las plantas fitorremediadoras es uno de los temas críticos en este campo de estudio. Las plantas se han asociado con microorganismos (bacterias, hongos) de la rizósfera como una estrategia de adaptación a condiciones adversas (Tanaka y col. 2006), y esto se ha utilizado como una variante de la fitorremediación, conocida como fitorremediación asistida por microorganismos (Glick 2010).

La rizósfera se define como el volumen del suelo adyacente a las raíces, que representa una región de intensa actividad microbiana tanto benéfica como patógena, que afecta el estado fisiológico y el crecimiento de las plantas (Schnoor y col. 1995). En la rizósfera se desarrollan relaciones simbióticas entre microorganismos y plantas, debido a que estas últimas exudan nutrimentos (azúcares, ácidos carboxílicos, ácidos grasos, aminoácidos, esteroles, flavonoides y enzimas, entre otros) útiles para el metabolismo microbiano. Al mismo tiempo, los microorganismos proveen muchos beneficios para la planta, ayudando en el crecimiento, regulando la actividad metabólica de la raíz e influenciando en las propiedades físicas y químicas del suelo y de sus contaminantes. Así, la degradación de compuestos orgánicos puede ocurrir más rápidamente en la zona de la rizósfera (Schnoor y col. 1995). Por lo anterior, los microorganismos que habitan en la rizósfera contribuyen de manera importante en la degradación de materia orgánica y material contaminante.

Además de que la asociación de plantas con rizobacterias aumenta la eficiencia de la fitorremediación, debido a que estas bacterias promueven el crecimiento vegetal, y atenúan el efecto tóxico de los contaminantes (Debiane y col. 2009), otros microorganismos, entre los que están los hongos micorrízicos arbusculares (HMA), han sido estudiado con el mismo fin. Se ha demostrado que contrarrestan el estrés de las plantas generado por los contaminantes, además de aumentar la captación de nutrimentos, la absorción de agua y la fijación de nitrógeno. La importancia de los HMA no sólo se debe su efecto benéfico sobre el crecimiento y nutrición de las plantas, sino también a su capacidad de adaptación a ecosistemas diversos (Liu y col. 2004; Alarcón y col. 2006).

Otro grupo microbiano que ha recibido atención creciente en el área de la fitorremediación asistida por microorganismos, son los hongos endófitos (Mei y Flinn 2010). Éstos habitan dentro de los tejidos de las plantas sin causar síntomas de enfermedad (Porras-Alfaro y Bayman 2011). En el caso particular de los hongos endófitos, se ha encontrado que mejoran el crecimiento vegetal a través de mejorar la captación de nutrimentos, inhibir el crecimiento de fitopatógenos, reducir enfermedades y aumentar la tolerancia al estrés ambiental por factores como la sequía, salinidad, calor y la presencia de contaminantes (Rodríguez y col. 2009). Benefician a plantas creciendo bajo condiciones de estrés provocado por la presencia de contaminantes - metales pesados (Ahmad 2011) y organoclorados (Becerra-Castro y col. 2013) - o altas concentraciones de sal y sequía (Tiwari y col. 2016), mediante 
el control del estrés oxidante. La colonización de los endófitos en las plantas causa cambios bioquímicos y modificaciones en la expresión genética, que permiten tanto el establecimiento de la asociación como la mejora de la tolerancia a los contaminantes (Dupont y col. 2015).

Hasta ahora, el papel que desempeñan los microorganismos endófitos en la fitorremediación no es claro (Zhuang y col. 2007), pero se sabe que la eficiencia del proceso puede modificarse debido a: (i) la transformación del contaminante; (ii) la reducción de su toxicidad mediante el control del estrés generado; y (iii) la mejora del crecimiento vegetal. El éxito de estas asociaciones en la fitorremediación de un suelo depende de la combinación planta-microorganismo-contaminante y está influenciado por las condiciones particulares de cada sitio (Gadd 2007).

La mayoría de los estudios acerca de la fitorremediación asistida con microorganismos se han enfocado en la asociación de plantas como Chichorium intybus o Glycine max cv. Don Mario 4800 con HMA del género Glomus sp. (Debiane y col. 2009; Bressano y col. 2010) o plantas como Festuca arundinacea en asociación con el endófito Neotyphodium coenophialum (Soleimani y col. 2010) bajo condiciones de estrés por HAP y metales pesados. Sin embargo, la asociación de $F$. arundinacea con $N$. coenophialum puede desarrollar "festucosis" en ganado vacuno, caballos y ovejas, lo que provoca disminución de peso, menores tasas de embarazo y disminución en la producción de leche (Walsh 1995). Particularmente, para el caso de los HAP, pocos son los estudios en los que se reporta la utilización de hongos endófitos diferentes a $N$. coenophialum en asociación con plantas de $F$. arundinacea, por lo que el estudio de otras asociaciones benéficas, no sólo para la planta, puede proporcionar una alternativa a la fitorremediación de suelos contaminados.

Recientemente, se reportó que un hongo endófito del género Lewia incrementa la tolerancia de $F$. arundinacea expuesta a una mezcla de hidrocarburos (Cruz-Hernández y col. 2013) y que mejoró la bioacumulación de plomo y el crecimiento de plantas de Dodonaea viscosa (Rojas-Loria y col. 2011). Lewia sp. es un hongo ascomiceto de la familia Pleosporaceae, y se ha reportado que el género incluye varias especies que actúan como fitopatógenos ( $L$. avenicola, L. infectoria) que reducen la calidad de los cultivos, especialmente de gramíneas (Kwasna y col. 2006). Además, Lewia sp. también fue identificado como un endófito de plantas halófilas como Limonium tetragonum y Phragmites australis (Khalmuratova y col. 2015). L. infectoria y L. eureka se identificaron como endófitos de Betula pendula (Kawasna y col 2008) y Theobroma gileri (Thomas y col. 2008), respectivamente.

Aunque los estudios reconocen la importancia de los hongos endófitos en la tolerancia y remoción de hidrocarburos, aún no está claro el papel que desempeñan, por lo que resulta relevante contribuir al conocimiento sobre los mecanismos que permiten mejorar la fitorremediación asistida con 
microorganismos endófitos y ofrecer alternativas a la fitorremediación de suelos contaminados con hidrocarburos. 


\section{JUSTIFICACIÓN}


El conocimiento sobre la respuesta biológica y los mecanismos de tolerancia de las plantas y los microorganismos a la exposición de compuestos orgánicos tóxicos, es una herramienta indispensable para mejorar las estrategias de limpieza de suelos y obtener mejores rendimientos durante la fitorremediación.

Varios estudios reconocen la importancia del papel que desempeñan los hongos micorrízicos arbusculares en asociación con las plantas, particularmente en la tolerancia y remoción de compuestos orgánicos. Sin embargo, poco se sabe acerca del papel y del potencial de los hongos endófitos para contrarrestar los efectos negativos de los hidrocarburos en plantas con potencial para fitorremediación.

Trabajos previos demostraron que Lewia sp. es un hongo endófito que se asocia con F. arundinacea, en una asociación inducible en el laboratorio. Asimismo, la aclimatación de la asociación a distintas concentraciones de una mezcla definida de hidrocarburos, durante al menos 45 días, favoreció la remoción de hexadecano, fenantreno y pireno (Mendarte-Alquisira y col. 2013). Si bien es cierto que aún se desconocen los mecanismos por los cuales se obtuvo esta respuesta, es importante resaltar que la remoción de los hidrocarburos no dependió de la concentración utilizada durante la aclimatación, pero sí del tiempo de contacto entre la asociación $F$. arundinacea-Lewia sp. y la mezcla de hidrocarburos.

Se ha confirmado que la presencia de hidrocarburos modifica el metabolismo en las plantas, provocando estrés. Si tal condición no es controlada, puede conducir a daños irreparables, e inclusive a la muerte. Como respuesta al estrés, las plantas han desarrollado mecanismos que involucran reacciones bioquímicas diversas. Estos mecanismos pueden mejorarse a través de la asociación de plantas con hongos endófitos. Sin embargo, la información acerca del papel que desempeñan los hongos endófitos en la reducción del estrés en las plantas durante la fitorremediación de hidrocarburos es aún escasa.

Considerando lo anterior, resulta relevante contribuir en el conocimiento acerca de los mecanismos que permitieron la mayor remoción de hidrocarburos por la asociación Festuca arundinacea-Lewia sp., así como ofrecer una alternativa promisoria para mejorar la fitorremediación de suelos contaminados con hidrocarburos. 


\section{HIPÓTESIS}


La remoción de una mezcla de hidrocarburos por la asociación inducida entre Festuca arundinacea y Lewia sp. aumenta debido a que el hongo favorece el control del estrés oxidante. 
4.OBJETIVOS 


\subsection{Objetivo general}

Evaluar el efecto de Lewia sp. en la asociación endófita inducida con Festuca arundinacea sobre el control del estrés oxidante durante la remoción de una mezcla de hidrocarburos en un suelo modelo.

\subsection{Objetivos específicos}

1. Establecer las condiciones particulares para el cultivo in vitro de $F$. arundinacea y la asociación entre F. arundinacea y Lewia sp.

2. Determinar el efecto de la inducción de la asociación en el crecimiento y el estrés oxidante.

3. Evaluar la tolerancia de $F$. arundinacea y la asociación entre $F$. arundinacea y Lewia sp. a una mezcla de hidrocarburos.

4. Evaluar el efecto de una mezcla de hidrocarburos sobre el estrés oxidante y la defensa antioxidante en $F$. arundinacea y la asociación entre $F$. arundinacea y Lewia sp.

5. Correlacionar la defensa antioxidante con la remoción de hidrocarburos en la asociación entre F. arundinacea y Lewia sp. 


\section{MATERIALES Y MÉTODOS}




\subsection{Estrategia experimental}

Para cumplir con el objetivo general del estudio, la estrategia experimental se dividió en cuatro etapas que se representan con número en los recuadros de la Figura 5. En la primera etapa, se establecieron las condiciones particulares para la obtención de plantas de $F$. arundinacea y para la inducción de la asociación endófita entre $F$. arundinacea y Lewia sp. en medio de cultivo MurashigeSkoog (MS) semisólido; así mismo, se determinó el efecto de la inducción de la asociación sobre el estrés oxidante y la defensa antioxidante de la planta. En la segunda etapa, se evaluó la tolerancia de la planta y de la asociación a concentraciones altas de una mezcla de hidrocarburos (MHC) en un suelo modelo, de donde se obtuvo la concentración inhibitoria media $\left(\mathrm{Cl}_{50}\right)$. En la tercera etapa, se ensayaron varias concentraciones del medio de cultivo (MS), manteniendo la misma relación $\mathrm{C} / \mathrm{N}$, con el objetivo de incrementar la supervivencia de la planta y la asociación en el suelo modelo sin contaminantes y, así, asegurar, en la cuarta etapa, que el estrés generado lo provocan los hidrocarburos. En la cuarta etapa, se evaluó la influencia del endófito sobre la remoción de hidrocarburos, el estrés oxidante y la defensa antioxidante de la planta, en presencia de una mezcla de hidrocarburos.

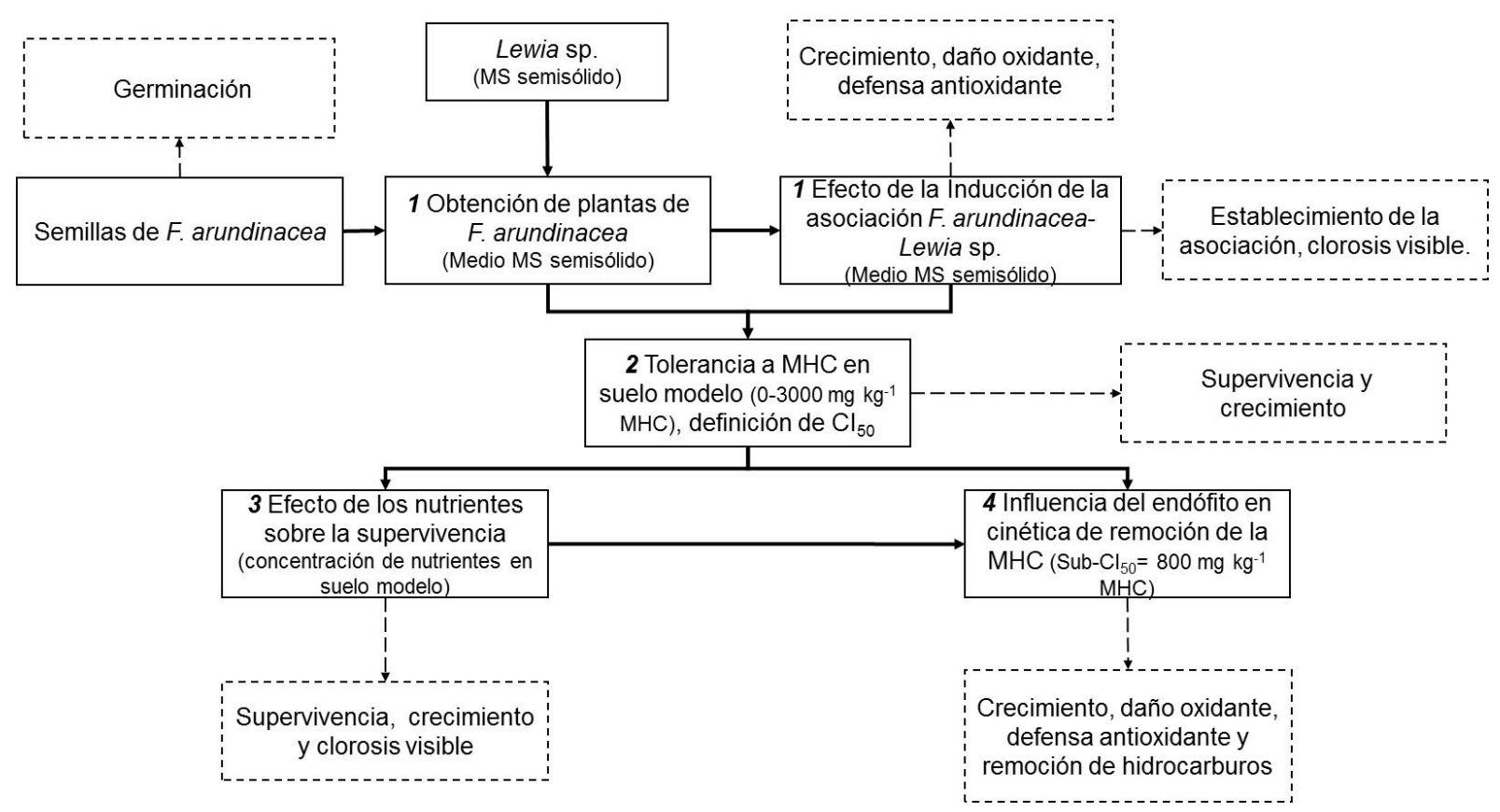

Figura 5. Estrategia experimental general utilizada para cumplir los objetivos del proyecto. Las etapas se presentan con número y las variables respuesta medidas en cada etapa se muestran en los recuadros con línea punteada. 


\subsection{Material biológico}

\subsubsection{Planta}

Las semillas de Festuca arundinacea se adquirieron en la Central de Abasto de la Ciudad de México y se conservaron a temperatura ambiente hasta su utilización. Para seleccionar las semillas a cultivar, se realizó una prueba de pre-viabilidad, donde aquellas que flotaron se descartaron (CruzHernández y col. 2013). Las semillas seleccionadas se colocaron en un papel filtro, se sumergieron en una solución (2\%) de detergente comercial (marca Roma) por 20 min con agitación constante, y se lavaron con abundante agua de la llave. Bajo una campana de flujo laminar, el sobre con las semillas se sumergió en etanol $70 \%$ (v/v) durante $30 \mathrm{~s}$, seguido por una solución de hipoclorito de sodio $1.2 \%(\mathrm{v} / \mathrm{v})$ adicionado con $0.1 \mathrm{~mL}$ de Tween-20 estéril por $30 \mathrm{~min}$. El sobre se lavó repetidamente con $150 \mathrm{~mL}$ de agua desionizada estéril y se abrió sobre una caja de Petri estéril y vacía, donde se mantuvieron hasta su siembra.

\subsubsection{Hongo}

Se inoculó la cepa del hongo filamentoso Lewia sp., aislado de semillas de $F$. arundinacea y conservado en el laboratorio W-108 de la UAM. Para su conservación, la cepa se sembró en medios de agar papa dextrosa (PDA) y medio Murashige y Skoog (MS, Sigma-Aldrich) (Murashige y Skoog 1962) con sacarosa (Sigma-Aldrich) ( $\mathrm{pH} 5.7 \pm 0.1)$, después de 15 días de crecimiento se obtuvieron cuadros de $1 \times 1 \mathrm{~cm}$ que se sumergieron en agua destilada estéril, los tubos con agua se mantuvieron a $4{ }^{\circ} \mathrm{C}$. Para la propagación de la cepa, se tomó un cuadro con la biomasa de Lewia sp. y se colocó en una caja con medio MS y $10 \mathrm{~g} \mathrm{~L}^{-1}$ de sacarosa (Sigma-Aldrich) y se incubaron durante 15 días a $30^{\circ} \mathrm{C}$. Para la preparación del inóculo, se tomaron 65 discos de $5 \mathrm{~mm}$ de la periferia de las colonias formadas y se colocaron en tubos con perlas de vidrio y solución isotónica para dispersar el micelio hasta obtener una suspensión homogénea. Dos mL de esta suspensión $\left(10.1 \pm 0.1 \mathrm{mg} \mathrm{mL}^{-1}\right)$ se utilizaron como inóculo para las plantas.

\subsection{Medios de cultivo}

Durante las etapas del estudio, se utilizaron 12 medios de cultivo diferentes. Para la primera etapa (obtención de plantas y establecimiento de la asociación), la siembra de las semillas desinfestadas y la inducción de la asociación se realizaron en cajas Magenta que contenían medio MS completo y medio MS con la mitad de la concentración (1/2MS) con 5, 10, 20 y $30 \mathrm{~g} \mathrm{~L}^{-1}$ de sacarosa cada medio. El pH de cada medio se ajustó a $5.7 \pm 0.1 \mathrm{con} \mathrm{KOH} 1 \mathrm{~N}$ y se agregaron $1.8 \mathrm{~g} \mathrm{~L}^{-1}$ de Phytagel (SigmaAldrich) como agente gelificante. Cada caja Magenta se adicionó con $80 \mathrm{~mL}$ de medio MS y se esterilizó a $15 \mathrm{lb}$ in ${ }^{-2}$ durante $15 \mathrm{~min}$. Se colocaron 16 semillas por caja Magenta y se incubaron durante 15 días con fotoperiodos de $16 \mathrm{~h}\left(50 \mu \mathrm{mol} \mathrm{m} \mathrm{m}^{-2} \mathrm{~s}\right)$ a $25 \pm 1^{\circ} \mathrm{C}$. La germinación se monitoreó 
durante ese periodo. La nomenclatura y composición de los medios utilizados se muestra en la Tabla 2. Para la segunda etapa (evaluación de la tolerancia de la planta y la asociación a una mezcla de hidrocarburos en suelo modelo), se utilizó el medio cuya $\mathrm{C} / \mathrm{N}$ permitió la mayor germinación y la inducción de la asociación en al menos 15 días, pero concentrado 3 veces (3X) para mantener la misma cantidad de nutrientes que en el cultivo semisólido. Durante la tercera etapa (aumento en supervivencia en suelo modelo sin contaminantes), se probaron cuatro medios con concentración diferente de sales y sacarosa, pero con la misma relación $\mathrm{C} / \mathrm{N}(3 \mathrm{X}, 4 \mathrm{X}, 5 \mathrm{X}$ y $6 \mathrm{X})$ para aumentar la supervivencia de plantas en ausencia de hidrocarburos en suelo modelo. Durante la cuarta etapa se utilizó el medio seleccionado en la etapa tres.

Tabla 2. Concentración de sacarosa y de nutrientes, y relación carbono/nitrógeno $(\mathrm{C} / \mathrm{N})$ resultante para los medios de cultivo en los tratamientos. El 1 representa la concentración de sales de MS completa recomendada por el proveedor, 1/2 representa la mitad de la concentración de las sales, los tratamientos $3 \mathrm{X}$ al $6 \mathrm{X}$ son las veces que se concentraron los nutrientes en el suelo modelo. *

\begin{tabular}{ccc}
\hline Tratamiento & Sacarosa $\left(\mathbf{g ~ L}^{-1}\right)$ & Relación $\mathbf{C} / \mathbf{N}$ \\
\hline $2.5-1$ & 5 & 2.5 \\
$5-1$ & 10 & 5 \\
$10-1$ & 20 & 10 \\
$15-1$ & 30 & 15 \\
$5-1 / 2$ & 5 & 5 \\
$10-1 / 2$ & 10 & 10 \\
$20-1 / 2$ & 20 & 20 \\
$30-1 / 2$ & 30 & 30 \\
$3 X$ & 30 & 5 \\
$4 X$ & 40 & 5 \\
$5 X$ & 50 & 5 \\
$6 X$ & 60 & 5 \\
\hline
\end{tabular}

*La composición de las sales de MS de acuerdo al proveedor (Sigma-Aldrich) se muestra en el Anexo I.

\subsection{Inducción de la asociación}

Con el propósito de determinar el tiempo necesario para establecer la asociación entre $F$. arundinacea y Lewia sp. en medio semisólido, se evaluó el efecto de la relación $\mathrm{C} / \mathrm{N}$ en el medio de cultivo (Tabla 2) sobre el tiempo en el que se formó la asociación endófita. La inducción de la asociación entre $F$. arundinacea y Lewia sp., se realizó en cajas Magenta que contenían medio MS y sacarosa con relación de $\mathrm{C} / \mathrm{N}$ diferente (Tabla 2). En el medio cercano a la raíz de las plantas de 15 días de edad se inocularon $2 \mathrm{~mL}$ de la suspensión de Lewia sp. Las plantas permanecieron en 
contacto con la suspensión durante $5,10,15$ y 20 días con fotoperiodos de $16 \mathrm{~h}\left(50 \mu \mathrm{mol} \mathrm{m}^{-2} \mathrm{~s}\right) \mathrm{a}$ $25 \pm 1^{\circ} \mathrm{C}$. Al finalizar cada tiempo de contacto se determinó si la asociación se había formado, verificando la presencia del micelio en el interior de las raíces y tallos de las plantas. Con base en estos resultados, se seleccionó el medio donde se obtuvo el mayor número de plantas con apariencia sana y el establecimiento de la asociación endófita en el menor tiempo.

Una vez seleccionado el medio de cultivo MS con C/N de 5 (5-1), que permitió la obtención de plantas y la asociación en el menor tiempo de cultivo (15 días) en medio semisólido, se realizó una nueva siembra de semillas en este medio. Las plantas y la asociación obtenidas fueron utilizadas para los experimentos en suelo modelo, cuyas condiciones de cultivo se describen más adelante.

\subsubsection{Pruebas de endofiticidad}

Para determinar el carácter endófito de la asociación, así como para verificar el tiempo en el que ésta se establece, se siguió el procedimiento descrito a continuación (Lucero y col. 2006). Bajo campana de flujo laminar, las plantas en contacto con el hongo se cosecharon, se retiró el exceso de hongo y se separaron las raíces de los tallos. Una vez separados, raíces y tallos se desinfestaron superficialmente con una solución de etanol $70 \%$ por $30 \mathrm{~s}$, seguido de una solución de hipoclorito de sodio $1.2 \%(\mathrm{v} / \mathrm{v})$ por $10 \mathrm{~min}$ y se finalizó con un enjuague con agua destilada estéril por $1 \mathrm{~min}$. Se cortaron segmentos de raíz y tallo de $1 \mathrm{~cm}$ de longitud que fueron identificados como zonas con los siguientes nombres: 1) zona de maduración o diferenciación, 2) zona de elongación, 3) zona de elongación cercana a la zona apical y 4) zona apical o de división celular (Fig. 6). Cada segmento se colocó sobre cajas Petri con medio PDA, para corroborar la desinfestación superficial y, posteriormente, se sembraron en cajas con medio PDA. Las cajas con el material vegetal se mantuvieron durante 20 días a $30^{\circ} \mathrm{C}$ y el crecimiento fúngico a partir de los extremos de los cortes se verificó cada $24 \mathrm{~h}$.

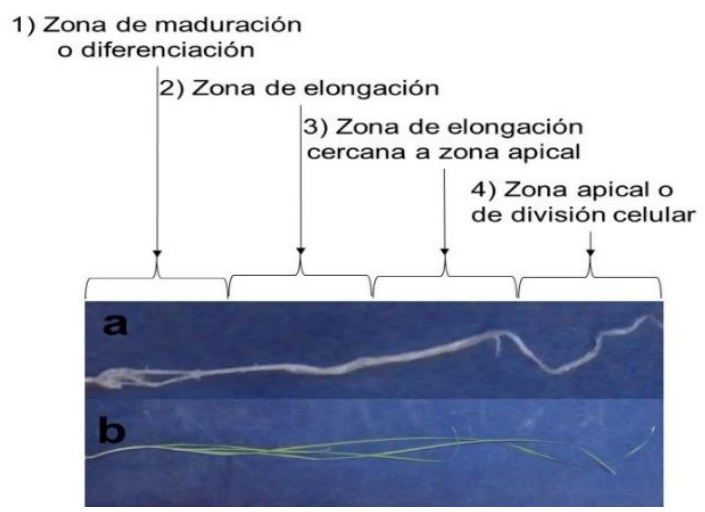

Figura 6. Criterios para la división de las a) raíces y b) tallos para verificar la endofiticidad de Lewia sp. en plantas de $F$. arundinacea: 1) zona de maduración o diferenciación, 2) zona de elongación, 3) zona de elongación cercana a la zona apical y 4) zona apical o de división celular 


\subsection{Preparación del sistema de cultivo}

\subsubsection{Suelo modelo}

Con el fin de evaluar la tolerancia de $F$. arundinacea y la asociación endófita inducida entre $F$. arundinacea y Lewia sp., a una mezcla de hidrocarburos definida en un suelo modelo, se utilizó un suelo modelo compuesto por una mezcla de arena:agrolita (1:1 v/v). La arena de sílice, tamizada hasta un tamaño de partícula entre 0.42 y $2 \mathrm{~mm} \varnothing$, se trató por $24 \mathrm{~h}$ con una solución de ácido clorhídrico (10\%, v/v) para eliminar el carbonato de calcio y la materia orgánica. La arena se lavó 10 veces con agua de la llave y 10 veces con agua destilada para eliminar el $\mathrm{HCl}$, con lo que se aseguró que el pH final del agua de lavado fuera cercano a 7. La agrolita se tamizó para obtener un tamaño de partícula entre 0.4 y $2.8 \mathrm{~mm} \varnothing$, para favorecer el anclaje de las raíces al suelo. Ya tamizada, se lavó con agua destilada caliente para retirar las impurezas. Tanto la arena como la agrolita se secaron durante $96 \mathrm{~h}$ a $60^{\circ} \mathrm{C}$. La mezcla arena:agrolita se impregnó con medio MS con sacarosa hasta alcanzar 30\% de humedad.

\subsubsection{Mezcla de hidrocarburos}

La mezcla de hidrocarburos (MHC) incluyó hexadecano (HXD, pureza 99\%) un hidrocarburo de cadena lineal, y dos hidrocarburos aromáticos policíclicos (HAP), fenantreno (PHE, con una pureza mayor a 96\%) y pireno (PYR con una pureza mayor a 98\%) en una proporción 2:1:0.5. El HXD es un compuesto que se encuentra en proporciones altas en los residuos de diésel (Krummenacher y col. 2003), mientras que los HAP han sido reportados como compuestos carcinogénicos encontrados en sitios contaminados (García-Gómez y col. 2004). Todos los reactivos fueron adquiridos en SigmaAldrich. Los compuestos fueron disueltos en acetona (J.T. Baker, pureza > 99\%) para adicionarlos al suelo modelo.

\subsection{Determinación de la tolerancia a una mezcla de hidrocarburos}

La tolerancia de $F$. arundinacea y la asociación $F$. arundinacea-Lewia sp. se determinó mediante la cuantificación de la supervivencia, el crecimiento y la concentración de clorofilas (apartado 5.7) en plantas crecidas con concentraciones crecientes de la MHC. La tolerancia se cuantificó a través de la concentración inhibitoria media $\left(\mathrm{Cl}_{50}\right)$, en este caso de la $\mathrm{MHC}$, que es la concentración necesaria para inhibir en un 50\% una variable determinada (Baud-Grasset y col. 1993).

Para lo anterior, las plantas de 30 días asociadas y no asociadas, obtenidas en medio semisólido, se transfirieron a cajas Magenta (Sigma-Aldrich) con suelo modelo preparado en las condiciones mencionadas en el apartado 5.4. La MHC se añadió a cada caja (Tabla 3) antes de su esterilización a $15 \mathrm{lb} \mathrm{in}{ }^{-2}$ durante $15 \mathrm{~min}$. Se verificó la concentración de los hidrocarburos en el suelo modelo 
utilizando la metodología descrita en el apartado 5.11, obteniendo que la concentración inicial teórica fue diferente a la cuantificada disponible (Tabla 3), ya que los hidrocarburos se sorbieron en el suelo modelo y las unidades experimentales.

Tabla 3. Concentraciones iniciales teóricas y disponibles de la mezcla de hidrocarburos (MHC) añadida al suelo modelo para la evaluación de la tolerancia de $F$. arundinacea y la asociación $F$. arundinacea-Lewia sp. a los contaminantes.

\begin{tabular}{cc}
\hline $\begin{array}{c}\text { Concentración inicial teórica } \\
\left(\mathbf{m g ~ k g}^{-1}\right)\end{array}$ & $\begin{array}{c}\text { Concentración inicial disponible } \\
\left(\mathbf{m g ~ k g}^{-1}\right)\end{array}$ \\
\hline 0 & 0 \\
375 & 160 \\
750 & 319 \\
1000 & 425 \\
1500 & 638 \\
3000 & 1276 \\
\hline
\end{tabular}

Cada caja Magenta contenía 16 plantas asociadas o no asociadas, cada concentración de la MHC se preparó por triplicado. Las unidades experimentales se mantuvieron durante 45 días a $25 \pm 1{ }^{\circ} \mathrm{C}$

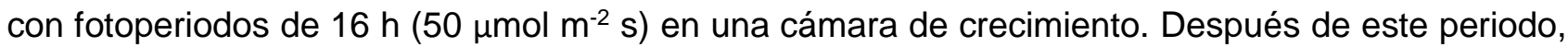
las plantas se cosecharon y se cuantificó la supervivencia, el crecimiento y la concentración de clorofilas (apartado 5.7).

Una vez que se cuantificó la tolerancia de $F$. arundinacea y la asociación $F$. arundinacea-Lewia sp.

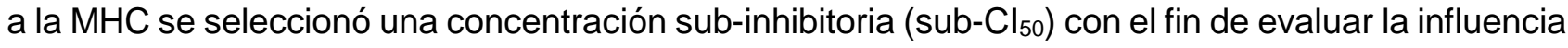
de la asociación endófita sobre $F$. arundinacea durante una cinética de remoción de la $\mathrm{MHC}$ en el suelo modelo. La sub- $\mathrm{Cl}_{50}$ (800 $\mathrm{mg} \mathrm{kg}^{-1}$ inicial teóricos $=275.7 \mathrm{mg} \mathrm{kg}^{-1}$ disponibles), se seleccionó para inducir cambios en las respuestas de defensa de la planta, pero sin inhibir el crecimiento, que en este estudio fue la variable más sensible a la MHC.

\subsection{Cinética de remoción de hidrocarburos}

La cinética de remoción de la MHC se llevó a cabo en frascos de vidrio conteniendo el suelo modelo contaminado con la sub- $\mathrm{Cl}_{50}$. Las plantas de 30 días asociadas y no asociadas, obtenidas en medio semisólido se transfirieron a las unidades experimentales (UE). Las UE utilizadas para la cinética fueron frascos de vidrio con el suelo modelo y 12 plantas cada una. Las plantas asociadas o no asociadas fueron expuestas a la MHC durante $0,7,14,21,28$ y 45 días e incubadas bajo las condiciones anteriores. Para los tiempos 0 y 7 , se cosecharon 60 plantas de cada tratamiento, las cuales se separaron en raíces y tallos para determinar el estrés oxidante (apartado 5.9), actividades enzimáticas (apartado 5.10) y el crecimiento mediante la producción de biomasa (apartado 5.7.2). 
Para los tiempos de 14, 21, 28 y 45 días, se cosecharon 36 plantas de cada tratamiento, las cuales se separaron en raíces y tallos para determinar el contenido de malondialdehído (apartado 5.9.2), la actividad enzimática (apartado 5.10) y el crecimiento mediante la producción de biomasa (apartado 5.7.2). Para cada tiempo ( 0 a 45 días) se determinó la remoción de la MHC (apartado 5.11).

\subsection{Determinación de la supervivencia y el crecimiento}

Al tiempo final de cada tratamiento, las plantas de F. arundinacea y F. arundinacea con Lewia sp. se cosecharon cuidadosamente, se lavaron con agua destilada y se separaron en raíces y tallos para determinar la supervivencia, el crecimiento y el contenido de clorofilas.

\subsubsection{Supervivencia}

Para cuantificar la supervivencia de $F$. arundinacea y la asociación entre $F$. arundinacea y Lewia sp. se consideraron aquellas plantas con color verde como vivas, mientras que las plantas cloróticas en su totalidad fueron consideradas como muertas.

\subsubsection{Crecimiento}

El crecimiento se cuantificó midiendo la biomasa y elongación de raíces y tallos por separado. La biomasa seca (BS), se terminó después de secarse los tejidos vegetales en una estufa $\left(60^{\circ} \mathrm{C}, 48 \mathrm{~h}\right)$. La elongación de los tallos se obtuvo midiendo desde la unión del coleóptilo con la raíz hasta el final del ápice de la hoja primaria. La elongación de la raíz se obtuvo midiendo desde la separación del coleóptilo hasta el ápice de la raíz primaria (Fig.7).

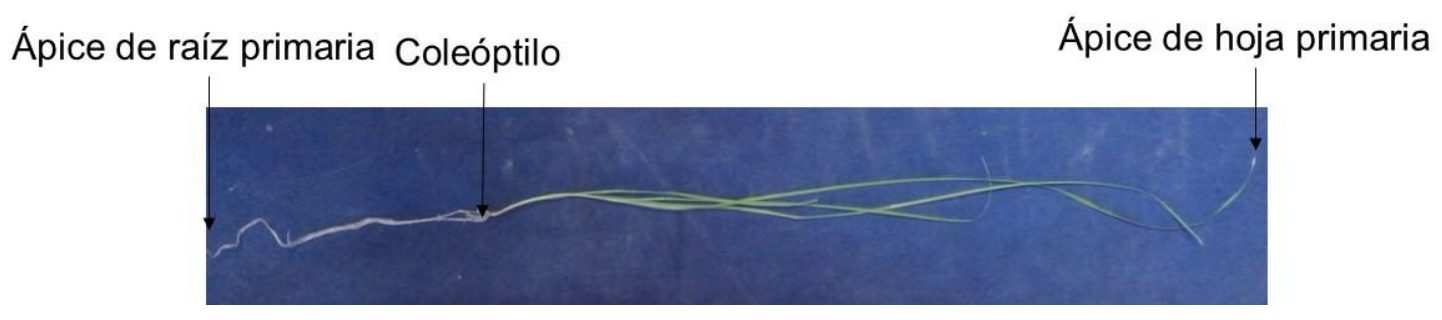

Figura 7. Criterios considerados para cuantificar la longitud de las raíces (desde la separación del coleóptilo hasta el ápice de la raíz primaria) y tallos (desde la unión del coleóptilo con la raíz hasta el final del ápice de la hoja primaria).

\subsubsection{Clorofilas}

Se cosecharon tres plantas de cada tratamiento para la extracción y cuantificación de clorofilas. Para lo anterior, los tallos frescos se pesaron por separado, se colocaron en un mortero, se adicionaron $2 \mathrm{~mL}$ de metanol frío y se trituraron con ayuda de un pistilo. El contenido del mortero se transfirió a un tubo de ensaye de plástico con tapón, y los restos en el mortero y el pistilo se enjuagaron con 1.5 $\mathrm{mL}$ de metanol que se añadieron al tubo de ensaye anterior. Los tubos con el extracto de clorofilas 
se centrifugaron a $804 \mathrm{~g}$ por $10 \mathrm{~min}$ a $4{ }^{\circ} \mathrm{C}$. Se recuperó el sobrenadante, se colocó en otro tubo de ensaye y la biomasa sedimentada se lavó con $1 \mathrm{~mL}$ de metanol frío y se centrifugó (804 g por 10 min a $4{ }^{\circ} \mathrm{C}$ ). Se recuperó el sobrenadante y se colocó con el resto de las clorofilas extraídas, las muestras se llevaron a un volumen total de $8 \mathrm{~mL}$ con metanol frío medido con una micropipeta.

Para cuantificar la concentración de clorofilas, mediante espectrofotometría (50 Conc, Varian) se colocó $1 \mathrm{~mL}$ de la solución en una celda de plástico de $1 \mathrm{~cm}$. Las lecturas de cada muestra se realizaron a 665 y $652 \mathrm{~nm}$, para determinar la concentración de clorofila a y $b$, respectivamente, mediante las ecuaciones propuestas por Porra y col. (1989):

$$
\begin{aligned}
& \text { Chl } a=16.29 X A^{665.2}-8.56 X A^{652.0} \\
& \text { Chl } b=30.66 X A^{652.0}-13.58 X A^{665.2}
\end{aligned}
$$

\subsection{Preparación de extractos crudos libres de células}

Con el fin de obtener extractos libres de células, para cada tratamiento, se separaron tallos de raíces, y aproximadamente $100 \mathrm{mg}$ del tejido fresco se pulverizó con nitrógeno líquido. El tejido fue homogenizado con amortiguador de fosfatos de sodio frío $(50 \mathrm{mM}, \mathrm{pH} 7)$ con polivinilpirrolidona ( $1 \%$ PVP, Sigma-Aldrich) e inhibidor de proteasas (P8215, Sigma-Aldrich, $5 \mu \mathrm{L}$ por $100 \mathrm{mg}$ de tejido fresco). El homogenizado fue tratado en un disruptor celular (Mikro-Dismembrator U, Sartorius) por $2 \mathrm{~min}$ a $2000 \mathrm{rpm}$ y posteriormente se centrifugó $\left(10629 \mathrm{~g}, 4^{\circ} \mathrm{C}, 10 \mathrm{~min}\right)$. El sobrenadante resultante (extracto crudo, EC) fue usado para medir el contenido de proteína en un lector de microplaca (ELx808, Bio-Tek) por el método de Lowry y col. (1951) modificado (Liu y col. 2009), usando un kit comercial (Bio-Rad) y albúmina sérica bovina como estándar.

\subsection{Determinación de estrés oxidante}

\subsubsection{Peróxido de hidrógeno}

El ensayo de $\mathrm{H}_{2} \mathrm{O}_{2}$ se realizó mezclando el $\mathrm{EC}$ con $\mathrm{KCN} 5 \mathrm{mM}$ para inhibir las actividades catalasa (CAT) y peroxidasas (POD). Se mezclaron $250 \mu \mathrm{L}$ del EC con la solución de reacción que contenía sulfato ferroso amónico $(250 \mu \mathrm{M})$, sorbitol $(100 \mu \mathrm{M})$ y naranja de xilenol $(100 \mu \mathrm{M})$ en ácido sulfúrico $25 \mu \mathrm{M}$ y etanol 1\%. La mezcla se incubó a temperatura ambiente por $30 \mathrm{~min}$, el complejo formado entre el Fe y el naranja de xilenol se cuantificó espectrofotométricamente (50 Conc Varian) a 560 nm. El resultado se comparó con una curva estándar de $\mathrm{H}_{2} \mathrm{O}_{2}$ realizada en un intervalo de 0.5 a 80 $\mu \mathrm{M}$ (Cheeseman 2006). 


\subsubsection{Peroxidación de lípidos}

La peroxidación de lípidos de membrana se cuantificó mediante el contenido de MDA en el EC. El EC en este caso, se obtuvo homogenizando $100 \mathrm{mg}$ de tejido fresco en amortiguador Tris- $\mathrm{HCl} 20$ $\mathrm{mM}(\mathrm{pH}$ 7.4) con $10 \mu \mathrm{L}$ de hidroxitolueno butilado 500 mM. La suspensión se centrifugó a $20817 \mathrm{~g}$ ( $4{ }^{\circ} \mathrm{C}, 15 \mathrm{~min}$ ). La mezcla de reacción contenía $0.1 \mathrm{~mL}$ del EC en $200 \mathrm{~mL}$ de solución de reacción (ácido tricloroacético 15\% (TCA), ácido tiobarbitúrico 0.5\% (TBA) y HCl 0.25 N). La mezcla se incubó a $90{ }^{\circ} \mathrm{C}$ por 25 min y el cromóforo producido se cuantificó espectrofotométricamente a $535 \mathrm{~nm}$. El contenido de MDA se estimó considerando un coeficiente de extinción molar $(\varepsilon)$ de $155 \mathrm{mM}^{-1} \mathrm{~cm}^{-1}$ (Buege y Aust 1978).

\subsubsection{Proteínas oxidadas}

El contenido de proteínas oxidadas se determinó mediante la cuantificación de los grupos carbonilo (grupos CO) en proteínas (Juszczuk y col. 2008). Los grupos CO reaccionan con la 2,4dinitrofenilhidrazina (DNPH) generando el conjugado proteína-hidrazona (proteína-DPH) que absorbe a $375 \mathrm{~nm}$. La mezcla de reacción contenía la cantidad adecuada del EC equivalente a 20 $\mu \mathrm{g}$ de proteína y $750 \mu \mathrm{L}$ de DNPH $10 \mathrm{mM}$ en HCl 2 M. Los grupos CO se estimaron considerando un $\varepsilon=22 \mathrm{mM}^{-1} \mathrm{~cm}^{-1}$ (Juszczuk y col. 2008).

\subsection{Actividades enzimáticas}

\subsubsection{Superóxido dismutasa}

La actividad superóxido dismutasa (SOD) se determinó espectrofotométricamente a $450 \mathrm{~nm}$ con un kit comercial (19160, Sigma). El ensayo utiliza la sal de tetrasolio soluble en agua (WST-1), que produce formazan soluble en agua después de la reducción del radical superóxido $\left(\cdot \mathrm{O}_{2}^{-}\right)$. La tasa de reducción del $\cdot \mathrm{O}_{2}^{-}$está relacionada linealmente con la actividad xantina oxidasa, que es inhibida por la SOD. Los resultados se compararon con una curva estándar de SOD realizada bajo las mismas condiciones. Una unidad SOD se definió como la cantidad de enzima necesaria para inhibir en un $50 \%$ la reducción del $\cdot \mathrm{O}_{2}^{-}$por minuto a $25^{\circ} \mathrm{C}$ y $\mathrm{pH} 7$.

\subsubsection{Peroxidasas totales}

La actividad peroxidasa (POD) se midió de acuerdo con el método propuesto por Chance y Maehly (1955), usando guayacol como donador de $\mathrm{H}^{+}$. La oxidación del guayacol a tetra-guayacol es catalizada por las POD en presencia de $\mathrm{H}_{2} \mathrm{O}_{2}$ y se determinó a $450 \mathrm{~nm}$ por 4 min en lector de microplacas. La mezcla de reacción contenía $200 \mu \mathrm{L}$ de amortiguador de fosfatos de sodio (50 mM, $\mathrm{pH} 7$ ), $10 \mu \mathrm{L}$ de guayacol al $1 \%$ y $10 \mu \mathrm{L}$ de EC. La actividad POD se calculó considerando un $\varepsilon=$ 
$26.6 \mathrm{mM}^{-1} \mathrm{~cm}^{-1}$ (Chance y Maehly 1955). Una unidad de actividad POD se define como la cantidad de enzima que cataliza la formación de $1 \mu \mathrm{mol}$ de tetraguayacol por minuto a $25^{\circ} \mathrm{C} \mathrm{y} \mathrm{pH}$.

\subsubsection{Glutatión S-transferasa}

La actividad Glutatión S-transferasa (GST) se determinó utilizando un kit comercial (CS0410, Sigma). La conjugación del glutatión (GSH) con 1-cloro-2,4-dinitrobenzeno (CDNB) catalizada por la GST fue espectrofotométricamente monitoreada a $340 \mathrm{~nm}$ por $4 \mathrm{~min}$. La mezcla de reacción contenía $10 \mu \mathrm{L}$ de EC y $180 \mu \mathrm{L}$ de solución de reacción (GSH 200 mM y CDNB 100 mM en amortiguador Dulbecco a pH 7). La actividad GST se calculó con la tasa de reacción inicial considerando un $\varepsilon=$ $9.6 \mathrm{mM}^{-1} \mathrm{~cm}^{-1}$ (Habig y Jakoby 1981). Una unidad de GST se define como la cantidad de enzima necesaria para catalizar la formación de $1 \mathrm{nmol}$ del conjugado GS-DNB por minuto a $25^{\circ} \mathrm{C}$ y $\mathrm{pH} 7$.

\subsubsection{Estimación de índices relativos de actividad enzimática}

Con el fin de evaluar el efecto de Lewia sp. o la MHC sobre la actividad enzimática de $F$. arundinacea, se estimaron cuatro índices relativos relacionando las actividades enzimáticas obtenidas en cada tratamiento realizado en el suelo modelo.

$$
\begin{aligned}
& I_{1}=((F a-L) / F a)-1 \\
& I_{2}=((F a-L+M H C) /(F a+M H C)-1 \\
& I_{3}=((F a+M H C) / F a)-1 \\
& I_{4}=((F a-L+M H C) /(F a-L))-1
\end{aligned}
$$

Donde,

Fa, corresponde a la planta sola.

Fa-L, corresponde a la asociación endófita planta-hongo.

$F a+M H C$, corresponde a la planta sola expuesta a la mezcla de hidrocarburos, y

Fa- $L+M H C$, corresponde a la asociación endófita planta-hongo expuesta a la mezcla de hidrocarburos.

Las ecuaciones (3) y (4) estiman el efecto de Lewia sp. sobre plantas de $F$. arundinacea cultivadas en ausencia y en presencia de la MHC, respectivamente. Las ecuaciones (5) y (6) son una medida del efecto de la MHC sobre $F$. arundinacea creciendo sin o con Lewia sp., respectivamente. 


\subsection{Extracción y cuantificación de hidrocarburos}

Para extraer la MHC residual del soporte modelo, se realizó una extracción con solventes asistida con microondas (MARS Xpress, CEM). Para lo anterior, a $5 \mathrm{~g}$ de suelo modelo seco se les adicionaron $30 \mathrm{~mL}$ de una mezcla diclorometano:acetona (DCM:acetona, 1:1 v/v) y se procesaron a 175-200 psig y $150{ }^{\circ} \mathrm{C}$ por $30 \mathrm{~min}$. El volumen se concentró en un rotavapor (BÜCHI, V-800) y al volumen obtenido se le adicionó DCM $(10 \mathrm{~mL})$, posteriormente, se tomaron $2 \mathrm{~mL}$ de la mezcla final para la cuantificación de los hidrocarburos (Cruz-Hernández y col. 2013).

Los hidrocarburos extraídos se cuantificaron utilizando un cromatógrafo de gases (Shimadzu GC-2010 Plus) con un detector de ionización de llama (FID) y una columna DB-H1T (15 m, 0.25 mm de diámetro interno $\times 0.10 \mu \mathrm{m}$ de espesor de película, Agilent). Se utilizó nitrógeno como gas acarreador,

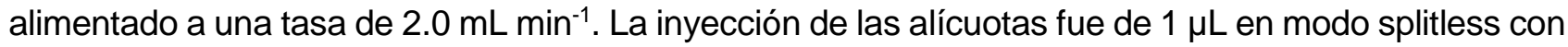
un auto-inyector (Shimadzu AOC-20i). El programa usado para la adquisición y tratamiento de datos fue LabSolutions Direct. Las condiciones de operación del cromatógrafo fueron las siguientes: temperatura inicial del horno de $100^{\circ} \mathrm{C}$ (2 min); la temperatura se aumentó a $200^{\circ} \mathrm{C}$ a $20^{\circ} \mathrm{C} \min ^{-1} \mathrm{con}$ un tiempo de permanencia de $1 \mathrm{~min}$ a esta temperatura; la temperatura del inyector y detector fue de $300{ }^{\circ} \mathrm{C}$.

\subsection{Análisis estadístico}

Cada tratamiento se aplicó de manera aleatoria por triplicado. Se determinó normalidad y homocedasticidad de los datos, una vez que se demostró que cumplían los requisitos para realizar pruebas paramétricas, se realizó una prueba t-Student $(\mathrm{P}<0.05)$ para comparar las medias de las variables medidas en plantas obtenidas en medio MS donde se indujo la asociación endófita. Los resultados derivados de las plantas que crecieron en suelo modelo durante la cinética fueron analizados usando ANOVA seguido de la comparación de medias usando la prueba Tukey-B $(\alpha=0.05)$. La correlación entre variables se realizó calculando coeficientes de Pearson, para dos variables dependientes. Las diferencias entre las medias se indican con letras diferentes 0 asteriscos. Los resultados se presentan como las medias con su desviación estándar (DE) correspondiente. Los análisis se realizaron usando el programa SPSS, versión PAWS 18 (IBM SPSS-IBM Corp, Armonk, 2009). 
6. RESULTADOS 


\subsection{Establecimiento de la asociación $F$. arundinacea-Lewia sp.}

Está confirmado que las condiciones de cultivo son determinantes para el crecimiento de plantas y microorganismos en un laboratorio; estas condiciones pueden ser manipuladas y se relacionan con factores internos y externos que permiten el establecimiento y crecimiento controlado de los organismos. Entre los factores internos destacan la viabilidad y el vigor de los organismos. Entre los factores externos la temperatura, así como la disponibilidad de agua y nutrientes (Rai y col. 2008) son relevantes. En el caso de las plantas, las semillas son las estructuras que dan lugar a la propagación sexual de las plantas y tienen la función de multiplicar la especie (Hardegree y Vactor 1999). Por ello, resulta importante establecer las condiciones de cultivo de semillas para la obtención de plantas sanas y la formación de asociaciones entre plantas y microorganismos.

\subsubsection{Efecto de la composición del medio sobre la germinación}

Las semillas dan lugar a un nuevo individuo, perpetuando y multiplicando a una especie. Para que una semilla pueda dar lugar a un individuo, las condiciones deben ser adecuadas. Dichas condiciones tienen que ver con factores ecológicos apropiados para la germinación, principalmente luz, humedad, sales minerales y temperatura (Hardegree y Vactor 1999). Con el objetivo de establecer las condiciones para la obtención de plantas sanas en tiempos cortos, las semillas de $F$. arundinacea se sembraron en ocho medios con relación carbono/nitrógeno $(\mathrm{C} / \mathrm{N})$ variable, modificando la concentración de sacarosa y sales del medio MS. En la Figura 8 se muestra el índice de germinación de semillas de F. arundinacea, con respecto al tiempo, en cada uno de los medios. En los primeros dos días, la germinación varió de 10 a 50\%, siendo el medio con $\mathrm{C} / \mathrm{N}$ de 5 y las sales MS 100\% (5-1) donde se alcanzó la mayor germinación. Después de 8 días, el mayor número de semillas germinadas se obtuvo en el medio 5-1 alcanzando el 83\%, mientras que, en el resto de los medios, la germinación varió entre 15 y 73\% en el mismo periodo. Después de 14 días de cultivo, en ningún tratamiento se alcanzó la germinación obtenida en el medio 5-1 (83\%)

Hawker, (1971) obtuvo índices de germinación mayores en semillas de maíz, en un medio con baja relación carbono-nitrógeno (C/N). Dekkers y col. (2004) reportaron mayores índices de germinación de semillas de Arabidopsis thaliana en medios con contenido bajo de glucosa. La diferencia en el rango de germinación puede deberse al azúcar utilizado (Rai y col. 2008). Se sabe que algunos genes involucrados en la germinación son regulados por la presencia de azúcares, por lo que concentraciones adecuadas, permiten una germinación de las semillas mayor en tiempos cortos (14 días) (Martin y col. 2002; Dekkers y col. 2004). Además de en la germinación, los azúcares afectan todo el metabolismo, así como las rutas de señalización durante la vida de la planta (Dekkers y col. 2004). 


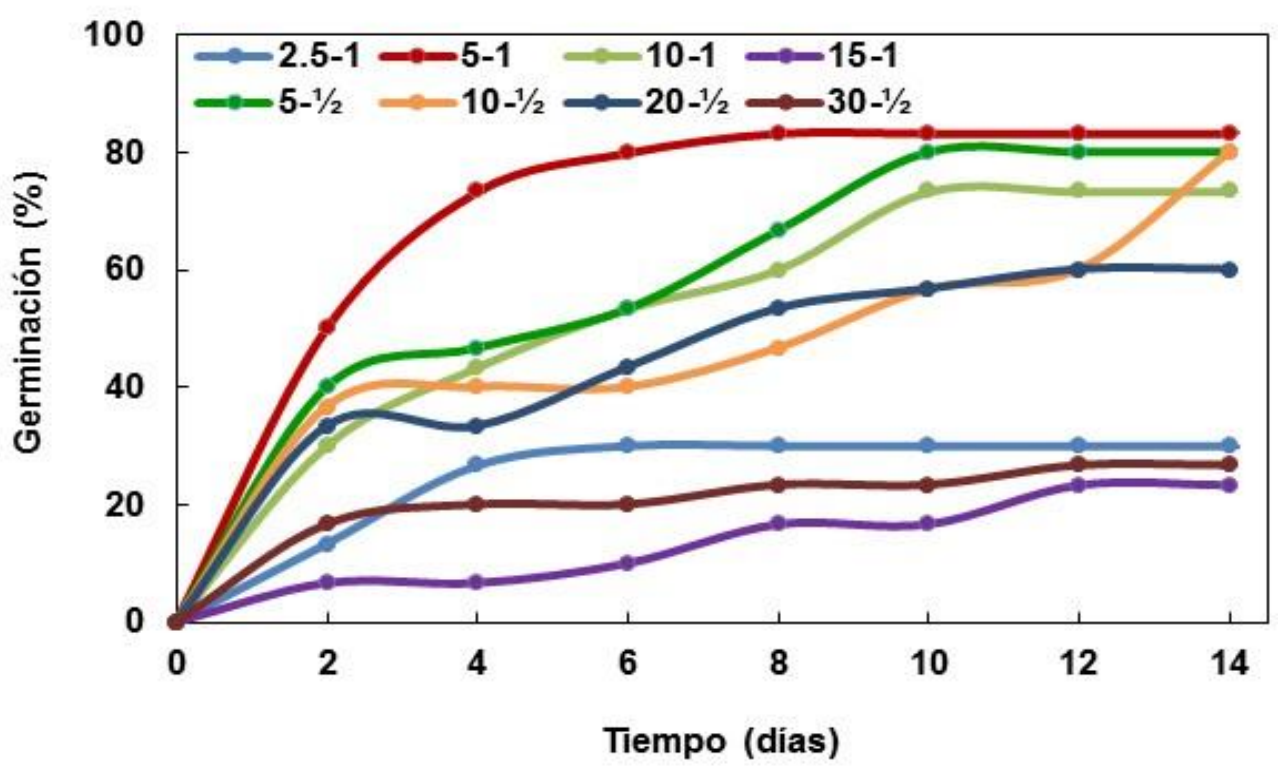

Figura 8. Índice de germinación acumulado de semillas de F. arundinacea durante 14 días, en medio con diferente relación de $\mathrm{C} / \mathrm{N}$ y contenido de sales del medio $\mathrm{MS}(\mathrm{C} / \mathrm{N}-\mathrm{MS})$.

Por otro lado, la limitación de nitrógeno disminuye la germinación, debido a la inhibición en la actividad ureasa, que se coordina con la arginasa para utilizar las proteínas de reserva de las semillas en la germinación; además de ayudar a asimilar el nitrógeno exógeno, evitando la acumulación de urea (Dekkers y col. 2004). Sin embargo, el exceso de nitrógeno excede la actividad ureasa, llevando a una acumulación de urea y provocando necrosis en las plantas.

En este estudio se demostró que la germinación de $F$. arundinacea depende de la concentración de nutrientes, así como de la relación de $\mathrm{C} / \mathrm{N}$ en el medio de cultivo, encontrando que concentraciones de sacarosa de $10 \mathrm{~g} \mathrm{~L}^{-1}$ y sales de MS al 100\% (5-1) permitieron una germinación máxima de semillas.

Con base en los resultados obtenidos, se seleccionó el medio 5-1 como el más adecuado para la obtención de plantas de $F$. arundinacea, dicho medio se utilizó para la germinación de semillas en los estudios posteriores.

\subsubsection{Efecto de la composición del medio sobre la inducción de la asociación endófita}

En la naturaleza, los organismos interaccionan, dando lugar a muchos tipos de asociaciones. A su vez, la formación de una asociación, depende tanto de factores bióticos (tipo de organismo) (Cheplick y col. 1989) como abióticos (temperatura, humedad y disponibilidad de nutrientes) (Hadacek y Kraus 2002). Con el objetivo de establecer el tiempo y las condiciones que permitieran la formación de la asociación entre F. arundinacea y Lewia sp., se evaluó el efecto de la concentración de nutrientes sobre el tiempo para inducir la asociación. Para lo anterior, se cultivaron 
segmentos de raíces de $F$. arundinacea que estuvieron en contacto con Lewia sp. durante periodos variables (hasta 20 días), en los medios de cultivo con relaciones $\mathrm{C} / \mathrm{N}$ distintas y de sales de MS. Se encontró que la asociación se estableció exitosamente después de cinco días en los medios 2.5$1,5-1 / 2,10-1 / 2$ y $20-1 / 2$, sin embargo, las plantas desarrolladas en estos medios presentaron clorosis (Fig. 9). En los medios 5-1 y 10-1 la asociación se formó después de 15 días de contacto (Fig. 9) y no se observó clorosis en las plantas.

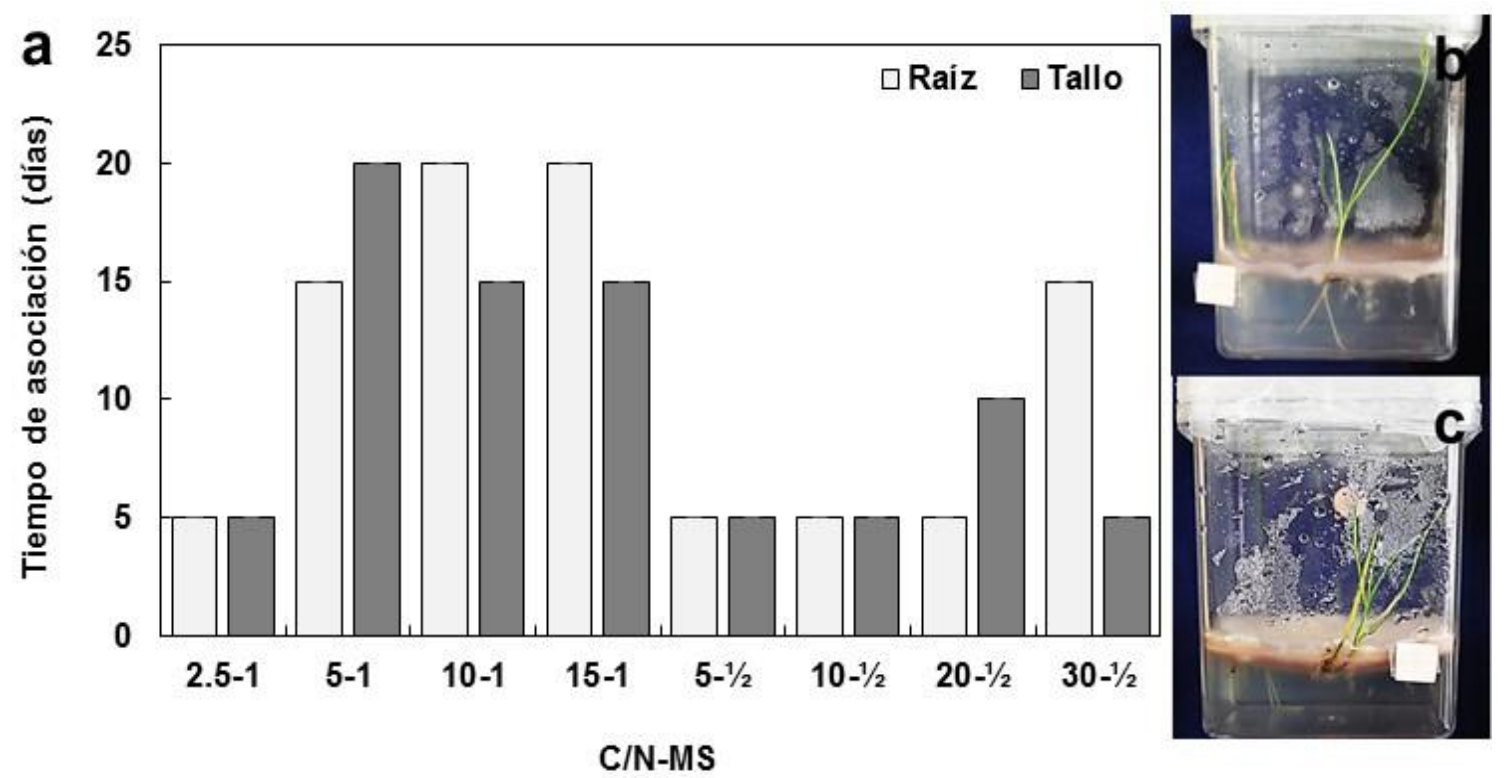

Figura 9. a) Tiempo de formación de la asociación $F$. arundinacea-Lewia sp. respecto a los tratamientos aplicados $(\mathrm{C} / \mathrm{N}$ MS) (media $\pm D E, n=3$ ). b) Plantas de $F$. arundinacea en asociación con Lewia sp. en medio 5-1 (15 días). c) Plantas de F. arundinacea en asociación con Lewia sp. en medio 5-1⁄2, (15 días).

Rasmussen y col. (2007) encontraron que un incremento en la concentración de nitrógeno reducía al $60 \%$ en la colonización de plantas de Lolium perenne por el hongo endófito Neotyphodium lolli, esto, con relaciones $\mathrm{C} / \mathrm{N}$ alrededor de 10. Lo que se atribuyó al aumento en la biomasa foliar y no a la disminución de la biomasa fúngica. Parece ser que los cambios en la $\mathrm{C} / \mathrm{N}$, generados por la modificación de la dosis de nitrógeno, afectan la colonización de plantas por endófitos, no por tener un efecto deletéreo en el microorganismo, sino debido a los cambios drásticos que ocasiona en la fisiología de la planta (Rasmussen y col. 2007). Asimismo, los cambios en la composición del medio de desarrollo de las plantas, conducen a cambios en la secreción de metabolitos que pueden funcionar como moléculas de señalización para los microorganismos; por lo que se ha concluido que el comportamiento de un endófito depende tanto del estado nutrimental de la planta como de la disponibilidad de nutrientes en el medio (Hadacek y Kraus 2002). 
En el caso particular de la asociación de F. arundinacea con Lewia sp. la mejor condición para establecer la asociación endófita y para mantener la planta en condiciones saludables, resultó un medio con el $100 \%$ de sales de MS con una relación C/N de 5 (5-1), utilizando $10 \mathrm{~g} \mathrm{~L}^{-1}$ de sacarosa.

En este estudio, también se demostró que la composición del medio, en cuanto a la relación $\mathrm{C} / \mathrm{N}$ tiene un efecto sobre el tiempo de formación de la asociación endófita entre $F$. arundinacea y Lewia sp. Aunque la asociación no se establece en tiempos menores a 10 días, se seleccionó el medio 51 como el más adecuado para la inducción de la asociación $F$. arundinacea-Lewia sp. ya que, con estas condiciones, las plantas crecieron saludables hasta el término del tratamiento.

\subsection{Efecto de la asociación endófita sobre $F$. arundinacea}

La formación de asociaciones planta-hongo endófito puede modificar procesos fisiológicos y bioquímicos en la planta, lo anterior debido al efecto de adaptación entre ambos organismos (Tanaka y col. 2006). En el presente estudio, se encontró que la asociación tiene un efecto positivo sobre el crecimiento vegetal y que también promueve cambios en la respuesta antioxidante y el estrés oxidante de la planta en condiciones de crecimiento controladas.

\subsubsection{Crecimiento}

Se ha demostrado que los endófitos aumentan el crecimiento de varias especies de plantas (Bailey y col. 2006). Por lo anterior, se evaluó el crecimiento de plantas de F. arundinacea cultivadas en medio MS (100\% de sales) con una C/N-MS de 5 (medio 5-1), con y sin el endófito Lewia sp. Después de 15 días de cultivo en medio semisólido, Lewia sp. mejoró significativamente el crecimiento de las raíces (3.4 veces) y los tallos (1.9 veces) con respecto a las plantas no inoculadas (Fig. 10). La modificación de la producción de biomasa vegetal, puede estar acompañada de cambios morfológicos y fisiológicos tanto en raíces como en hojas, lo que a su vez afecta la forma de responder a las condiciones de estrés ambiental (Torres y col. 2012).

En la Fig. 10b se observa que la presencia de Lewia sp. provocó la coloración café de las raíces, además de un aumento visible en su grosor. En las hojas, la presencia del hongo incrementó el ancho (Fig. 10c) y el largo. La modificación de los tejidos y las células de las plantas se ha observado en plantas de Agrostis hyemalis asociada con el endófito Epichloë amarillans (White y col. 1997), así como en F. arundinacea asociada con el endófito Neotyphodium coenophialum (Soleimani y col. 2010). De hecho, se sabe que los endófitos pueden mejorar el crecimiento de las plantas a través de mecanismos como la regulación de la producción de fitohormonas, cambios morfológicos en la raíz y aumento en la captura de nutrientes (Mei y Flinn 2010; Porras-Alfaro y Bayman 2011). 


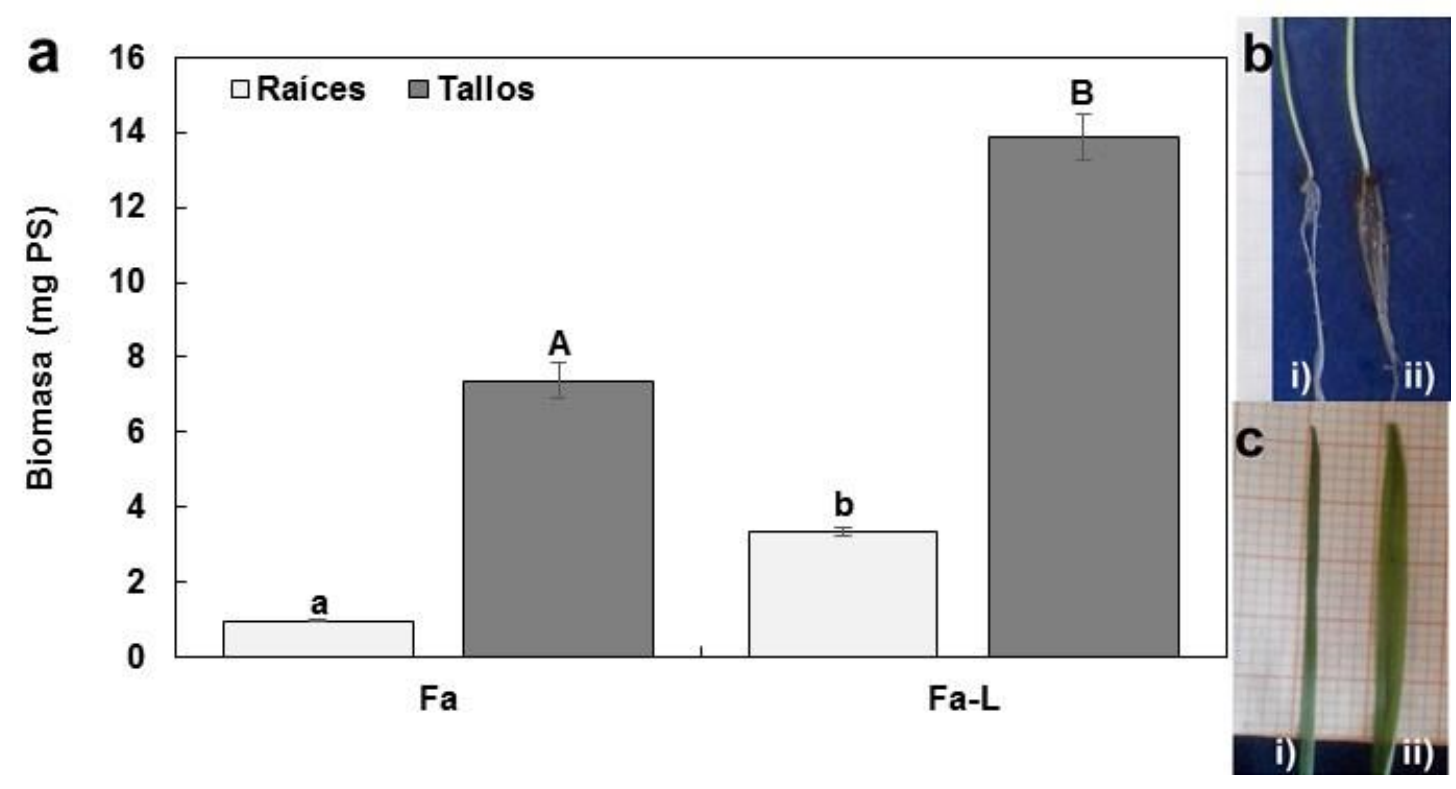

Figura 10. a. Efecto de la asociación entre $F$. arundinacea y Lewia sp. sobre la producción de biomasa en raíces y tallos después de 15 días de contacto, letras distintas (minúsculas para raíces, mayúsculas para tallos) indican diferencias significativas $(p<0.01, n=12)$. b. raíces i) no asociadas $(F a)$ y ii) asociadas (Fa-L). c. hojas i) no asociadas y ii) asociadas.

Otros mecanismos que inciden en el crecimiento, incluyen la sobreproducción y el control de moléculas de señalización como el $\mathrm{H}_{2} \mathrm{O}_{2}$ (White y Torres 2010). El $\mathrm{H}_{2} \mathrm{O}_{2}$ induce la respuesta de enzimas de las vías de señalización, requeridas por las plantas para generar resistencia contra microorganismos. A su vez, las enzimas de estas vías tienen diversas actividades, entre las que se incluyen la degradación de proteínas y la señalización hormonal. Algunas enzimas de señalización inducidas por el $\mathrm{H}_{2} \mathrm{O}_{2}$, se encuentran implicadas en la cascada de las proteínas quinasas activadas por mitógenos (MAPK), que controlan la activación de diferentes mecanismos de defensa en respuesta al estrés por ERO (Tripathy y Oelmüller 2012). Sin embargo, el exceso de $\mathrm{H}_{2} \mathrm{O}_{2}$ podría causar daños en las células vegetales, por lo que resulta importante monitorear este parámetro junto con otros marcadores del estrés oxidante.

\subsubsection{Daño oxidante}

El $\mathrm{H}_{2} \mathrm{O}_{2}$ es una ERO producida de manera natural en las plantas, opera como molécula de señalización durante el crecimiento y puede ser producida en exceso durante el establecimiento de asociaciones planta-microorganismo (Cheeseman 2006). Por lo tanto, en este estudio se evaluó el efecto de la inducción de la asociación endófita sobre la producción de $\mathrm{H}_{2} \mathrm{O}_{2}$ en $F$. arundinacea.

La inducción in vitro de la asociación endófita entre $F$. arundinacea y Lewia sp. incrementó significativamente la acumulación de $\mathrm{H}_{2} \mathrm{O}_{2}$ en raíces y tallos (3.4 y 4.8 veces, respectivamente) comparado con las plantas no inoculadas (Tabla 4). Una respuesta similar se registró durante la 
simbiosis entre Gigaspora margarita y dos leguminosas (Lanfranco y col. 2005), y entre Pisolithus tinctorius y Castanea sativa (Baptista y col. 2007).

Tabla 4. Efecto de la inducción de la asociación endófita entre $F$. arundinacea y Lewia sp. sobre la acumulación de $\mathrm{H}_{2} \mathrm{O}_{2}$ y el daño oxidante (MDA y CO), después de 15 días de contacto.

\begin{tabular}{|c|c|c|c|c|}
\hline \multirow{2}{*}{ Variable respuesta } & \multicolumn{2}{|c|}{ Raíces } & \multicolumn{2}{|c|}{ Tallos } \\
\hline & F. $a$ & F. $a-L$ & F. $a$ & F. $a-L$ \\
\hline $\mathrm{H}_{2} \mathrm{O}_{2}\left(n m o l g^{-1} P F\right)$ & $92.8 \pm 3.0^{a}$ & $313.8 \pm 13.6^{b}$ & $94.2 \pm 2.9^{\mathrm{A}}$ & $466.4 \pm 22.2^{B}$ \\
\hline MDA (nmol $\left.g^{-1} P F\right)$ & $11.4 \pm 2.2^{\mathrm{a}}$ & $33.9 \pm 0.9^{b}$ & $37.8 \pm 2.8^{\mathrm{A}}$ & $46.3 \pm 1.4^{\mathrm{B}}$ \\
\hline Grupos CO ( $\mu \mathrm{mol} \mathrm{g}^{-1}$ proteína) & $461.9 \pm 29^{b}$ & $163.6 \pm 10^{a}$ & $349.4 \pm 9^{B}$ & $193.2 \pm 11^{\mathrm{A}}$ \\
\hline
\end{tabular}

* Medias con letras diferentes (minúsculas para raíces, mayúsculas para tallos) indican diferencias significativas entre tratamientos $(\mathrm{P}<0.05)$. Tratamientos por órgano (medias $\pm \mathrm{DE}, \mathrm{n}=3$ para tallos, $\mathrm{n}=2$ para raíces).

Este incremento podría deberse a un déficit de nutrientes en el medio debido al crecimiento del hongo o a un aumento en la producción de ERO por Lewia sp. El déficit de nutrientes como el $\mathrm{K}^{+}$ puede incrementar la acumulación de $\mathrm{H}_{2} \mathrm{O}_{2}$ y etileno (Shin y Schachtman 2004). Así mismo, se ha demostrado que los endófitos sobreproducen ERO para inactivar la defensa de la planta, manteniendo así el mutualismo (Tanaka y col. 2006). Además, la sobreproducción de ERO durante la simbiosis planta-hongo endófito podría ser una manera de controlar la proliferación del hongo (Nanda y col. 2010). La sobreproducción de ERO conduce a un incremento en la oxidación de proteínas y peroxidación de lípidos de membrana. El malondialdehído (MDA) es el producto final de la peroxidación lipídica y sus niveles indican el daño en la membrana celular (Hu y col. 2015).

En raíces y tallos de $F$. arundinacea, el contenido total de $\mathrm{H}_{2} \mathrm{O}_{2}$ y MDA se incrementó significativamente por efecto de Lewia sp. (Tabla 4), lo anterior puede atribuirse a la disminución de la defensa antioxidante en la planta para mantener la asociación (Tanaka y col. 2006). En contraste, los grupos carbonilo (grupos CO) disminuyeron ( 2 veces) en las plantas asociadas en comparación con las plantas no asociadas. Lo anterior pudo deberse a dos procesos: (i) reparación de las proteínas dañadas por la vía de las chaperonas; y/o (ii) proteólisis de las proteínas oxidadas que no tienen reparación (Vallentine y col. 2014; Pulido y col. 2017). Uno o ambos procesos podrían haberse incrementados por la presencia de Lewia sp. Nuestros resultados sugieren que, con el fin de establecer la asociación con F. arundinacea, Lewia sp. incrementó la producción de ERO y la oxidación de lípidos de membrana, mientras promovió la eliminación de proteínas oxidadas de la planta en cultivo en medio semisólido. Aunado a lo anterior, las asociaciones endófitas también pueden promover cambios en la expresión y actividad de enzimas involucradas en la defensa antioxidante (Dupont y col. 2015). 


\subsubsection{Defensa antioxidante}

Varias enzimas actúan en la defensa antioxidante de las plantas y su actividad puede ser modificada por la presencia de microorganismos endófitos (Tanaka y col. 2006). La superóxido dismitasa (SOD) es la primera defensa enzimática antioxidante e interviene en la detoxificación de ERO mediante la catálisis de la conversión de $\bullet_{2}^{-} \quad \mathrm{O}_{2} \mathrm{H}_{2} \mathrm{O}_{2}$, este último es degradado por catalasas y peroxidasas (Becerra-Castro y col. 2013). Las peroxidasas (POD) tienen más afinidad por el $\mathrm{H}_{2} \mathrm{O}_{2}$ que las CAT, y se consideran un marcador del estrés (Kvesitadze y col. 2009). Por lo tanto, se evaluó el efecto de la inducción de la asociación endófita sobre la defensa enzimática antioxidante en plantas de $F$. arundinacea.

La actividad SOD en raíces de $F$. arundinacea disminuyó ( 1.5 veces) después de 15 días de contacto con el hongo, mientras que, en tallos la asociación no modificó esta actividad (Tabla 5). Las raíces son el primer punto de contacto entre el hongo y la planta y, por lo tanto, son el primer punto de supresión en la defensa antioxidante para facilitar la formación de la asociación (Bailey y col. 2006). La actividad POD, por otra parte, fue dos veces menor en los tallos que en las raíces, particularmente en las plantas asociadas (Tabla 5). Mientras que Lewia sp. no modificó de manera significativa esta actividad en las raíces, el hongo causó una disminución (1.5 veces) en los tallos. Lo anterior pudo deberse a la presencia de enzimas como las catalasas que contribuyen a contrarrestar la acumulación de $\mathrm{H}_{2} \mathrm{O}_{2}$ (Mhamdi y col. 2010).

Tabla 5. Efecto de la inducción de la asociación endófita entre $F$. arundinacea y Lewia sp. sobre la defensa antioxidante $(\mathrm{SOD}, \mathrm{POD}$ y GST)*.

\begin{tabular}{lcccc}
\hline \multirow{2}{*}{$\begin{array}{l}\text { Actividad enzimática } \\
\left.\text { (U g } \mathbf{~}^{-1} \text { proteína }\right)\end{array}$} & $\boldsymbol{F} \cdot \boldsymbol{a}$ & $\boldsymbol{F} \cdot \boldsymbol{a}-\boldsymbol{L}$ & $\boldsymbol{F} \cdot \boldsymbol{a}$ & $\boldsymbol{F} \cdot \boldsymbol{a}-\boldsymbol{L}$ \\
\cline { 2 - 5 } SOD & $1280 \pm 168^{\mathrm{b}}$ & $811 \pm 93^{\mathrm{a}}$ & $3990 \pm 271^{\mathrm{A}}$ & $3732 \pm 572^{\mathrm{A}}$ \\
POD & $1022 \pm 100^{\mathrm{a}}$ & $1174 \pm 62^{\mathrm{a}}$ & $821 \pm 113^{\mathrm{B}}$ & $552 \pm 39^{\mathrm{A}}$ \\
GST & $84.8 \pm 4.6^{\mathrm{b}}$ & $11.0 \pm 1.2^{\mathrm{a}}$ & $135.6 \pm 6.3^{\mathrm{B}}$ & $40.2 \pm 3.9^{\mathrm{A}}$ \\
\hline
\end{tabular}

* Medias con diferentes letras (minúsculas para raíces, mayúsculas para tallos) indican diferencias significativas entre tratamientos $(P<0.05)$. Los valores son las medias $\pm D E(n=3$ para tallos, $n=2$ para raíces $)$.

Otro grupo de enzimas que contribuye de forma importante en la defensa antioxidante y en procesos de detoxificación de xenobióticos, son las GST. Éstas, catalizan la conjugación de compuestos endógenos y exógenos con el glutatión (GSH) y tienen un papel importante en el desarrollo de las plantas y su respuesta a condiciones de estrés abiótico y biótico (Dixit y col. 2011; Kumar y col. 
2013). Se ha encontrado que la expresión génica de las GST se relaciona con la tolerancia y susceptibilidad de las plantas a hongos (Kumar y col. 2013). Los microorganismos endófitos pueden modificar su actividad y expresión (Zhang y col. 2010), lo que puede cambiar la producción de hormonas y/o ERO. Comparado con las plantas no inoculadas, la actividad GST de raíces y tallos fue significativamente menor (7.7 y 3.4 veces, respectivamente) en respuesta a la inducción de la asociación. Contrario a lo anterior, Bailey y col. (2006) encontraron un incremento en la actividad GST de plantas de Theobroma cacao en asociación con Trichoderma hamatum-DIS 219b. E decremento en la actividad GST, en las plantas asociadas, sugiere que esta actividad es reprimida durante el establecimiento y mantenimiento de la asociación.

Factores bioquímicos, además de la producción de ERO y la acción del sistema antioxidante, están involucrados en la señalización del estrés (Baxter y col. 2013) y pueden facilitar la interacción plantaendófito a nivel bioquímico (Tanaka y col. 2006). Se ha reportado que los cambios bioquímicos debidos a la formación de asociaciones pueden contribuir al aumento en la tolerancia y crecimiento de las plantas expuestas a estresores como HAP (Debiane y col. 2009), metales pesados (Ahmad 2011) y sequías (Tiwari y col. 2016). Como se observa en la Tablas 5, los resultados del presente estudio sugieren que, con el fin de establecer la asociación con F. arundinacea, Lewia sp. promueve la reducción de la actividad de enzimas involucradas en la defensa antioxidante de la planta en cultivo semisólido.

El uso de cultivo semisólido para este tipo de estudios, permite eliminar la complejidad del uso de suelos, sin embargo, se aleja de lo que sucede realmente en la naturaleza. Con el propósito de aproximarse a las condiciones físicas de un suelo, pero evitando la interferencia de otros organismos o sustancias diferentes a las utilizadas en el estudio, en el presente se empleó un suelo modelo. El uso de los suelos modelo permiten este tipo de acercamiento, ya que su modificación en el transcurso de los experimentos es mínima y pueden retener agua y nutrientes (Alkan y col. 2005). Con base en lo anterior, para evaluar la tolerancia de $F$. arundinacea y la asociación $F$. arundinaceaLewia sp. a una mezcla de hidrocarburos, se utilizó un suelo modelo como soporte de crecimiento.

\subsection{Evaluación de la tolerancia a hidrocarburos en un suelo modelo}

Se ha demostrado que contaminantes orgánicos como los HAP afectan el metabolismo de las plantas, alterando su crecimiento y supervivencia (Lin y col. 2002). El efecto adverso de ambos factores puede modificarse a través de asociaciones endófitas particulares (Porras-Alfaro y Bayman 2011). 


\subsubsection{Supervivencia de $F$. arundinacea y la asociación endófita}

El éxito de una planta para la fitorremediación depende de factores como la concentración y naturaleza de los contaminantes, así como de las condiciones del suelo y de su tolerancia a los contaminantes, lo anterior permitirá o no, el establecimiento de la planta en un sitio contaminado (Debiane y col. 2009). Por lo anterior, resulta importante determinar la tolerancia de una planta a un contaminante en particular. En este estudio, se evaluó la tolerancia, medida a través de la supervivencia y el crecimiento, de F. arundinacea y la asociación F. arundinacea-Lewia sp. a concentraciones crecientes de una mezcla de hidrocarburos (MHC) en un suelo modelo.

En ausencia de la MHC se observó una disminución (50\%) en la supervivencia de las plantas no asociadas, después de 45 días de cultivo. Al aumentar la concentración de la MHC la supervivencia disminuyó hasta ser nula en la concentración más alta de la MHC (Fig. 11). La baja supervivencia de $F$. arundinacea en el suelo modelo sin la MHC se atribuyó a una baja disponibilidad de nutrientes. Se sabe que la supervivencia de las plantas en un suelo depende de la disponibilidad de nutrientes, lo cual repercute en su salud (Andersson y Milberg 1998). Los procesos de desarrollo de las plantas están controlados por señalizaciones moleculares que dependen del suministro adecuado de nutrientes minerales (Dakora y Phillips 2002). En contraste, se encontró un $97.9 \%$ de supervivencia en las plantas asociadas con Lewia sp. cultivadas en el suelo modelo sin contaminantes (Fig. 11). Sin embargo, la supervivencia también disminuyó al aumentar la concentración de hidrocarburos, encontrando que el $25 \%$ de las plantas asociadas sobreviven en la concentración más alta de la MHC (1276 mg kg-1). A pesar de esta disminución, la asociación de F. arundinacea con Lewia sp. incrementó ( 2 veces) la supervivencia de las plantas en el suelo modelo sin contaminantes con respecto a las plantas no asociadas.

Reynoso-Cuevas y col. (2008), encontraron $100 \%$ de supervivencia de $F$. arundinacea en un medio semisólido contaminado con una mezcla de hidrocarburos (pireno, fenantreno, benzo[a]pireno y petróleo crudo maya), en un intervalo de concentraciones de 500 a $4000 \mathrm{mg} \mathrm{kg}^{-1}$. La diferencia en la supervivencia de las plantas entre ambos estudios puede atribuirse al soporte de crecimiento que, el medio semisólido utilizado, permite la disponibilidad total de los nutrientes. En el presente estudio se evaluó el efecto de dos factores estresantes sobre las plantas, la baja disponibilidad de nutrientes y la presencia de hidrocarburos en el suelo modelo. De hecho, se ha demostrado que hidrocarburos como el fenantreno y el pireno pueden quedar adsorbidos o acumulados en las células de la raíz, impidiendo el paso del agua y los nutrientes (Gao y Zhu 2004), lo que puede causar la baja sobrevivencia de las plantas de F. arundinacea. 


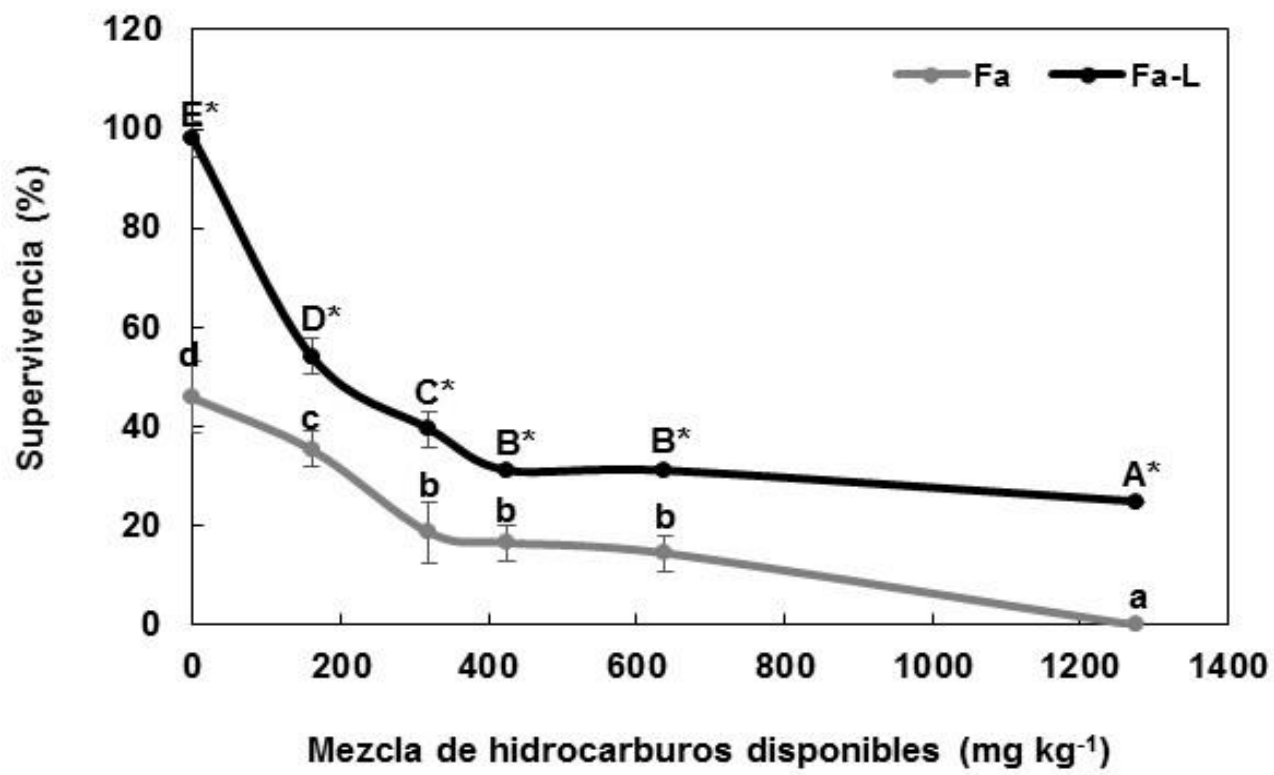

Figura 11. Supervivencia de $F$ arundinacea (Fa) y la asociación $F$. arundinacea-Lewia sp. (Fa-L) después de 45 días de exposición a concentraciones crecientes de la MHC. Letras distintas indican diferencias significativas entre los niveles de concentración, los asteriscos indican diferencias significativas entre plantas no asociadas (Fa) y asociadas (Fa-L) ( $p<0.001, \mathrm{n} \geq 3$ cajas con 16 plantas cada una).

La presencia de hongos endófitos, como Chaetomium globosum (Schulz y col. 2002) y Penicillium janthinellum (Khan y col. 2011), beneficia a las plantas por la producción de metabolitos (alcaloides, antibióticos o reguladores de crecimiento) y por cambios en la composición de exudados radiculares que modifican físicamente el suelo, aumentando la disponibilidad de nutrientes. Así, nuestros resultados (Fig. 11), indican que la asociación de F. arundinacea con Lewia sp. promueve la supervivencia de las plantas en el suelo modelo sin y con contaminantes. Lo anterior, podría atribuirse a una modificación en el metabolismo de la planta, además de que Lewia sp. incrementa la disponibilidad de nutrientes del suelo modelo.

\subsubsection{Crecimiento de $F$. arundinacea y la asociación endófita}

Uno de los parámetros usados para determinar la tolerancia de las plantas a los contaminantes es la cuantificación del crecimiento. Una manera de evaluarlo, es la medición de la biomasa y la elongación de las raíces y tallos (Lin y col. 2002). En este estudio, se evaluó el efecto de la concentración de la MHC sobre la producción de biomasa vegetal y la elongación de raíces y tallo de F. arundinacea y la asociación $F$. arundinacea-Lewia sp. durante 45 días en el suelo modelo (Fig. 12).

\subsubsection{Elongación de raíces y tallos}

El análisis realizado en las plantas no asociada mostró que, después de 45 días de cultivo, no hubo un efecto significativo en la elongación de las raíces por efecto de la MHC. En contraste, en las raíces 
asociadas, los contaminantes provocaron un aumento significativo (20\%) con respecto al control. La comparación entre las plantas asociadas y no asociadas permite observar que Lewia sp. provocó una disminución significativa ( 1.5 veces) en la longitud de las raíces de $F$. arundinacea en comparación con las plantas no asociadas (Fig. 12a). Para el caso de los tallos, la elongación de las plantas no asociadas expuestas a $319 \mathrm{mg} \mathrm{kg}^{-1}$ de la $\mathrm{MHC}$ inicial disponible disminuyó significativamente. En las plantas asociadas, la disminución se registró a partir de la exposición a $160 \mathrm{mg} \mathrm{kg}{ }^{-1}$ de la MHC inicial disponible (Fig. 12b). Sin embargo, la longitud de los tallos de F. arundinacea fue significativamente mayor ( 1.6 veces) en las plantas asociadas con Lewia sp. respecto de las no asociadas (Fig. 12b).
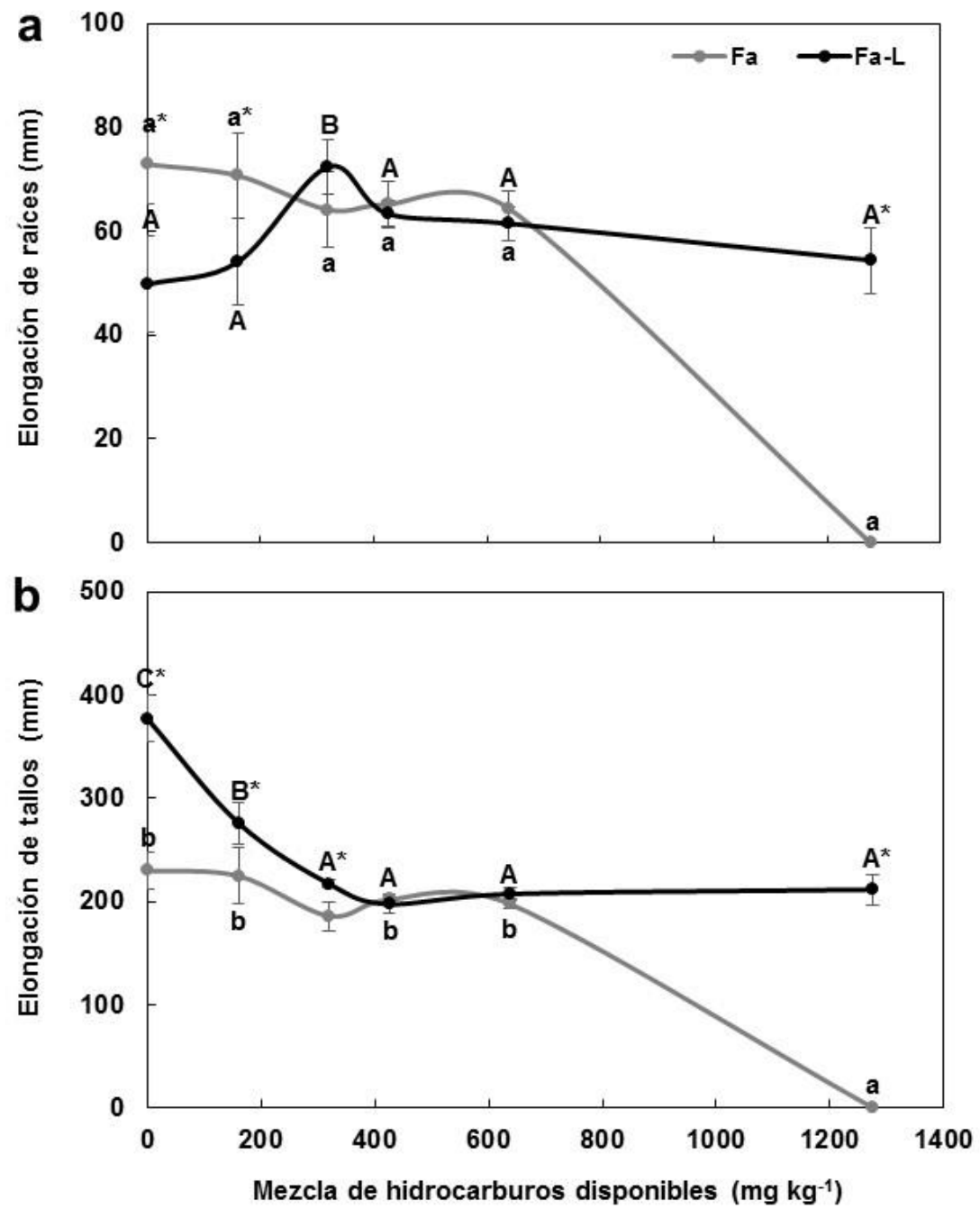

Figura 12. Elongación de a) raíces y b) tallos de $F$ arundinacea ( $F a)$ y la asociación $F$. arundinacea-Lewia sp. (Fa-L) después de 45 días de exposición a concentraciones crecientes de la MHC. Letras distintas indican diferencias significativas entre los niveles de concentración, los asteriscos indican diferencias significativas entre plantas no asociadas (Fa) y asociadas (Fa-L) $(p<0.001, \mathrm{n} \geq 12)$. 
Las gramíneas como $F$. arundinacea son especies comúnmente seleccionadas para su uso en la fitorremediación de suelos contaminados con herbicidas, metales pesados e hidrocarburos por su extenso crecimiento radicular (Zhao y col. 2013). Sin embargo, esta característica puede modificarse por la presencia de los contaminantes, así como se observa en los resultados mostrados en la Figura 12. Al respecto, Reynoso-Cuevas y col. (2008) reportaron una reducción del $50 \%$ en la elongación de raíces de cinco gramíneas ( $F$. arundinacea, Cenchrus ciliaris, Bouteloua curtipendula, Echinochloa crusgalli y Rhynchelytrum repens) expuestas por 40 días a $1000 \mathrm{mg} \mathrm{kg}^{-1}$ de una MHC compuesta por fenantreno, pireno, benzo[a]pireno y petróleo crudo maya. La diferencia en el efecto de la MHC en el estudio de Reynoso-Cuevas y col. (2008) y el presente trabajo, podría deberse a la composición de la $\mathrm{MHC}$, ya que, en dicho estudio, la mezcla contiene compuestos con mayor disponibilidad y toxicidad para las plantas (benzo[a]pireno y petróleo crudo maya).

En plantas sometidas a estrés, la respuesta morfológica también depende del tipo de contaminantes y del órgano en estudio (Gao y Zhu 2004). Por ejemplo, Lin y col. (2002) demostraron que concentraciones de 14000 y $29000 \mathrm{mg} \mathrm{kg}^{-1}$ de aceite combustible provocaron aumento significativo en la elongación de tallos de Spartina alterniflora. Sin embargo, una concentración mayor (171000 $\mathrm{mg} \mathrm{kg}^{-1}$ ) del contaminante disminuyó de forma importante la elongación. Reynoso-Cuevas y col. (2008) observaron una disminución en la elongación de tallos de cinco gramíneas expuestas a 500 $\mathrm{mg} \mathrm{kg}^{-1}$ de una MHC (fenantreno, pireno, BaP y petróleo crudo maya). La alteración en la elongación de los tallos puede atribuirse a alteraciones fisiológicas en la raíz, las cuales modifican el transporte de agua y nutrientes a través del xilema de un órgano a otro (Gao y Zhu 2004). Cruz-Hernández y col. (2013), también encontraron una reducción significativa (31\%) en la elongación de tallos de plantas de $F$. arundinacea asociadas con Lewia sp. expuestas a $1500 \mathrm{mg} \mathrm{kg}^{-1}$ de una MHC (hexadecano, fenantreno y pireno) por 45 días. La diferencia entre los resultados del trabajo mencionado y el nuestro, se puede deber a que en su estudio las plantas se regaban dos veces por semana con una solución de nutrientes (Long-Ashton) y en nuestro estudio los riegos fueron con agua cada cinco días.

De acuerdo con los resultados (Fig. 12), la elongación de raíces y tallos no resultó ser una variable sensible a cambios en la concentración de una $\mathrm{MHC}$, tal que permita cuantificar la tolerancia de $F$. arundinacea y la asociación $F$. arundinacea-Lewia sp. Por lo anterior, y con el fin de cuantificar la tolerancia para esta planta y esta asociación en particular, se determinó el crecimiento a través de la producción de biomasa y el contenido de clorofilas.

\subsubsection{Producción de biomasa}

La biomasa vegetal es uno de los parámetros más utilizados para determinar los efectos fitotóxicos de contaminantes como los hidrocarburos (Lin y col. 2002). La MHC redujo significativamente (desde 15 y hasta $47 \%$ ) la biomasa de las raíces de plantas de $F$. arundinacea no asociadas desde la dosis 
más baja estudiada. En las plantas asociadas la biomasa de las raíces disminuyó, pero a partir de una concentración de $319 \mathrm{mg} \mathrm{kg}^{-1}$ de la MHC inicial disponible. La biomasa de las raíces asociadas fue significativamente mayor ( 2 veces) que, en las no asociadas, tanto en ausencia como en presencia de la MHC (Fig. 13a).

En el caso de los tallos, se observó que concentraciones de la MHC mayores a $319 \mathrm{mg} \mathrm{kg}^{-1}$, causaron una disminución significativa (32-45\%) en la biomasa de plantas no asociadas. En la concentración máxima ensayada, las plantas se encontraron totalmente cloróticas, y, por lo tanto, se consideraron muertas, por lo que la producción de biomasa fue considerada como nula (Fig. 11-13). En los tallos de plantas asociadas con Lewia sp. la biomasa disminuyó (15\%) por efecto de la MHC. Sin embrago, la biomasa de los tallos en las plantas asociadas fue significativamente mayor (1.5-2.2 veces) que la obtenida en los tallos de las plantas no asociadas, sin importar la concentración de la MHC (Fig. 13b).

Similar a nuestros resultados, se ha observado el efecto de reducción en la biomasa de raíces y tallos de F. arundinacea sola (Cheema y col. 2009) y en asociación con Lewia sp. (Cruz-Hernández y col. 2013) por exposición a HAP. Lo anterior, puede atribuirse a una reducción en la disponibilidad de agua y nutrientes en el suelo modelo contaminado (Cheema y col. 2009) y a la toxicidad de los hidrocarburos (Gao y Zhu 2004). Otra posibilidad podría ser la translocación y el metabolismo de los hidrocarburos en los tallos (Gao y Zhu 2004). De hecho, se sabe que la acumulación de compuestos tóxicos en los tallos causa alteraciones en los sistemas fotosintéticos, provocando un déficit en la nutrición de las plantas y con ello en su crecimiento (Wei y col. 2014), lo cual podría estar sucediendo en el caso de F. arundinacea.

A pesar de que el efecto de los contaminantes en ambos grupos de plantas es similar, la presencia del endófito provocó que la biomasa vegetal siempre fuera mayor que en las plantas no asociadas. Al respecto, Soleimani y col. (2010), observaron que la biomasa de raíces y tallos de $F$. arundinacea y $F$. pratensis era significativamente mayor ( 1.5 veces) al asociar las plantas con los endófitos Neotyphodium coenophialum y $N$. uncinatum crecidas en un suelo contaminado con $8.5 \pm 0.9 \mathrm{mg}$ $\mathrm{kg}^{-1}$ de HAP. Cruz-Hernández y col. (2013) también observaron que la biomasa de raíces de $F$. arundinacea era significativamente mayor ( 1.7 veces) que en plantas no asociadas y expuestas a una $\mathrm{MHC}$ en un suelo modelo contaminado.

El aumento en la biomasa de gramíneas como $F$. arundinacea podría deberse a cambios en la respuesta fisiológica, que incluyen aumentos en los niveles de fitohormonas de crecimiento (Kuldaua y Bacon 2008) y mejora en el transporte de nutrientes (Mei y Flinn 2010). De hecho, uno de los 
efectos positivos de las asociaciones endófitas, es el aumento en la tolerancia y crecimiento de las plantas expuestas a agentes estresores (Debiane y col. 2009; Ahmad 2011; Tiwari y col. 2016).
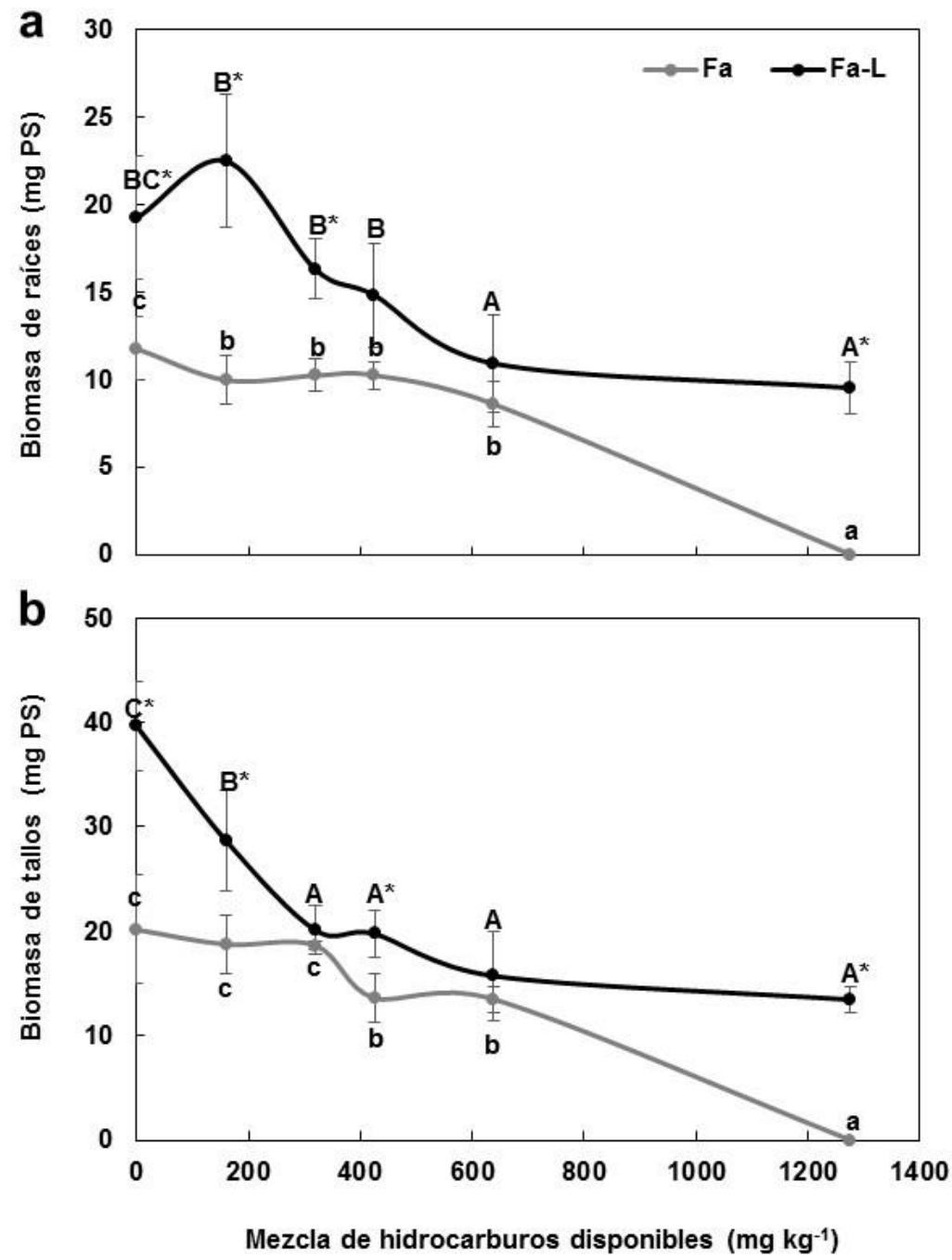

Figura 13. Producción de biomasa de a) raíces y b) tallos de $F$ arundinacea (Fa) y la asociación endófita $F$. arundinaceaLewia sp. (Fa-L) expuestas a concentraciones crecientes de la MHC durante 45 días. Letras distintas indican diferencias significativas entre los niveles de un mismo factor. Asteriscos indican diferencias significativas entre plantas no asociadas (Fa) y asociadas (Fa-L) $(p<0.001, \mathrm{n} \geq 8)$.

\subsubsection{Contenido de clorofilas}

Las modificaciones en la biomasa de tallos de plantas de $F$. arundinacea asociadas y no asociadas son el resultado de un conjunto de variaciones bioquímicas relacionadas con el estado nutrimental de las plantas; esto, a su vez, puede relacionarse con los niveles de clorofila en los tallos, ya que se consideran un indicador sensible, tanto al estrés abiótico (Yang y col. 2010) como al biótico (Li y col. 2014). En el presente trabajo, después de 45 días de crecimiento, el contenido de ambas clorofilas en plantas expuestas o no a la MHC aumentó significativamente (2-4 veces) en respuesta a la 
presencia de Lewia sp. (Fig. 14). En las plantas expuestas a la MHC, el contenido de ambas clorofilas decreció, siendo mayor la pérdida en la clorofila a (Fig. 14b).

En general, la MHC provocó una reducción ( $40-90 \%$ ) en el contenido de clorofila $a$ y $b$, en las plantas no asociadas. En las plantas asociadas, ambas clorofilas fueron entre $\sim 70$ y $80 \%$ menores que en las plantas control (Fig. 14).
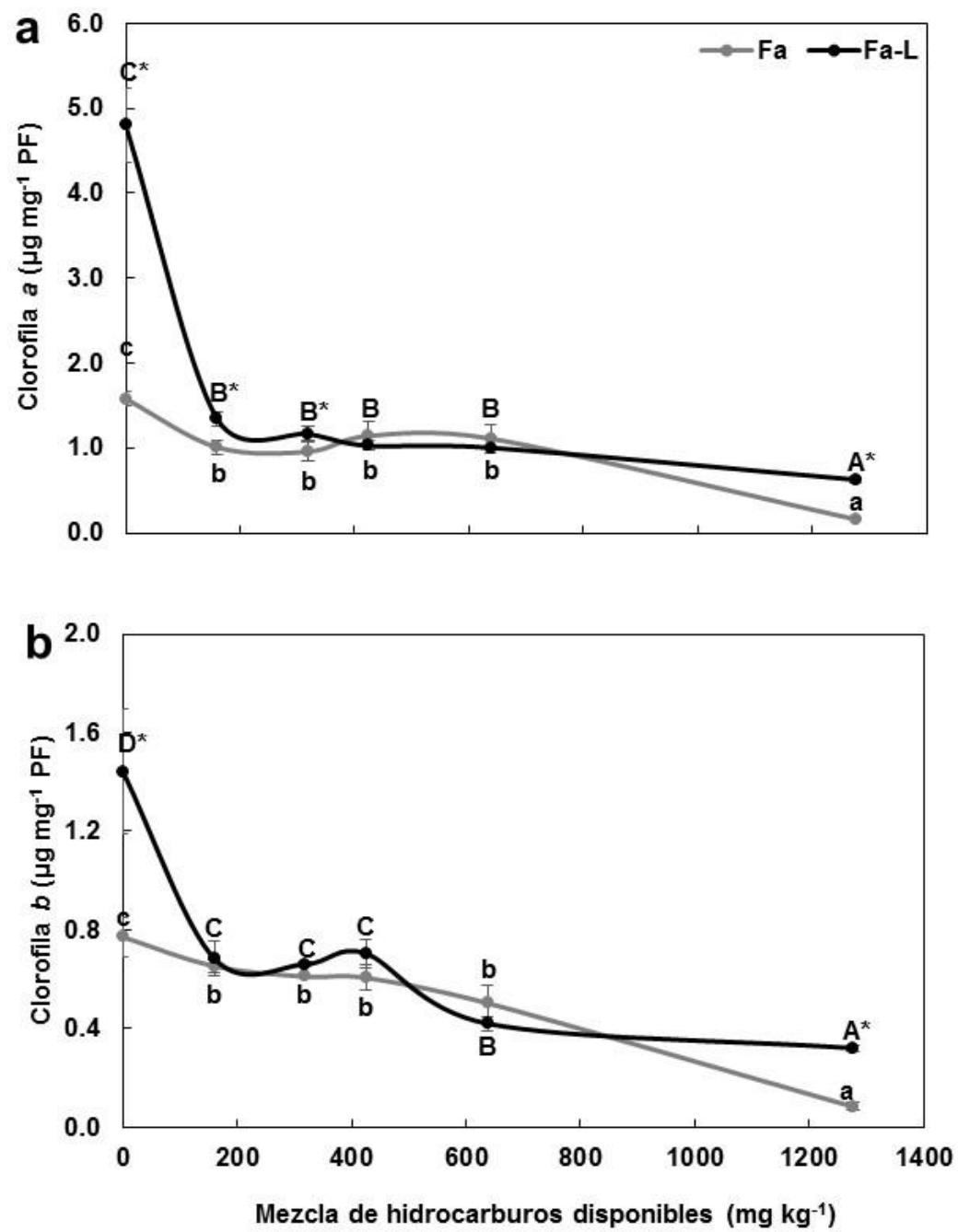

Figura 14. Concentración de a) clorofila a y b) clorofila $b(\mu \mathrm{g} \mathrm{mg} \mathrm{PF}-1) F$ arundinacea $(\mathrm{Fa})$ y la asociación $F$. arundinaceaLewia sp. (Fa-L) después de 45 días de exposición a concentraciones crecientes de la MHC. Letras distintas indican diferencias significativas entre los niveles de un mismo factor. Asteriscos indican diferencias significativas entre plantas no asociadas (Fa) y asociadas (Fa-L) $(p<0.001, \mathrm{n} \geq 3)$.

La concentración de clorofilas en plantas expuestas a hidrocarburos ha sido utilizada como una medida del estrés oxidante. Al respecto, Wei y col. (2014) reportaron una disminución (56\%) en la concentración de clorofilas a y $b$ en plantas de trigo expuestas a $200 \mathrm{mg} \mathrm{kg}^{-1}$ de fenantreno. Lo que fue atribuido a una ineficiente transferencia de energía, que resulta en la generación del estado de 
triplete de las clorofilas, las que reaccionan con tripletes de oxígeno produciendo el altamente reactivo oxígeno singulete $\left({ }^{1} \mathrm{O}_{2}\right)$ muy reactivo; esto conduce a la generación de estrés oxidante en las plantas (Wei y col. 2014). La generación de estrés por hidrocarburos en las plantas provoca cambios morfológicos, lo que podría relacionarse con el descenso en la biomasa y la elongación observadas en las raíces y tallos (Fig. 12 y 13).

Se sabe que la asociación entre plantas y endófitos modifica la producción de clorofilas. Similar al presente trabajo, Waqas y col. (2012) encontraron un aumento en el contenido de clorofilas $a$ y $b$ en plantas de Cucumis sativus asociadas con Phoma glomerata y Penicillium sp. no sometidas a estrés. El aumento en la concentración de clorofilas en las plantas control asociadas, puede relacionarse con un aumento en la expresión de genes que codifican para proteínas que participan en el ciclo de Calvin y en la ruta de tetrapirrol, donde se producen clorofilas (Dupont y col. 2015). La fotosíntesis es un proceso modificado por la presencia de endófitos (Tripathy y Oelmüller 2012) que durante el metabolismo de los hidrocarburos modifican la estructura de los cloroplastos y el cierre de los estomas. En el caso particular de la asociación entre F. arundinacea y Lewia sp. crecida en ausencia de hidrocarburos, el aumento en el contenido de clorofilas se conserva aún bajo condiciones de estrés por falta de nutrientes y por exposición a los contaminantes.

Comparando todas las variables utilizadas para cuantificar el crecimiento, la producción de biomasa de los tallos de plantas no asociadas, fue la más sensible a la MHC, ya que disminuyó más con respecto a las plantas control y con las plantas asociadas. Por lo que, la biomasa de tallos se utilizó para estimar el índice de tolerancia (IT) a la presencia de concentraciones crecientes de la MHC (Fig. 15).

Con base en los datos calculados para el IT, se encontró una $\mathrm{Cl}_{50}$ cercana a $757 \mathrm{mg} \mathrm{kg}^{-1}$ para $F$. arundinacea y de $1100 \mathrm{mg} \mathrm{kg}^{-1}$ para las plantas asociadas, lo que muestra que Lewia sp. provoca un incremento en la tolerancia de F. arundinacea (Fig. 15). El IT obtenido para las plantas no asociadas se usó como referencia para definir una concentración sub-inhibitoria (sub-Cl$\left.{ }_{50}\right)$ de la MHC, tal que estimulara los mecanismos de defensa antioxidante sin alterar la producción de biomasa en tallos. Por lo anterior, para los estudios cinéticos, se seleccionó una sub- $\mathrm{Cl}_{50}$ de $800 \mathrm{mg}$ $\mathrm{kg}^{-1}$ de la MHC, lo que corresponde a $275.72 \mathrm{mg} \mathrm{kg}^{-1}$ disponibles de la MHC.

Nuestros resultados difieren de los reportados por Cheema y col. (2009), quienes encontraron una inhibición del $\sim 50 \%$ en la producción de biomasa de tallos de $F$. arundinacea por exposición a concentraciones de hidrocarburos menores que las usadas en nuestro estudio (680 $\mathrm{mg} \mathrm{kg}^{-1}$ ), sugiriendo que esta reducción es inherente a la toxicidad de los hidrocarburos. Por otro lado, Soleimani y col. (2010) encontraron que la biomasa de tallos de F. arundinacea y F. pratensis 
asociadas con $N$. coenophialum y $N$. uncinatum se reducía en un $50 \%$ por exposición a $8.5 \pm 0.9 \mathrm{mg}$ $\mathrm{kg}^{-1}$ de una mezcla de HAP.
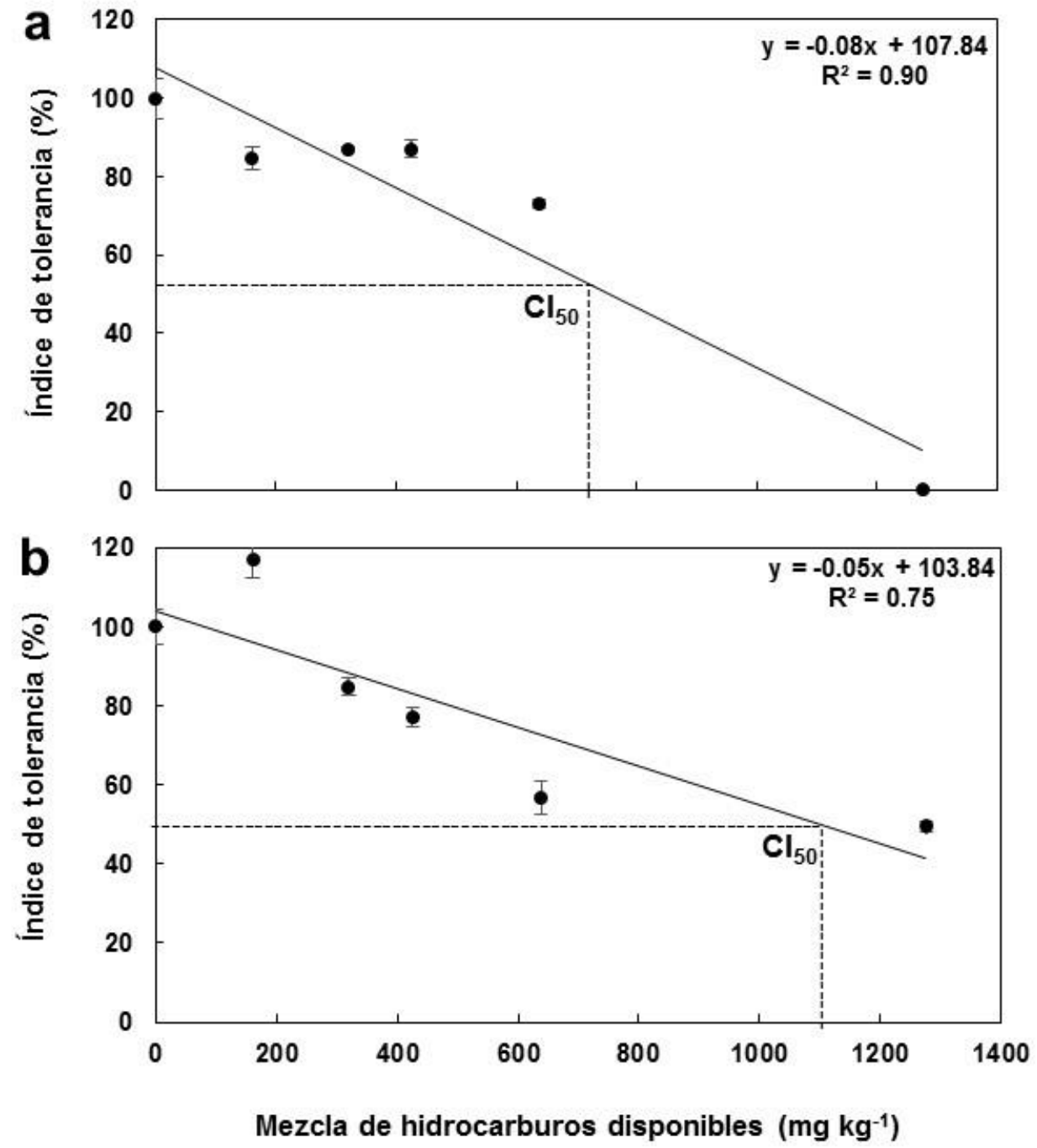

Figura 15. Índices de tolerancia de a) F. arundinacea y b) F. arundinacea-Lewia sp. expuestas a concentraciones crecientes de una mezcla de hidrocarburos durante 45 días. La línea punteada indica el valor considerado para la estimación de la $\mathrm{Cl}_{50}(p<0.001, \mathrm{n}=3)$

La inhibición en el crecimiento de los tallos podría atribuirse al metabolismo del fenantreno y el pireno en este tejido, ya que implica la formación de compuestos tóxicos en la planta (Narro y col. 1992), lo anterior podría estar provocando modificaciones en la expresión de proteínas implicadas en la defensa antioxidante y la actividad fotosintética, afectando su crecimiento. Aunado al estrés causado por los contaminantes, la falta de nutrientes que se observó (Fig. 11-14) en el suelo modelo disminuyó la supervivencia de las plantas, este resultado nos llevó a modificar la concentración de los nutrientes para asegurar que el estrés generado en las plantas solas o asociadas se debía a la MHC, los resultados se muestran a continuación. 


\subsubsection{Efecto de la concentración de nutrientes}

Debido a la baja supervivencia registrada en los experimentos en suelo modelo en ausencia de contaminantes (Fig. 11), se evaluó el efecto de la concentración de nutrientes sobre la supervivencia y la incidencia de clorosis visual de las plantas no asociadas crecidas por 45 días (Fig. 16). Las unidades experimentales contenían suelo modelo humectado (30\%) con medio MS concentrado 3 , 4,5 y 6 veces (3X, 4X, 5X y 6X, respectivamente). En los medios concentrados 3 y 6 veces ( $3 \mathrm{X}$ y $6 X)$, la supervivencia de las plantas disminuyó 20 y 25\%, respectivamente. Mientras que en los medios concentrados 4 y 5 veces (4X y 5X) la supervivencia fue del 100\% (Fig. 16). Del total de plantas al final del ensayo en cada medio, el 25\% presentó clorosis en hojas en los medios $3 X$ y 4X, mientras que en los medios 5X y 6X, el 100 y 80\% (respectivamente) de las plantas presentó clorosis (Fig. 16).
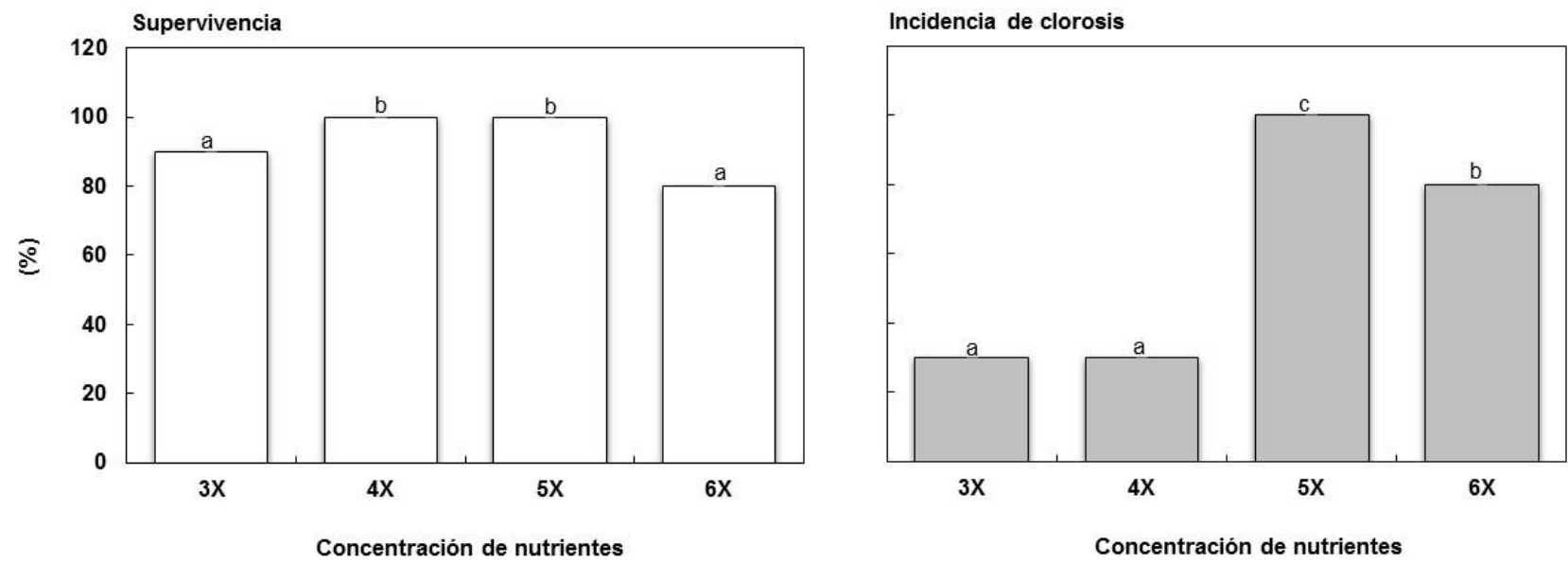

Figura 16. Supervivencia e incidencia de clorosis de plantas de $F$. arundinacea en medios de cultivo concentrados 3,4 , 5 y 6 veces ( $3 X, 4 X, 5 X$ y $6 X$, respectivamente). Letras diferentes indican diferencias significativas $(p<0.001, n=3)$.

Concentrar el medio 4 veces (4X) permitió que el 100\% de plantas supervivieran, así como presentaran una menor incidencia de clorosis. Varios estudios demuestran que los azúcares, incluida la sacarosa, son esenciales en las plantas como substratos en la cadena respiratoria para la generación de energía e intermediarios metabólicos que son usados para la síntesis de macromoléculas. Además, los carbohidratos son moléculas de señalización para la producción de hormonas de crecimiento en plantas (Morkunas y col. 2012), además de que están asociados a la captación de otros nutrientes esenciales. Asimismo, concentraciones de azúcares altas, generalmente, reprimen la fotosíntesis y promueven el almacenamiento de carbohidratos; por el contrario, concentraciones bajas incrementan la fotosíntesis y la secreción de carbohidratos (Nicolaï y col. 2006). Lo anterior podría explicar la clorosis observada en los medios concentrados 5 y 6 veces (5X y 6X, respectivamente). 

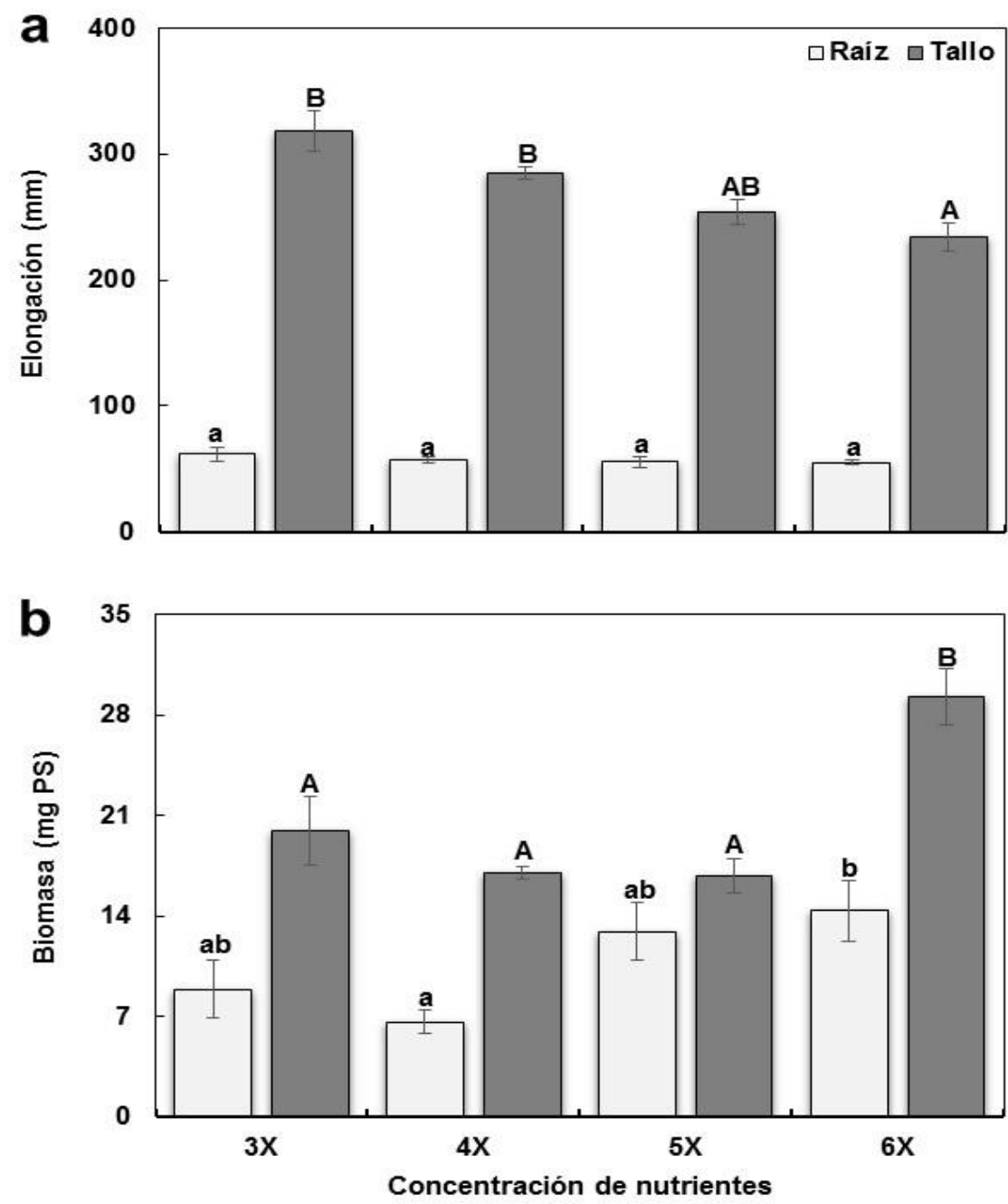

Figura 17. a) Elongación y b) producción de biomasa de raíces y tallos de $F$. arundinacea en medio de cultivo MS con las sales concentradas $3,4,5$ y 6 veces ( $3 X, 4 X, 5 X$ y $6 \mathrm{X}$, respectivamente). Letras diferentes indican diferencias significativas entre concentración de nutrientes $(p<0.001, \mathrm{n}=3)$.

Además de la supervivencia y la clorosis, la concentración de nutrientes afecta el crecimiento de las plantas. Por lo anterior, se evaluó el efecto de la concentración de nutrientes en el suelo modelo, sobre la elongación y la biomasa de tallos y raíces de plantas no asociadas (Fig. 17). Después de 45 días, la concentración de nutrientes no tuvo efecto significativo sobre la elongación de las raíces. En el caso de los tallos, con la mayor concentración utilizada (6X), se observó una disminución del $36 \%$ (Fig. 17a). La biomasa de tallos en las plantas crecidas en el medio $6 \mathrm{X}$ fue mayor que en el resto de los medios (Fig. 17b); sin embargo, el $80 \%$ de las plantas presentó clorosis (Fig. 16).

Con base en los resultados mostrados en la Figura 16 y 17, se escogió la formulación del medio con nutrientes 4 veces mayor ya que se obtuvo el 100\% de supervivencia de las plantas y la menor incidencia de clorosis en las plantas. Lo que resulta importante para asegurar que en los 
experimentos siguientes los efectos observados se deban sólo a la presencia de los contaminantes (800 $\mathrm{mg} \mathrm{kg}^{-1}$ de la MHC al suelo modelo) y no al del déficit de nutrientes.

\subsection{Efecto de una mezcla de hidrocarburos sobre $F$. arundinacea y la asociación endófita}

Con el objetivo de evaluar la influencia de la asociación inducida entre Lewia sp. y $F$. arundinacea al estrés por la MHC, se expuso a plantas no asociadas y asociadas a $800 \mathrm{mg} \mathrm{kg}^{-1}$ de la MHC en el suelo modelo durante $0,7,14,21,28$ y 45 días. Para lo anterior, se cuantificó el crecimiento. el daño oxidante y la defensa antioxidante.

\subsubsection{Crecimiento}

El crecimiento se determinó a través de la biomasa vegetal, esto, debido a que resultó ser la variable más sensible a la presencia de hidrocarburos. Se encontró que la biomasa de las raíces no asociadas aumentó significativamente entre los 7 y 14 días, mientras que en las raíces asociadas con Lewia sp. la biomasa aumentó desde los 7 y hasta los 28 días (Fig. 18). En plantas asociadas, la biomasa de las raíces aumentó ( 3 a 4 veces) con respecto a las plantas no asociadas (Fig. 18). Respecto a los tallos, no se observó efecto significativo de la MHC en ningún grupo de plantas (Fig. 18). La biomasa de los tallos en las plantas asociadas fue significativamente mayor ( 0.9 veces) que la de las plantas no asociadas, tanto en ausencia como en presencia de la MHC (Fig. 18). Los resultados (Fig. 18) demuestran que Lewia sp. promueve el incremento de la biomasa de $F$. arundinacea expuesta a $800 \mathrm{mg} \mathrm{kg}^{-1}$ de una MHC durante 45 días.
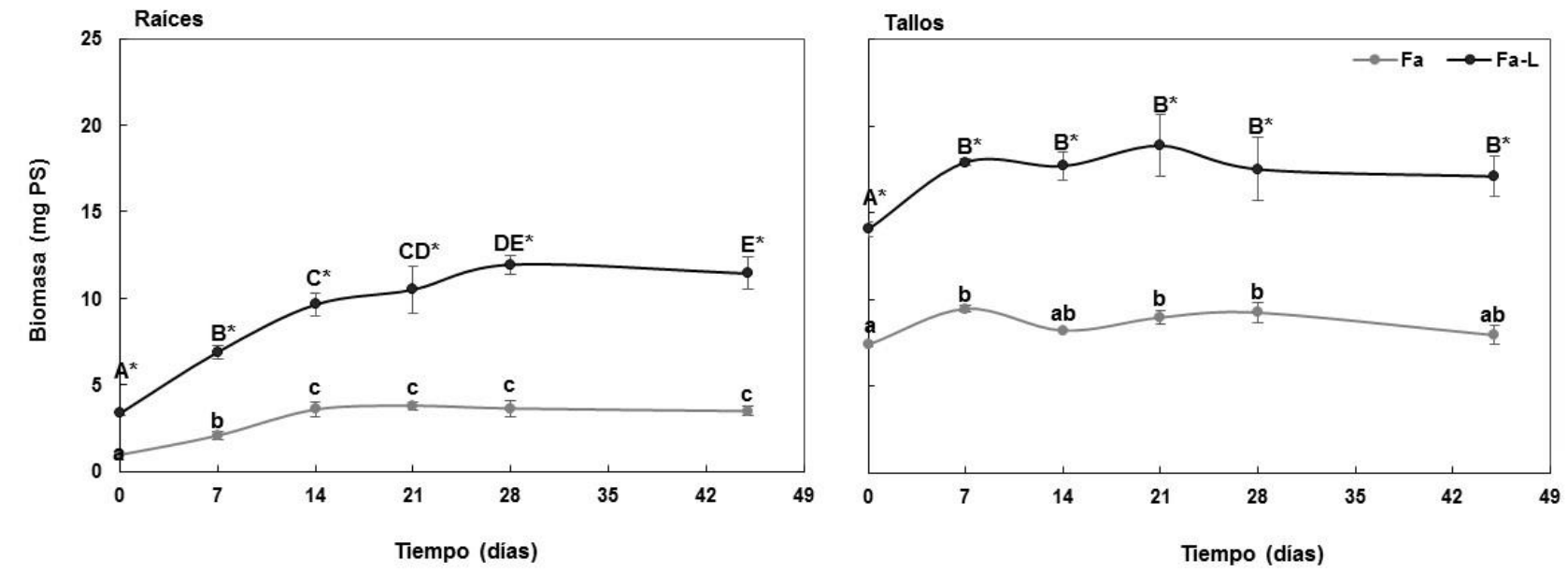

Figura 18. Producción de biomasa en raíces y tallos de plantas de $F$. arundinacea $(\mathrm{Fa}$ ) y la asociación endófita entre $F$. arundinacea y Lewia sp. (Fa-L) expuestas a $800 \mathrm{mg} \mathrm{kg}^{-1}$ de la MHC en el suelo modelo durante 45 días. Letras distintas indican diferencias significativas entre los niveles de concentración. Asteriscos indican diferencias significativas entre plantas solas ( $\mathrm{Fa}) \mathrm{o}$ asociadas $(\mathrm{Fa}-\mathrm{L})(p<0.001, \mathrm{n} \geq 8)$. 
La capacidad de las plantas para tolerar a los contaminantes está determinada por varias vías metabólicas que protegen las funciones de los organelos celulares, manteniendo así la homeostasis. La función de estas vías se modifica constantemente, en especial cuando las plantas se asocian con microorganismos endófitos, por lo que el monitoreo constante de las rutas involucradas en la defensa antioxidante, puede generar información valiosa acerca de asociaciones endófitas y la exposición a condiciones de estrés como la contaminación por hidrocarburos.

\subsubsection{Daño oxidante}

Para evaluar la influencia de la asociación endófita entre Lewia sp. y $F$. arundinacea en el estrés por la MHC en función del tiempo de exposición, se cuantificó el contenido de malondialdehído (MDA) en raíces y tallos de plantas no asociadas y asociadas (Fig. 19). La peroxidación de lípidos es comúnmente considerada como un proceso perjudicial que conduce a modificaciones estructurales de los lípidos de membrana, así como en lipoproteínas. Las ERO se introducen en las colas hidrofóbicas de los ácidos grasos insaturados para producir los hidroperóxidos lípidos (Yoshimura y col. 2004). En la peroxidación de los lípidos de membrana insaturados, el MDA es el producto final en la descomposición, así, el MDA puede reflejar el daño celular ocasionado por la sobreproducción de ERO (Hu y col. 2015).

De manera general, se encontró que el tiempo de exposición a la $\mathrm{MHC}$ tiene un efecto sobre el contenido de MDA en raíces y tallos de plantas no asociadas y asociadas (Fig. 19). En raíces y tallos de las plantas no asociadas, el contenido de MDA aumentó con el tiempo de exposición a la MHC, encontrando niveles hasta $\sim 5$ veces mayores con respecto al inicio (Fig. 19). En las raíces de las plantas asociadas, el contenido de MDA disminuyó con el tiempo de exposición, encontrando concentraciones hasta $\sim 2$ veces menores que al inicio (Fig. 19a), sin embargo, para los tallos, el contenido de MDA aumentó desde los 7 días (Fig. 19).

Durante 45 días, el contenido de MDA en las raíces fue reducido por la presencia del hongo (Fig. 19). No ocurrió lo mismo para los tallos, en donde el contenido de MDA en los tallos de las plantas asociadas fue ligeramente mayor que en las plantas no asociadas (Fig. 19). Varios estudios han demostrado que la exposición a HAP como el fenantreno, inducen la producción de MDA en plantas como Solanum lycopersicum (Ahammed y col. 2012), así como en Cucumis sativus, Brassica rapa, B. campestris y Lactuca sativa (Ahammed y col. 2012). El aumento en la producción de MDA por la exposición a hidrocarburos, sugiere un incremento en la producción de ERO y por consiguiente, en el estrés oxidante. Sin embargo, los resultados sugieren que el hongo controla la sobreproducción de $\mathrm{ERO}$, al menos en las raíces, protegiendo a la planta expuesta a la MHC. 

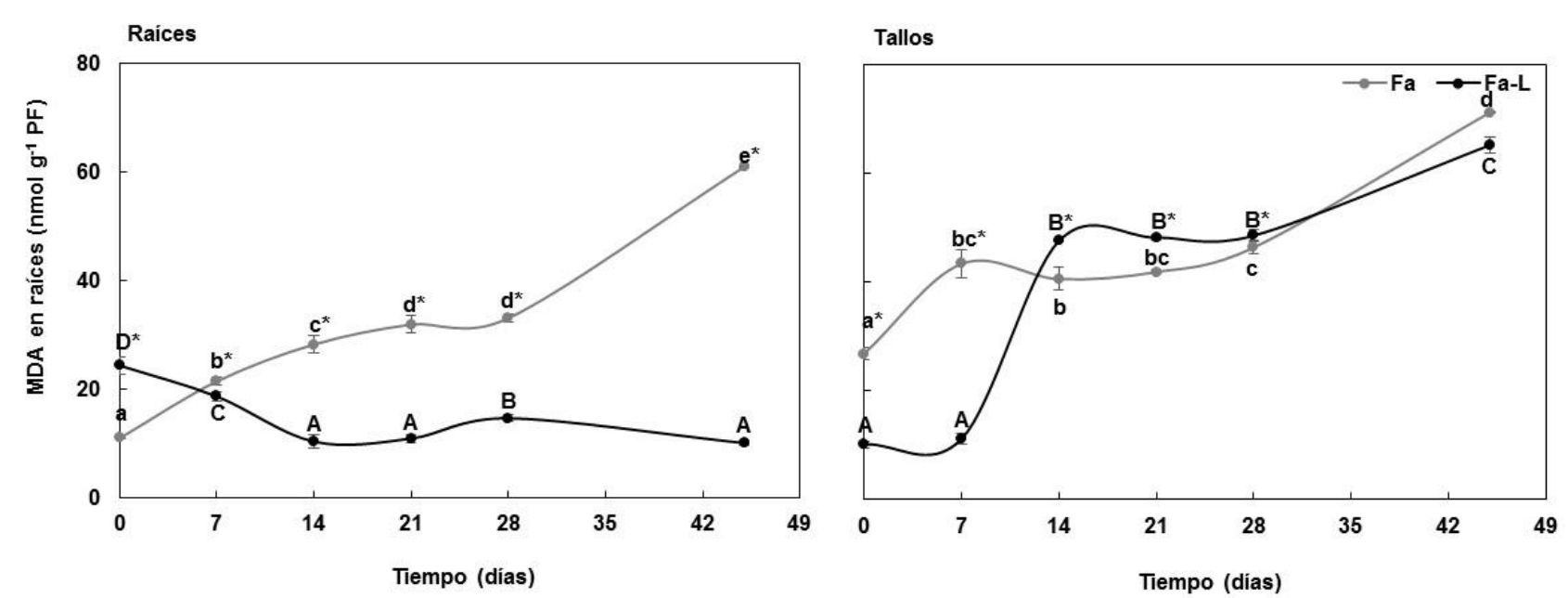

Figura 19. Efecto del tiempo de exposición a $800 \mathrm{mg} \mathrm{kg}^{-1}$ de la $\mathrm{MHC}$ sobre el contenido de malondialdehído en raíces y tallos de plantas de $F$. arundinacea $(\mathrm{Fa})$ y $F$. arundinacea asociada con Lewia sp. (Fa-L). Letras distintas indican diferencias significativas entre los niveles de concentración. Asteriscos indican diferencias significativas entre plantas solas (Fa) o asociadas (Fa-L) $(p<0.001, n=3)$.

HAP como el fenantreno, provocan niveles de oxidación diferentes en las membranas de diversas plantas (Ahammed y col. 2012). El nivel de daño oxidante en las células expuestas a una condición de estrés como un contaminante, depende de su concentración, estructura y del tiempo de exposición. La asociación de plantas con hongos, ya sea micorrízicos arbusculares (Debiane y col. 2009) o endófitos (Li y col. 2014), ayuda a atenuar el daño oxidante provocado por diversos tipos de estrés. Debiane y col. (2009) reportan menores niveles de MDA en raíces de Cichorium intybus asociadas con Glomus intraradices expuestas a $\mathrm{BaP}$ en una concentración menor a la utilizada en este estudio $\left(70 \mathrm{mg} \mathrm{L}^{-1}\right)$. La contribución de los hongos en el control del estrés oxidante a nivel de membrana puede relacionarse con la actividad de enzimas antioxidantes que participan en la degradación de las ERO o la detoxificación directa de los hidrocarburos (Kvesitadze y col. 2009).

\subsubsection{Defensa antioxidante}

La influencia de la asociación endófita entre Lewia sp. y $F$. arundinacea sobre la respuesta de la defensa antioxidante de las plantas expuestas a la MHC se evaluó en función del tiempo, cuantificando la actividad de las enzimas superóxido dismutasa (SOD), peroxidasas (POD) y glutatión-S-transferasas (GST). La defensa antioxidante, que incluye la acción de enzimas y moléculas, alivia o atenúa el daño oxidante causado por la sobreproducción de ERO en las células de las plantas (Hu y col. 2015). La defensa antioxidante enzimática está constituida por enzimas como las SOD, POD y GST, entre otras, que degradan ERO, evitando la oxidación en cadena de diversas biomoléculas y por consiguiente reduciendo el daño oxidante (Debiane y col. 2009). 
La SOD cataliza la dismutación del radical superóxido a oxígeno molecular y peróxido de hidrógeno y, por lo tanto, constituye la primera línea de defensa celular contra las ERO en condiciones de estrés durante periodos largos (Ming Xu y col. 2010). El tiempo de exposición a la MHC disminuyó significativamente la actividad SOD en las raíces de plantas no asociadas y asociadas (Fig. 20). Sin embargo, en las plantas asociadas, a los 7 días se observó un incremento significativo en la actividad, en comparación con las plantas control. En los tallos de plantas asociadas, la actividad SOD se mantuvo sin cambios significativos hasta los 14 días; posteriormente, aumentó ( 2 veces) y se mantuvo alrededor de $1147 \mathrm{U}$ g proteína ${ }^{-1}$ hasta los 45 días. En el caso de las plantas no asociadas, se registró un incremento significativo en la actividad SOD con respecto al inicio desde los 7 hasta los 21 días de exposición a la MHC. Después de 21 días, la actividad de ambos grupos de plantas se mantuvo sin cambios significativos entre sí (Fig. 20).
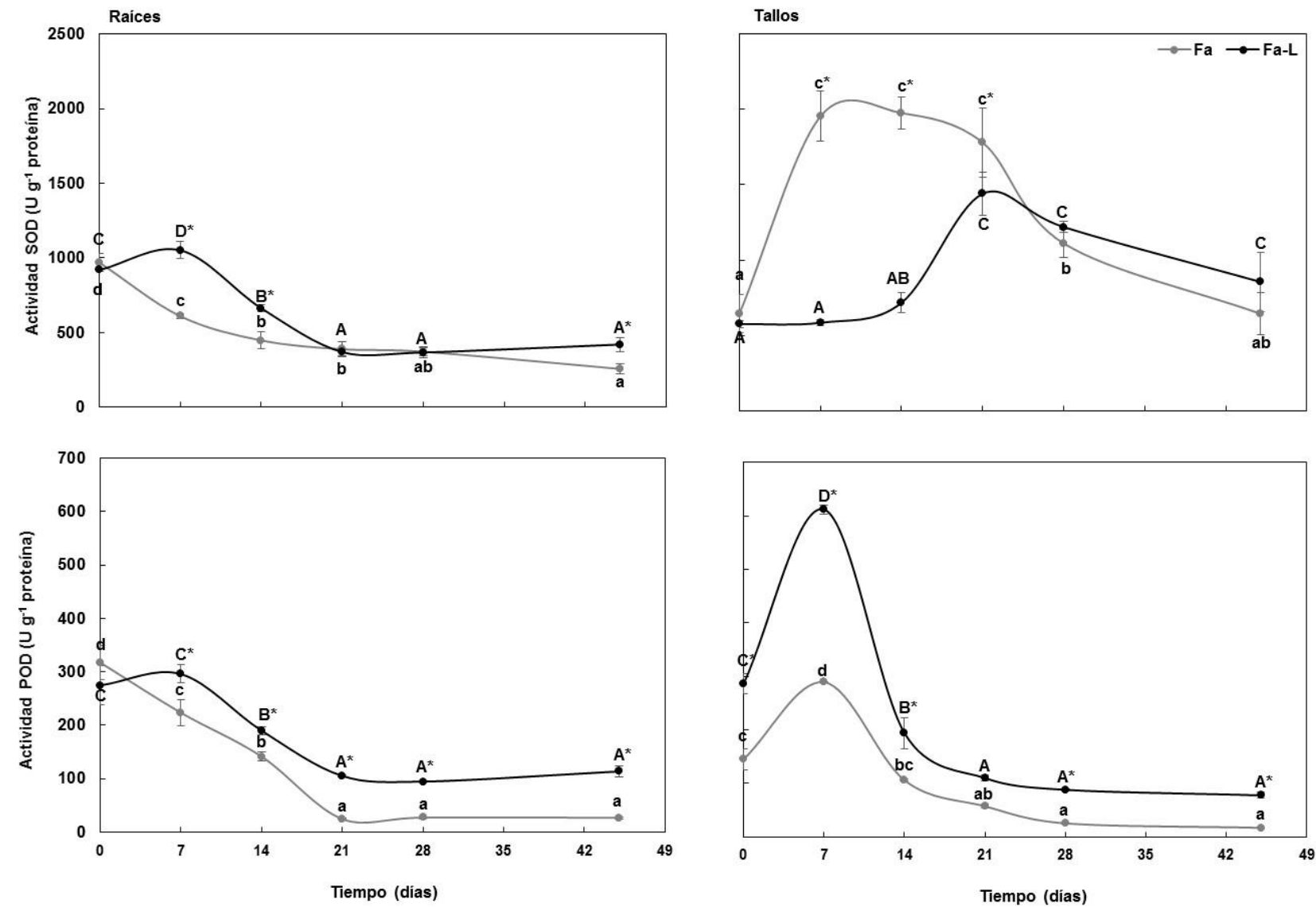

Figura 20. Efecto del tiempo de exposición a $800 \mathrm{mg} \mathrm{kg}^{-1}$ de la MHC sobre la actividad SOD y POD en raíces y tallos de plantas de F. arundinacea (Fa) y F. arundinacea asociada con Lewia sp. (Fa-L). Letras distintas indican diferencias significativas entre los niveles de concentración. Asteriscos indican diferencias significativas entre plantas solas (Fa) o asociadas (Fa-L) $(p<0.001, \mathrm{n}=3)$.

La actividad SOD podría estar coordinada con otras enzimas antioxidantes como las POD durante la detoxificación de las ERO, ya que las POD se encargan de oxidar el peróxido de hidrógeno 
resultante de la actividad de la SOD, a agua. De manera similar que en la actividad SOD, el tiempo de exposición a la MHC modificó la actividad POD (Fig. 20). En este caso, la actividad en las plantas inoculadas con Lewia sp. resultó mayor (2-3 veces) que en las plantas control y en ambos grupos de plantas se observó la misma tendencia. (Fig. 20). En los tallos, la actividad POD disminuyó significativamente durante los primeros 7 días y, a partir de los 14 días, disminuyó a niveles cercanos a los iniciales, manteniéndose así hasta los 45 días de exposición a la MHC (Fig. 20). En las raíces, la actividad de esta enzima disminuyó (4-12 veces) hasta los 21 días y se mantuvo en niveles de 26.2 U g proteína ${ }^{-1}$ (plantas no asociadas) y 104.5 U g proteína ${ }^{-1}$ (plantas asociadas) hasta los 45 días. A pesar de que la respuesta en la actividad POD fue similar en ambos grupos de plantas, la asociación mostró mayor actividad que las plantas no asociadas.

Además de las actividades SOD y POD en la defensa antioxidante de plantas, destacan las GST, que representan un grupo complejo de proteínas que se localizan en varios compartimentos de la célula, incluso, asociadas a proteínas de la membrana (Sherratt y Hayes 2001). Las GST son una familia de enzimas diméricas que catalizan la conjugación de la forma reducida del glutatión (GSH) con compuestos xenobióticos; son un grupo de enzimas multifuncionales y versátiles involucradas en muchos procesos bioquímicos en todas las células y, en especial, en las vegetales (Moons 2005). En plantas, las GST pueden usar GSH, ya sea como sustrato o como coenzima y catalizar una variedad de reacciones de conjugación, como isomerizaciones dependientes del GSH, además de participar con peroxidasas, tioltransferasa y dehidroascorbato reductasa dependientes del GSH. También, pueden tener funciones no catalíticas como proteínas de unión de compuestos fitoquímicos entre compartimentos celulares. Algunas GST tienen funciones catalíticas y no catalíticas en el desarrollo normal, así como durante diversas condiciones de estrés biótico o abiótico (Sherratt y Hayes 2001).

La MHC provocó un incremento en la actividad GST de raíces de $F$. arundinacea no asociadas y asociadas con Lewia sp. a los 7 días con respecto al valor inicial (Fig. 21). En las raíces no asociadas, la actividad GST disminuyó a los 14 días de exposición a la MHC, manteniéndose en valores cercanos a $7.5 \mathrm{U}$ g proteína ${ }^{-1}$ hasta los 45 días, mientras que, en las raíces asociadas, la actividad se mantuvo alrededor de $10.1 \mathrm{U}$ g proteína ${ }^{-1}$ hasta los 45 días. En los tallos, la MHC provocó un aumento en la actividad en plantas no asociadas entre los 7 y los 21 días y, a partir de ahí, la actividad disminuyó a niveles basales (Fig. 21). Contrario a lo observado en las actividades SOD y POD, la actividad GST en los tallos de las plantas asociadas fue menor que en las plantas no asociadas durante los primeros 21 días de exposición a la MHC (Fig. 21). 

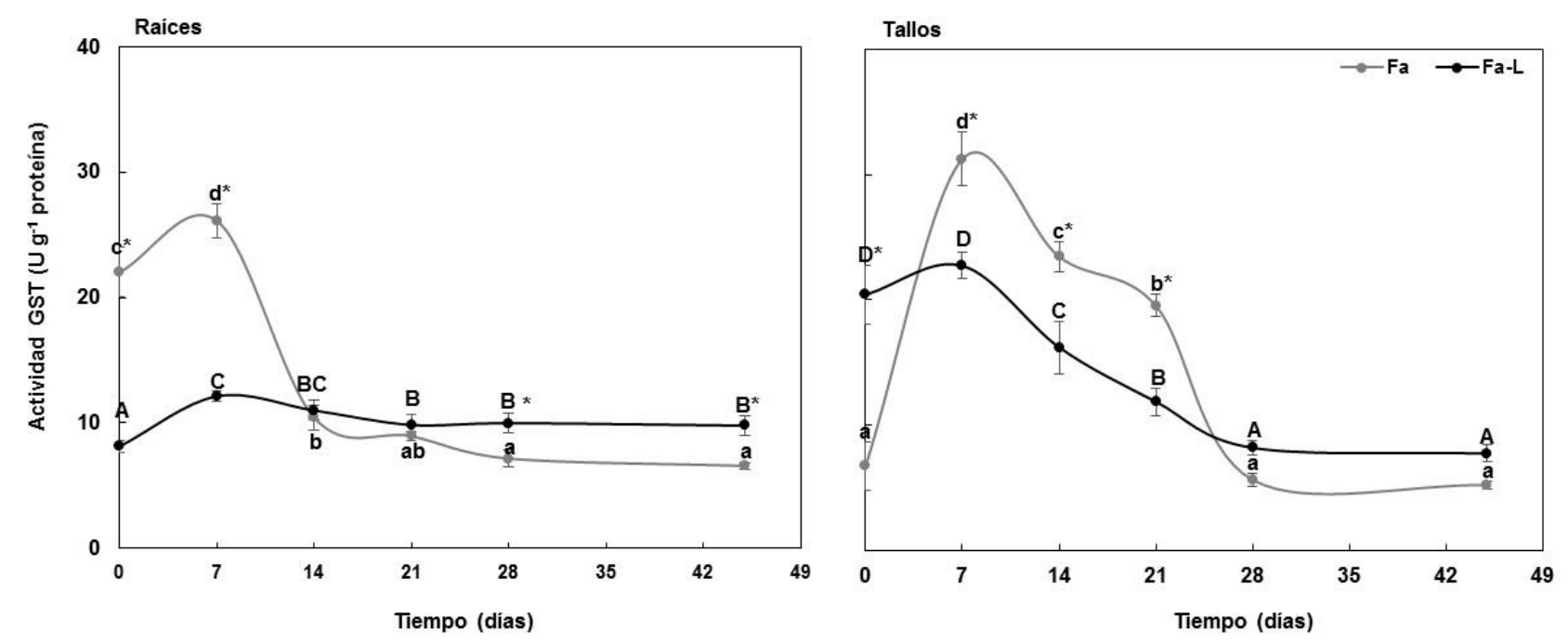

Figura 21. Efecto del tiempo de exposición a $800 \mathrm{mg} \mathrm{kg}^{-1}$ de la MHC sobre la actividad GST en raíces y tallos de plantas de $F$. arundinacea $(\mathrm{Fa}$ ) y $F$. arundinacea asociada con Lewia sp. ( $\mathrm{Fa}-\mathrm{L}$ ). Letras distintas indican diferencias significativas entre los niveles de concentración. Asteriscos indican diferencias significativas entre plantas solas (Fa) o asociadas (FaL) $(p<0.001, \mathrm{n}=3)$.

La disminución de la actividad de las enzimas SOD y POD observada en las raíces de $F$. arundinacea no asociadas podría estar relacionada con el aumento de MDA observado en este grupo de plantas (Fig. 19). Lo anterior, debido a que el radical $\cdot \mathrm{O}_{2}{ }^{-}$, podría estar reaccionando con el $\mathrm{H}_{2} \mathrm{O}_{2}$ (Reacciones 1 y 3 ), produciendo el radical $\bullet \mathrm{OH}$ que puede oxidar los lípidos de membrana (Minotti y Aust 1987). Sin embargo, la presencia de Lewia sp. incrementa la actividad de las enzimas SOD y POD, ayudando a disminuir el contenido de MDA. Por lo anterior, se propone que Lewia sp. controla el daño oxidante a nivel de membrana en plantas de $F$. arundinacea a través del aumento en las actividades SOD y POD y, por consiguiente, el control de la sobreproducción de ERO. Los resultados expuestos en la Figura 21 sugieren que Lewia sp. promueve la disminución de la actividad GST en plantas de $F$. arundinacea para mantener la asociación endófita.

Es importante mencionar que las actividades enzimáticas antioxidantes también participan en la degradación de los contaminantes, en especial las POD (Kvesitadze y col. 2009). Se ha reportado que las POD de plantas catalizan varias reacciones químicas (oxidación, oxigenación, peroxidación, halogenación, deshalogenación, deshidrogenación, N-desalquilación, entre otras) y además, tienen gran afinidad por compuestos xenobióticos, incluidos los HAP (Stiborová y Anzenbachlr 1991). Por lo anterior, se evaluó el efecto de la presencia o ausencia de las actividades antioxidante asociadas a la cinética de remoción de la MHC por $F$. arundinacea y la asociación endófita inducida entre $F$. arundinacea y Lewia sp. 


\subsubsection{Remoción de hidrocarburos}

Durante la fitorremediación de compuestos orgánicos, las plantas pueden ser beneficiadas por la presencia de microorganismos endófitos, que poseen sus propias vías de degradación de contaminantes, así como capacidades metabólicas diferentes, provocando una mejora en la eficiencia de degradación de los contaminantes y reduciendo la fitotoxicidad y la evapotranspiración de los contaminantes volátiles (Soleimani y col. 2010). Por lo tanto, bajo la hipótesis de que en las plantas asociadas con Lewia sp. aumenta la remoción de los hidrocarburos, se evaluó la influencia de la asociación inducida entre Lewia sp. y F. arundinacea sobre la remoción de hidrocarburos en el suelo modelo en el tiempo. Los hidrocarburos fueron removidos por la planta y la asociación siguiendo diferentes patrones a lo largo del tiempo (Fig. 22).

Después de 45 días, la remoción de hexadecano y pireno fue significativamente mayor en el suelo donde creció la asociación F. arundinacea-Lewia sp. que en el suelo en donde crecieron las plantas no asociadas. Sin embargo, en el caso del fenantreno no hubo diferencias significativas debido a la asociación con Lewia sp. Después de 45 días, en el suelo donde crecieron las plantas asociadas con Lewia sp. se alcanzó una remoción máxima para el hexadecano de 95\%, 83\% para el fenantreno y $91 \%$ para el pireno. En contraste, en el suelo donde creció sólo $F$. arundinacea, se alcanzó una remoción (a los 45 días) de 51, 76 y 80\% para hexadecano, fenantreno y pireno, respectivamente.
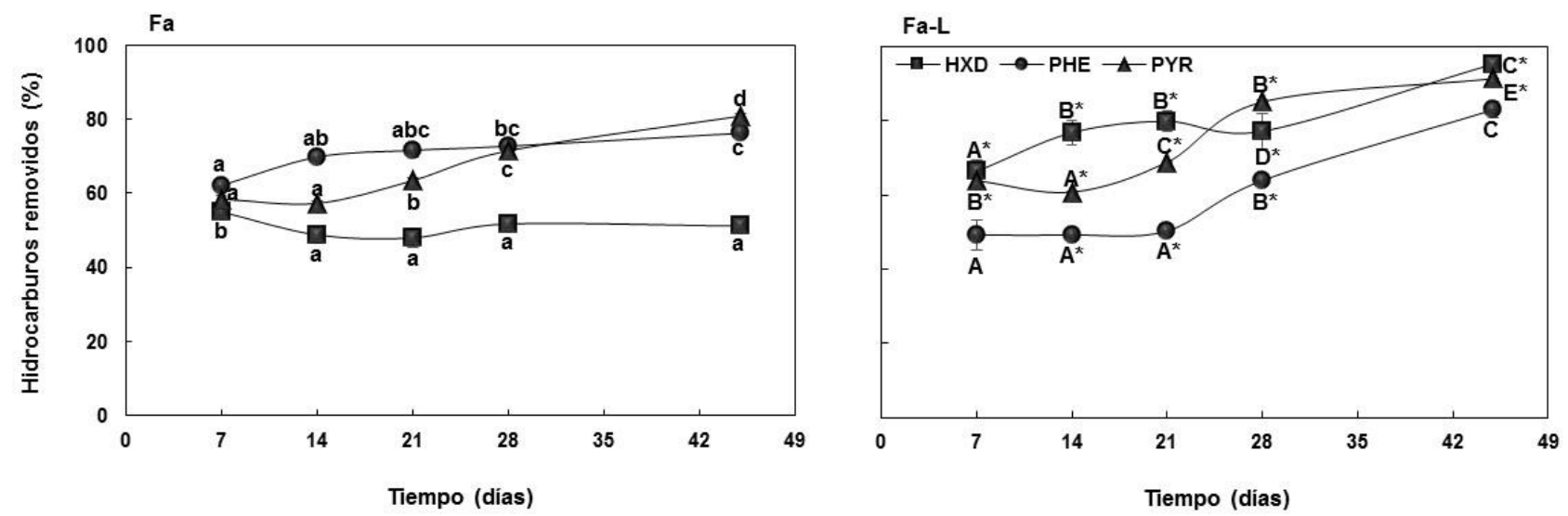

Figura 22. Remoción de hexadecano (HXD), fenantreno (PHE) y pireno (PYR) por a) $F$. arundinacea (Fa) 0 b) $F$. arundinacea asociada con Lewia sp. (Fa-L) durante el tiempo de muestreo en el suelo modelo. Letras iguales por serie indican que no hay diferencias significativas en la remoción por efecto del tiempo. Los asteriscos indican diferencias significativas entre los hidrocarburos removidos por la planta sola (Fa) o asociada (Fa-L).

Contrario a nuestros resultados, Cheema y col. (2009) reportaron una remoción mayor de fenantreno y pireno (87 y 97\%, respectivamente) después de 65 días de cultivo de $F$. arundinacea en un suelo no estéril. La diferencia en los resultados podría atribuirse a la presencia de microorganismos nativos del suelo contaminado, que promovieron la degradación de los contaminantes en la rizósfera de la 
planta (Cheema y col. 2009). Cruz-Hernández y col. (2013) observaron una remoción de 91\% para el hexadecano, $100 \%$ para fenantreno y $70 \%$ para pireno después de 45 días de cultivo en un suelo modelo no estéril. Esta diferencia puede atribuirse, también, al efecto adicional de microorganismos degradadores de hidrocarburos en el sistema abierto que se utilizó. Soleimani y col. (2010) no observaron diferencias significativas en la remoción de fenantreno y pireno en suelos cultivados por 7 meses con F. arundinacea y F. arundinacea asociada con Neotyphodium coenophialum en condiciones de invernadero.

La remoción tan alta de los hidrocarburos, observada en los primeros siete días de cultivo pueden deberse a un fenómeno de sorción de contaminantes en las raíces de las plantas, tanto asociadas como no asociadas. Varios estudios han demostrado que la mayoría de los compuestos orgánicos lipofílicos como fenantreno y pireno, son afines a la epidermis de las raíces. Lo anterior, generalmente depende del coeficiente de partición (Kow) de los compuestos orgánicos lipofílicos, en el suelo y en las membranas de las células vegetales, así como del contenido lipídico en las raíces (Gao y Zhu 2004). El contenido lipídico en las raíces puede modificarse por la presencia de microorganismos como los hongos endófitos, lo que podría modificar la sorción de los contaminantes en plantas asociadas con endófitos. Así, nuestros resultados muestran que Lewia sp. es un hongo endófito que estimula la remoción de hidrocarburos alifáticos e HAP. Lo que podría estar relacionado con los cambios bioquímicos registrados en $F$. arundinacea asociada con el hongo, especialmente con una modificación de la cantidad de lípidos en las raíces, variable que no se determinó en este estudio.

\subsubsection{Correlación entre las variables de respuesta en estudio}

Con el objetivo de correlacionar la defensa antioxidante con la remoción de hidrocarburos por $F$. arundinacea y la asociación entre $F$. arundinacea y Lewia sp. se realizó un análisis de correlación entre los parámetros bioquímicos y la remoción de la MHC observada durante los 45 días (Tabla 6). La remoción de los tres hidrocarburos correlacionó de forma positiva (>80\%) y significativa con el aumento en la biomasa, tanto de las plantas asociadas como no asociadas. También se observó una correlación significativa positiva (>70\%) entre la producción de MDA y la remoción de pireno en el suelo, siendo más importante en la planta sola que en la asociación, lo que sugiere que la remoción de pireno pudiera provocar la oxidación de los lípidos de membrana en $F$. arundinacea no asociada. La actividad POD fue la única variable relacionada con la defensa de la planta que mostró correlación significativa negativa $(-71 \%)$ con la remoción de pireno en la planta sola. Lo anterior sugiere que la actividad POD es insuficiente para oxidar el pireno que está siendo removido. 
Tabla 6. Análisis de correlación de Pearson entre la remoción de hexadecano (HXD), fenantreno (PHE) y pireno (PYR) y la biomasa (BM), malondialdehído (MDA), actividades enzimáticas superóxido dismutasa (SOD), peroxidasas (POD) y glutatión-S-transferasas (GST)) en F. arundinacea o F. arundinacea inoculada con Lewia sp. durante 45 días¹.

\begin{tabular}{lccc}
\hline \multicolumn{1}{c}{ Parámetros } & HXD & PHE & PYR \\
\hline F. arundinacea & & & \\
BM & $0.85^{* *}$ & $0.86^{* *}$ & $0.81^{* *}$ \\
MDA & 0.60 & $0.70^{*}$ & $0.80^{* *}$ \\
SOD & 0.20 & 0.05 & -0.12 \\
POD & -0.49 & -0.67 & $-0.71^{* *}$ \\
GST & 0.06 & -0.15 & -0.25 \\
F. arundinacea-Lewia sp. & & & \\
BM & $0.92^{* *}$ & $0.84^{* *}$ & $0.89^{* *}$ \\
MDA & $0.72^{* *}$ & $0.75^{* *}$ & $0.71^{* *}$ \\
SOD & -0.01 & -0.11 & 0.00 \\
POD & -0.45 & -0.46 & -0.46 \\
GST & -0.46 & -0.55 & -0.54 \\
\hline
\end{tabular}

${ }^{*}$ Confianza a $\mathrm{P}<0.001 ;{ }^{* *}$ Confianza a $\mathrm{P}<0.0001$.

Una vez que los HAP son absorbidos por la superficie radicular, pueden moverse a través del apoplasto (entre los espacios intercelulares o alrededor de la pared celular) o a través del simplasto (atravesando la pared y membrana celular y pasando por el citoplasma). En el primer caso, los HAP podrían quedar acumulados en la pared celular, en el segundo, además de acumularse en la pared celular podrían acumularse en las vacuolas (Wild y col. 2005). La absorción depende, principalmente, del contenido de lípidos en las raíces, donde las lipoproteínas, los fosfolípidos, las grasas y los tejidos de celulosa contienen componentes lipofílicos que parecen ser los dominios primarios donde los HAP se acumulan una vez que penetran en las células de las raíces (Gao y Zhu 2004). Lo anterior puede conducir a un aumento en la oxidación de los lípidos de membrana (MDA) observado a lo largo de la cinética en los dos grupos de plantas (Fig. 19), o deberse al incremento de ERO por efecto de la presencia de la MHC.

Además de lo anterior, el metabolismo de los HAP puede producir moléculas más fitotóxicas, conduciendo al aumento en el daño oxidante (Gao y Zhu 2004). El metabolismo del fenantreno produce moléculas como la 9,10-fenantrenoquinona (Narro y col. 1992), una quinona con un potencial de reducción que le permite interactuar con biomoléculas tiólicas, reduciendo el potencial reductivo en la célula que conduce al aumento en la producción de ERO y, por consiguiente, causando daño oxidante (Rodríguez y col. 2005; Wang y col. 2007). El pireno puede ser acumulado en las raíces de F. arundinacea para metabolizarlo posteriormente (Pan y col. 2016). Además, la 
distribución de los contaminantes dentro de las células puede variar según la planta y el contaminante (Kang y col. 2010). La acumulación de hidrocarburos y la formación de los productos mencionados implican la actividad de las enzimas antioxidantes como las polifenol oxidasas (PPO), las peroxidasas (POD) y las glutatión S-transferasas (GST), que contribuyen al metabolismo de compuestos químicos aromáticos (Gao y col. 2013). Sin embargo, se requiere de más estudios para proponer certeramente los mecanismos a través de los cuales los hidrocarburos presentes en la MHC, son removidos por $F$. arundinacea y la asociación $F$. arundinacea-Lewia sp.

Es importante destacar que, durante la cinética, se observó una remoción de hidrocarburos alta en los primeros 7 días de exposición a los contaminantes (Tabla 5). Además, en este periodo, se observó un incremento en el crecimiento (Fig. 18) y las actividades SOD y POD (Fig.20), así como una disminución del MDA (Fig. 19) y la actividad GST (Fig. 21) en F. arundinacea solas y asociadas con Lewia sp., sin embargo, hasta este momento se desconoce si el efecto se debía a los hidrocarburos o a la presencia de Lewia sp. Por lo anterior, se realizó un análisis detallado en este día. El análisis se muestra enseguida.

\subsection{Influencia de Lewia sp. sobre plantas de F. arundinacea expuestas a hidrocarburos}

\subsubsection{Crecimiento}

De acuerdo con los resultados anteriores (apartado 6.4.1) se observó que la producción de biomasa en raíces y tallos de $F$. arundinacea se modificó después de 7 días de contacto con la MHC, sin embargo, se desconocía si el efecto se debía a los hidrocarburos o a la presencia de Lewia sp. Por lo anterior, y con el objetivo de distinguir el efecto de Lewia sp. del efecto de la MHC, se añadieron dos puntos, los correspondientes a F. arundinacea y la asociación F. arundinacea-Lewia sp. en el suelo modelo, pero en ausencia de la MHC (Fig. 23). Después de 7 días de exposición a la MHC, el hongo estimuló la producción de biomasa, particularmente de raíces, 3.8 veces más que en las plantas no asociadas (Fig. 23). Se sabe que los microorganismos endófitos aumentan el crecimiento de las plantas expuestas a agentes estresores (Soleimani y col. 2010). Estos resultados confirman que la asociación endófita entre $F$. arundinacea y Lewia sp. estimula el crecimiento de las plantas aún bajo condiciones de estrés generado por la $\mathrm{MHC}$ en un periodo de 7 días. 


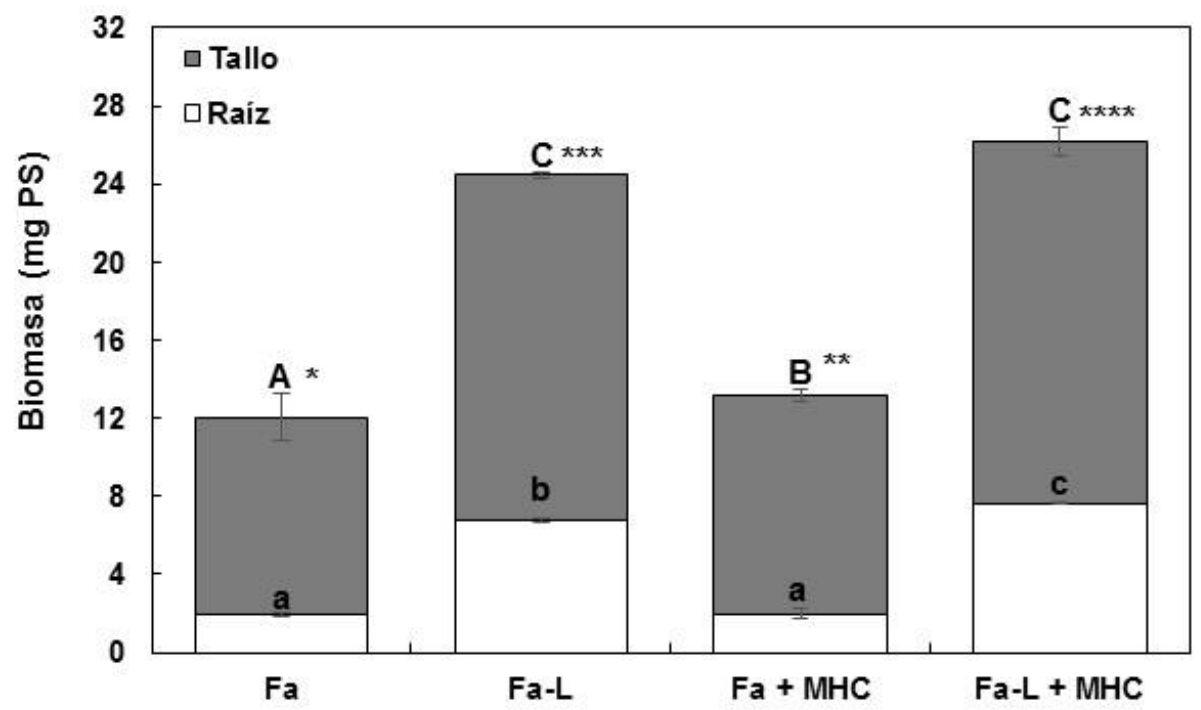

Figura 23. Producción de biomasa de $F$. arundinacea (Fa) y F. arundinacea asociada con Lewia sp. (Fa-L) expuesta o no a $800 \mathrm{mg} \mathrm{kg}^{-1}$ de hidrocarburos (MHC) por 7 días en suelo modelo. Asteriscos indican diferencias significativas en la comparación de la biomasa total (raíz + tallo), letras diferentes (minúscula para raíz y mayúsculas para tallo) ( $p<0.001)$.

La biomasa vegetal es una variable de respuesta comúnmente utilizada como indicador de rendimiento en plantas expuestas a xenobióticos como los HAP (Soleimani y col. 2010). Un resultado similar al presentado aquí se observó en $F$. arundinacea expuesta a hidrocarburos cuando la planta creció en asociación con el endófito Neotyphodium coenophialum (Soleimani y col. 2010) y Lewia sp. (Cruz-Hernández y col. 2013). Los hongos endófitos pueden incrementar el crecimiento de las plantas a través de la producción de fitohormonas, cambios morfológicos en la raíz, el aumento en la solubilización y captura de nutrientes (Porras-Alfaro y Bayman 2011) o mediante la sobreproducción y el control de moléculas de señalización como el $\mathrm{H}_{2} \mathrm{O}_{2}$ (White y Torres 2010). El $\mathrm{H}_{2} \mathrm{O}_{2}$ induce la respuesta de enzimas de señalización con diversas actividades, incluidas la degradación de proteínas y la señalización hormonal. Algunas de estas enzimas de señalización se encuentran implicadas en la cascada de las MAPK que controlan la activación de varios mecanismos de defensa en respuesta al estrés por ERO (Tripathy y Oelmüller 2012).

\subsubsection{Daño oxidante}

Con base en lo anterior, se analizó el contenido de $\mathrm{H}_{2} \mathrm{O}_{2}$ en las plantas asociadas o no asociadas y expuestas o no a la MHC (Tabla 7). Se encontró un incremento (1.3 veces) en el contenido de $\mathrm{H}_{2} \mathrm{O}_{2}$ de las raíces de $F$. arundinacea no asociadas por efecto de la MHC. En contraste, la concentración de $\mathrm{H}_{2} \mathrm{O}_{2}$ no se modificó en raíces y tallos de las plantas asociadas expuestas a la MHC. Independientemente de la $\mathrm{MHC}$, la concentración de $\mathrm{H}_{2} \mathrm{O}_{2}$ en las raíces de las plantas asociadas fue menor ( 35\%) que en las plantas no asociadas (Tabla 7 ). 
Es importante examinar la concentración de $\mathrm{H}_{2} \mathrm{O}_{2}$ en conjunto con otros marcadores de estrés en las plantas ya que, si los niveles de $\mathrm{H}_{2} \mathrm{O}_{2}$ no son controlados, esta $\mathrm{ERO}$ puede ser transformada en el radical hidroxilo y oxidar proteínas y lípidos de membrana, causando un incremento en el contenido de grupos CO y MDA, respectivamente (Kreslavski y col. 2014; Hu y col. 2015). Por lo anterior, se analizó el daño oxidante, medido como contenido de MDA y proteínas oxidadas (grupos $\mathrm{CO}$ ), en raíces y tallos de $F$. arundinacea y la asociación endófita entre $F$. arundinacea y Lewia sp. en exposición o no a la MHC durante 0 y 7 días (Tabla 8).

Tabla 7. Contenido de $\mathrm{H}_{2} \mathrm{O}_{2}$ en raíces y tallos de $F$. arundinacea (Fa) y la asociación endófita $F$. arundinacea-Lewia sp. (Fa-L) después de 7 días de crecimiento con y $\sin 800 \mathrm{mg} \mathrm{kg}^{-1}$ de la MHC en suelo modelo*.

\begin{tabular}{ccc}
\hline & \multicolumn{2}{c}{$\mathrm{H}_{2} \mathrm{O}_{2}\left(\mathrm{nmol} \mathrm{g} \mathrm{g}^{-1}\right.$ PF $)$} \\
\hline Fa & Raíces & Tallos \\
\cline { 2 - 3 } Fa-L & $450.1 \pm 49.7^{\mathrm{ab}}$ & $480.9 \pm 38.8^{\mathrm{B}}$ \\
Fa + MHC & $427.4 \pm 24.7^{\mathrm{ab}}$ & $308.5 \pm 28.1^{\mathrm{A}}$ \\
Fa-L + MHC & $583.1 \pm 52.3^{\mathrm{c}}$ & $489.2 \pm 12.3^{\mathrm{B}}$ \\
\hline
\end{tabular}

* Datos con letras diferentes por columna indican diferencias significativas entre tratamiento $(p<0.001)$. Los valores son la media de 3 réplicas (4 plantas por réplica). Mayúsculas y minúsculas indican análisis diferente para cada órgano.

Tabla 8. Daño oxidante medido como contenido de malondialdehído (MDA) y proteínas oxidadas (grupos CO) en raíces y tallos de $F$. arundinacea (Fa) y la asociación endófita $F$. arundinacea-Lewia sp. (Fa-L) creciendo con y sin $800 \mathrm{mg} \mathrm{kg}^{-1}$ de la MHC durante 7 días en suelo modelo*.

\begin{tabular}{|c|c|c|c|c|}
\hline \multirow[b]{2}{*}{ Tratamiento } & \multicolumn{2}{|l|}{ Raíces } & \multicolumn{2}{|c|}{ Tallos } \\
\hline & MDA (nmol $\left.g^{-1} P F\right)$ & $\begin{array}{c}\mathrm{CO}\left(\mu \mathrm{mol} \mathrm{g}^{-1}\right. \\
\text { proteína) }\end{array}$ & MDA (nmol $\left.g^{-1} P F\right)$ & CO ( $\mu \mathrm{mol} g^{-1}$ proteína) \\
\hline $\mathbf{F a}$ & $28.1 \pm 0.3^{b}$ & $157.2 \pm 6.8^{a}$ & $53.1 \pm 3.1^{\mathrm{BC}}$ & $330.3 \pm 1.1^{\mathrm{C}}$ \\
\hline Fa-L & $28.3 \pm 0.2^{b}$ & $196.0 \pm 2.4^{a}$ & $58.2 \pm 10.0^{\mathrm{B}}$ & $265.3 \pm 10.0^{\mathrm{B}}$ \\
\hline $\mathrm{Fa}+\mathrm{MHC}$ & $48.6 \pm 1.4^{c}$ & $909.5 \pm 21.2^{c}$ & $58.6 \pm 2.4^{\mathrm{B}}$ & $167.2 \pm 2.0^{\mathrm{A}}$ \\
\hline Fa-L + MHC & $25.4 \pm 0.9^{a}$ & $368.1 \pm 14.5^{b}$ & $27.5 \pm 2.0^{A}$ & $573.3 \pm 13.2^{\mathrm{D}}$ \\
\hline
\end{tabular}

* Datos con diferentes letras por columna indican diferencias significativas entre tratamiento $(p<0.001)$. Los valores son la media de 3 réplicas (4 plantas por réplica). Mayúsculas y minúsculas indican análisis diferente para cada órgano. 
El contenido de MDA en raíces de plantas no asociadas y expuestas a la MHC fue 1.7 veces mayor que en las plantas crecidas sin la MHC (Tabla 8). Sin embargo, el contenido de MDA en las raíces de las plantas asociadas no se modificó significativamente por la $\mathrm{MHC}$, comparado con su respectivo control. EI MDA en los tallos de plantas asociadas y expuestas a los hidrocarburos, se redujo significativa (53\%) en comparación con las plantas no asociadas. Por otro lado, la concentración de los grupos $\mathrm{CO}$ en las raíces de las plantas asociadas y expuestas a la MHC fue menor (2.5 veces) que en las plantas no asociadas. En contraste, la presencia de la MHC incrementó significativamente la concentración de los grupos CO (3.4 veces) en los tallos de las plantas asociadas que en las plantas no asociadas (Tabla 8).

Se ha observado que los hongos micorrízicos (Debiane y col. 2009) y los endófitos (Mirzahosseini y col. 2014, 2015), pueden aliviar el daño oxidante producido por la acumulación de ERO en las células de plantas como F. arundinacea. De hecho, se registró un incremento en el contenido de MDA, particularmente en las raíces de las plantas expuestas a la $\mathrm{MHC}$, el cual fue significativamente reducido tanto en raíces como en tallos por efecto de Lewia sp. Esta reducción en la peroxidación de lípidos podría deberse a un incremento en la actividad de enzimas como las peroxidasas (POD) por efecto de Lewia sp. Las POD son las enzimas responsables de degradar los hidroperóxidos lipídicos, utilizando GSH u otra molécula de poder reductor equivalente, evitando así su acumulación (Pryor y Castle 1984). Otra consecuencia de la sobreproducción de las ERO generada por estrés abiótico es la oxidación de proteínas (Cvjetko y col. 2010). Sin embargo, en raíces de $F$. arundinacea expuestas a la MHC, la concentración de proteínas oxidadas se redujo en presencia de Lewia sp. Se ha demostrado que los organismos tolerantes al estrés, son capaces de aumentar la actividad de enzimas antioxidantes con el fin de atenuar la sobreproducción de ERO debida a la acumulación de hidrocarburos (Balasubramanlyam y col. 2015). Lo anterior, podría conducir a un decremento en la concentración de los dos marcadores del estrés oxidante estudiados en este periodo.

\subsubsection{Defensa antioxidante}

El análisis de las actividades enzimáticas antioxidantes (SOD, POD y GST) después de 7 días de exposición a la MHC (Fig. 24 y 26) se utilizó para determinar la actividad enzimática relativa (Fig. 25 y 27), con el fin de identificar el efecto de la MHC o del hongo sobre la actividad enzimática de las plantas expuestas a la MHC durante 7 días. Independientemente de la exposición a la MHC, las actividades SOD y POD fueron estimuladas en las raíces de las plantas asociadas (Fig. 24 y 25). En presencia de hidrocarburos, la actividad SOD en las raíces no asociadas fue menor (5.6 veces) que la registrada en las asociadas (Fig. 24a y 25a). En los tallos, la actividad SOD disminuyó por efecto de la MHC tanto en las plantas no asociadas (50\%) como en las asociadas (60\%), ambas comparadas con las plantas cultivadas en ausencia de la MHC. 
La disminución de las actividades SOD y POD se ha observado en plantas de Arabidopsis thaliana (Liu y col. 2009) y Triticum aestivum (Tomar y Jajoo 2015) durante la exposición a HAP. Esta disminución se relaciona con el aumento desproporcionado de ERO que supera la capacidad antioxidante de las plantas (Cvjetko y col. 2010). La disminución de la actividad SOD en los tallos y raíces de $F$. arundinacea se podría considerar como una evidencia indirecta de la acumulación de $\cdot \mathrm{O}_{2}^{-}$en respuesta a la $\mathrm{MCH}$ (Debiane y col. 2008). Comparado con los controles, el aumento en la actividad SOD en las raíces de plantas asociadas indica que Lewia sp. ayuda a regular la concentración de $\cdot \mathrm{O}_{2}^{-}$en presencia de hidrocarburos. Becerra-Castro y col. (2013) demostraron que la actividad de SOD, es comúnmente mayor en las plantas expuestas a un contaminante cuando se asocian con endófitos.
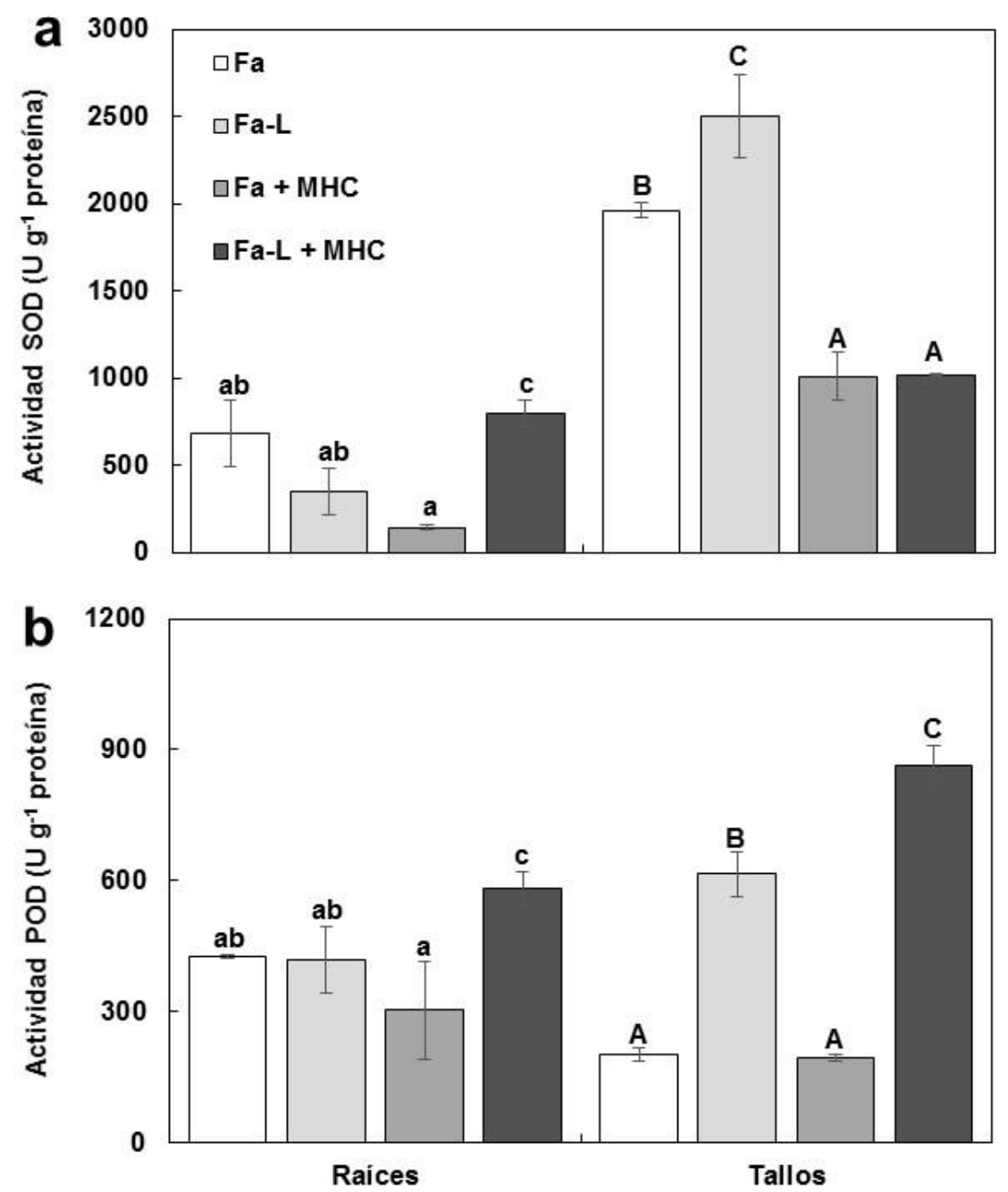

Figura 24. Actividades SOD (a) y POD (b) en raíces y tallos de plantas de F. arundinacea creciendo por 7 días no asociadas (Fa) o asociadas con Lewia sp. (Fa-L) en un suelo modelo conteniendo o no $800 \mathrm{mg} \mathrm{kg}-1$ de una mezcla de hidrocarburos (MHC). 

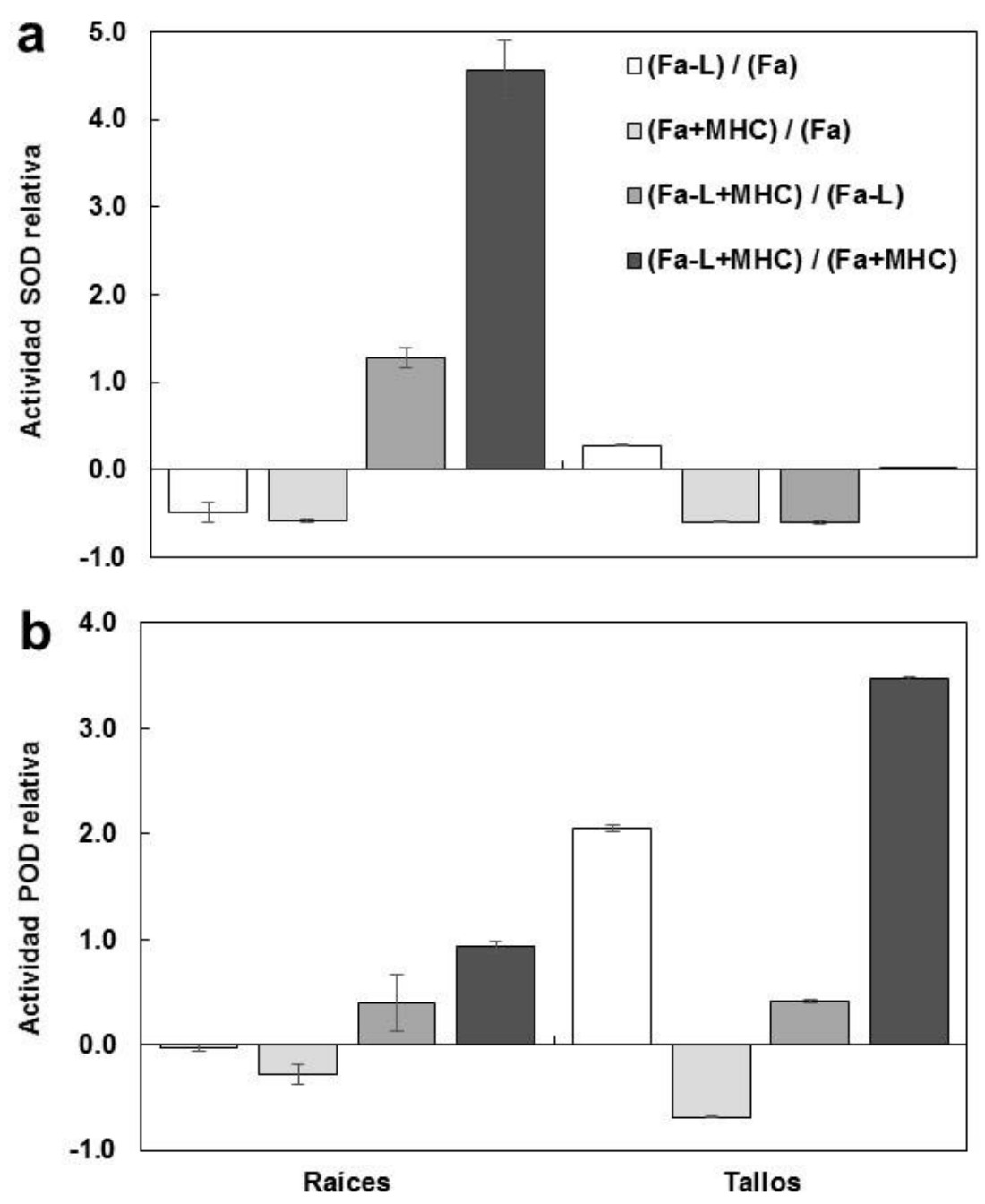

Figura 25. Actividad relativa de SOD (a) y POD (b) en raíces y tallos de plantas de $F$. arundinacea creciendo por 7 días solas (Fa) o asociadas con Lewia sp. (Fa-L) en un suelo modelo contaminado con una mezcla de hidrocarburos (MHC).

El aumento de la actividad POD independientemente de la presencia de la MHC, especialmente en los tallos de plantas asociadas (Fig. 24b y 25b), indica que Lewia sp. estimula la defensa de la planta mediante el control del nivel de $\mathrm{H}_{2} \mathrm{O}_{2}$. De hecho, se registró una menor concentración de $\mathrm{H}_{2} \mathrm{O}_{2}$ en las plantas asociadas, en particular en las que crecieron en presencia de hidrocarburos (Tabla 7). En estas mismas plantas, también se registró un contenido menor de MDA (Tabla 8). Las POD pueden reducir los hidroperóxidos al alcohol correspondiente, evitando así que los hidroperóxidos de lípidos se acumulen y mejorando el crecimiento vegetal (Pryor y Castillo 1984). Kawaoka y col. (2003) demostraron que la actividad POD tiene un papel en el crecimiento de $F$. arundinacea a través de la modificación de funciones tales como el control de la producción de hormonas de senescencia. El aumento en las actividades SOD y POD en las raíces de $F$. arundinacea asociadas con Lewia sp. y cultivadas en la MHC sugieren que el hongo ayuda a controlar la sobreproducción de ERO inducida 
por la presencia de la MHC. Estos resultados se confirman por el hecho de que el contenido de MDA y los grupos $\mathrm{CO}$ se redujeron significativamente por efecto de Lewia sp. Lo anterior, podría contribuir al mejor crecimiento registrado en la planta (Fig. 23).

En cuanto a la actividad GST, esta fue mayor en los tallos que en las raíces de las plantas no asociadas (Fig. 26 y 27) y en las raíces fue significativamente estimulada por la presencia de la MHC. Esta actividad se redujo fuertemente tanto en tallos como en raíces de las plantas asociadas con Lewia sp., especialmente en plantas expuestas a la MHC.

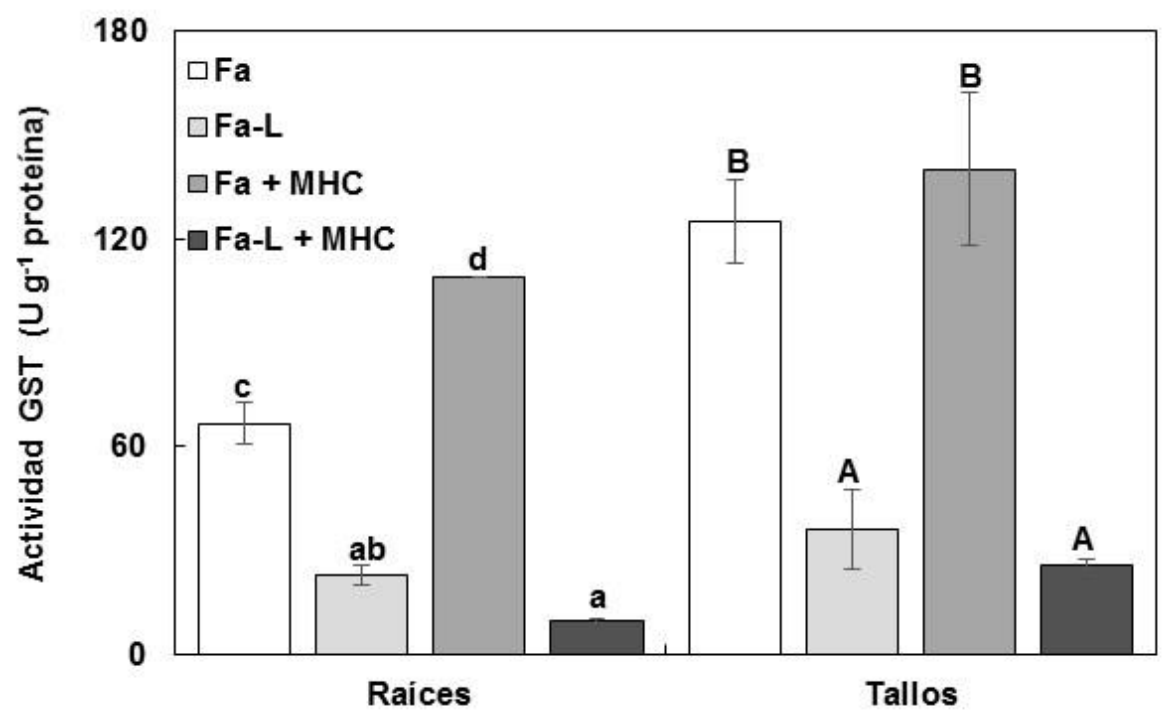

Figura 26. Actividad GST en raíces y tallos de plantas de $F$. arundinacea creciendo por 7 días solas ( $F a)$ o asociadas con Lewia sp. (Fa-L) en un suelo modelo conteniendo o no $800 \mathrm{mg} \mathrm{kg}^{-1}$ de una mezcla de hidrocarburos (MHC).

Contrario a lo observado en las actividades SOD y POD en este mismo periodo de exposición a la MHC, la actividad GST disminuyó en las plantas asociadas con el hongo y expuestas a la MHC, lo que podría atribuirse a cambios en los niveles de las fitohormonas en las plantas por efecto de Lewia $\mathrm{sp}$. Ya que se ha demostrado que la actividad de esta enzima es modulada por estos compuestos (Kumar y col. 2013). Este hecho también puede contribuir a la mejora del crecimiento registrado en las plantas asociadas (Fig. 23). Hasta ahora, la mayoría de los estudios relacionados con la actividad GST en plantas se ha centrado en las respuestas a la presencia de metales pesados (Mirzahosseini y col. 2014; Rojas-Loria y col. 2014). Similar a nuestros resultados, la actividad GST en los tallos de F. arundinacea expuestos a concentraciones bajas $\left(30 \mathrm{mg} \mathrm{kg}^{-1}\right)$ de níquel, disminuyó en plantas asociadas con el hongo Neotyphodium coenophialum (Mirzahosseini y col. 2014). 


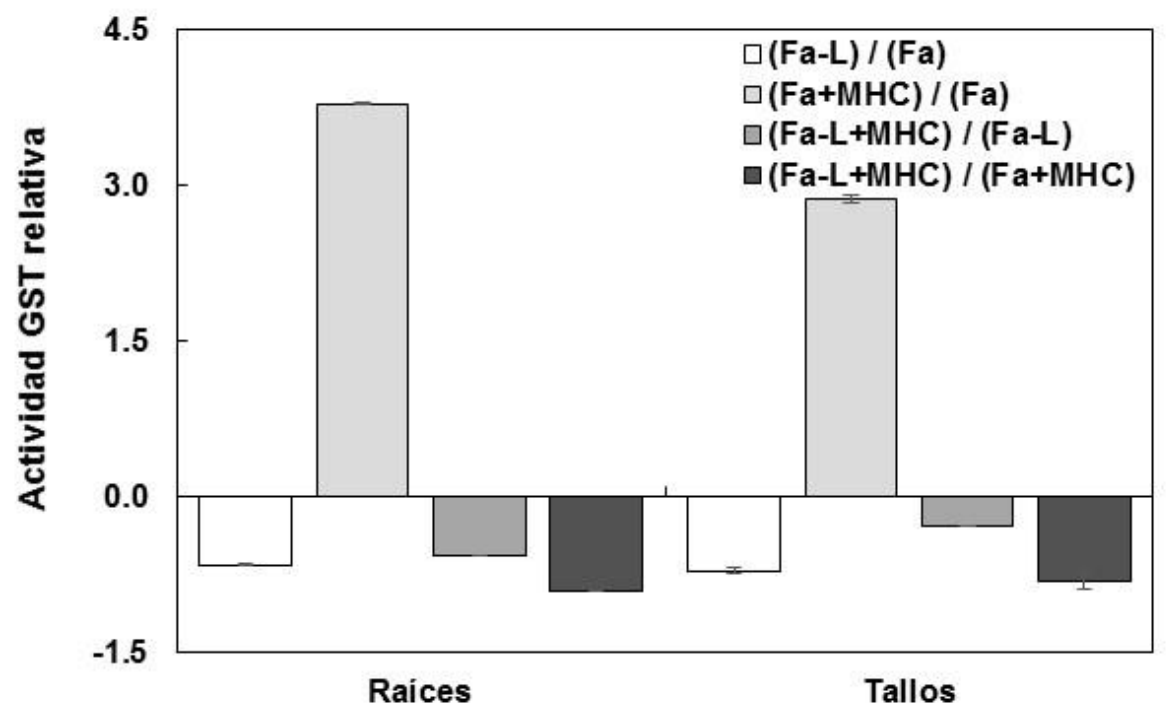

Figura 27. Actividad relativa GST en raíces y tallos de plantas de $F$. arundinacea creciendo por 7 días solas (Fa) o asociadas con Lewia sp. (Fa-L) en un suelo modelo contaminado con una mezcla de hidrocarburos (MHC).

La estimación de actividades relativas tanto SOD como POD y GST (Fig. 21-26), ayudó a distinguir claramente el efecto ya sea de los hidrocarburos o del hongo en las plantas en un periodo de 7 días. La disminución de las actividades SOD y POD y el aumento de la actividad GST por efecto de la MHC en las plantas de $F$. arundinacea no asociadas, sugieren que las GST de la planta pueden estar relacionadas con la detoxificación de los hidrocarburos, mientras que las SOD y POD parecen no estar involucradas en este tipo de procesos. Contrario a lo anterior, en las plantas asociadas y expuestas a la MHC, el aumento de las actividades SOD y POD, particularmente en las raíces, indica que Lewia sp. estimula la actividad de ambas enzimas, contribuyendo a un incremento en el sistema de defensa antioxidante bajo condiciones de estrés por hidrocarburos. La disminución de la actividad GST por influencia de Lewia sp., incluso en presencia de hidrocarburos, sugiere que podría estar relacionada con el mantenimiento de la asociación endófita. Estos resultados demuestran que los mecanismos de defensa de la planta contra los efectos adversos de los hidrocarburos están influenciados por la asociación endófita con Lewia sp. 


\section{CONCLUSIONES}


Se logró inducir la asociación endófita entre $F$. arundinacea y Lewia sp., después de 15 días de contacto, en un medio con relación $\mathrm{C} / \mathrm{N}$ de 5 y concentración de sales completas de MS

La asociación planta-endófito promovió el crecimiento de la planta, así como el contenido de $\mathrm{H}_{2} \mathrm{O}_{2}$ y MDA, y disminuyó el contenido de proteínas oxidadas y la actividad enzimática GST en condiciones in vitro.

La asociación endófita entre $F$. arundinacea y Lewia sp. incrementó la tolerancia a una mezcla de hidrocarburos después de 45 días de exposición, encontrando una $\mathrm{Cl}_{50}$ de $757 \mathrm{mg} \mathrm{kg}^{-1}$ para $F$. arundinacea y de $1100 \mathrm{mg} \mathrm{kg}^{-1}$ para la asociación endófita inducida entre $F$. arundinacea y Lewia sp. en un suelo modelo con déficit de nutrientes.

Después de 45 días de exposición a la mezcla de hidrocarburos Lewia sp. promovió la remoción de hexadecano y pireno, alcanzando remociones del 95 y $91 \%$, respectivamente.

Lewia sp. promueve el crecimiento de $F$. arundinacea a través del control en el contenido de $\mathrm{H}_{2} \mathrm{O}_{2}$ y MDA, lo anterior se puede relacionar con el incremento de la actividad de las enzimas antioxidantes SOD y POD de la planta expuesta a hidrocarburos.

La disminución de la actividad GST por influencia de Lewia sp. en la asociación expuesta o no a la mezcla de hidrocarburos, sugiere que esta actividad enzimática podría estar relacionada con el mantenimiento de la asociación endófita.

Se observó un incremento entre el daño oxidante de las plantas y la asociación, con la remoción de los hidrocarburos. De la defensa antioxidante, la actividad POD de F. arundinacea no asociada se disminuyó al incrementar la remoción de los hidrocarburos, en especial el pireno, lo que sugiere una inhibición en la actividad.

Este estudio demuestra el rol positivo de Lewia sp. en la promoción del crecimiento y el alivio del estrés oxidante en $F$. arundinacea expuesta a una mezcla de hidrocarburos.

La asociación endófita $F$. arundinacea-Lewia sp. es una alternativa promisoria para mejorar la fitorremediación de suelos contaminados con hidrocarburos. 


\section{RECOMENDACIONES}


Con base en el trabajo realizado y los resultados obtenidos, se recomiendan los siguientes estudios con $F$. arundinacea y la asociación inducida entre $F$. arundinacea y Lewia sp.

Para proponer el mecanismo de remoción de los hidrocarburos, analizar las actividades enzimáticas polifenol oxidasas, ascorbato peroxidasas, glutatión peroxidasas, glucuronil transferasas, y proteínas de choque térmico, así como moléculas antioxidantes glutatión y ascorbato.

Para identificar las modificaciones a la expresión genética que permiten la asociación y la respuesta a las condiciones de estrés, realizar una comparación de los perfiles en la expresión genética de $F$. arundinacea y la asociación F. arundinacea-Lewia sp.

Para mejorar el entendimiento de los mecanismos de degradación y detoxificación de los hidrocarburos en este sistema, cuantificar los hidrocarburos acumulados en raíz y translocados a tallos, así como la distribución de los contaminantes en los organelos celulares

Para determinar la toxicidad del cultivo, investigar el metabolismo de los hidrocarburos y su distribución celular en la planta y la asociación. 


\section{REFERENCIAS BIBLIOGRÁFICAS}


Alarcón A, Delgadillo-Martínez J, Franco-Ramírez A, Davies F, Ferrera-Cerrato R (2006) Influence of two polycyclic aromatic hydrocarbons on spore germination, and phytoremediation potential of Gigaspora margarita-Echynochloa polystachya symbiosis in benzo[a]pyrene-polluted substrate. Rev. Int. Contam. Ambient. 22: 39-47.

Alkan M, Demirbas Ö, Doğan M (2005) Zeta potential of unexpanded and expanded perlite simple in various elctrolyte media. Micropor. Mesopor. Mater. 84: 192-200.

Alkio M, Tabuchi TM, Wang XC, Colón-Carmona A (2005) Stress responses to polycyclic aromatic hydrocarbons in Arabidopsis include growth inhibition and hypersensitive response-like symptoms. J. Exp. Bot. 56: 2983-2994.

Almroth BC, Albertsson E, Sturve J, Forlin L (2008) Oxidative stress, evident in antioxidant defenses and damage products in rainbow trout cabage outside a sewage treatment plant. Ecotoxicol. Environ. Saf. 70: 370-378.

Ahmad P, Nabi G, Ashraf M (2011) Cadmium-induced oxidative damage in mustard [Brassica juncea (L.) Czern. \& Coss.] plants can be alleviated by salicylic acid. S. Afr. J. Bot. 77: 36-44.

Ahammed GJ, Gao C-J, Ogweno JO, Zhou Y.H, Xia X-J, Mao W-H, Shi K, Yu J-Q (2012) Brassinosteroids induce plant tolerance against phenanthrene by enhancing degradation and detoxification in Solanum lycopersicum L. Ecotoxicol. Environ. Saf. 80: 28-36.

Ahammed GJ, Wang M-M, Zhou Y-H, Xia X-J, Mao W-H, Shi K, Yu J-Q. (2012b) The growth, photosynthesis and antioxidant defense response of five vegetable crops to phenanthrene stress. Ecotoxicol. Environ. Saf. 80. 132-139.

Andersson L, Milberg P (1998) Variation in seed dormancy among mother plants, populations and years of seed collection. Seed Sci. Res. 8: 29-38.

Aprill W, Sims RC (1990) Evaluation of the use of prairie grasses for stimulating polycyclic aromatic hydrocarbon treatment in soil. Chemosphere. 20: 253-265.

Badu ST, Tripuranthakam S, Greenberg BM (2005) Biochemical responses of the aquatic higher plant Lemna gibba to a mixture of copper and 1,2-dihydroxyanthraquinone: synergistic toxicity via reactive oxygen species. Environ. Toxicol. Chem. 24: 3030-3036

Bailey BA, Bae H, Strem MD, Roberts DP, Thomas SE, Crozier J, Samuels GJ, Choi I-Y, Holmes KA (2006) Fungal and plant gene expression during the colonization of cacao seedlings by endophytic isolates of four Trichoderma species. Planta. 224: 1449-1464. 
Balasubramanlyam A, Chapman MM, Harvey JP (2015) Responses of tall fescue (Festuca arundinacea) to growth in naphthalene-contaminated sand: xenobiotic stress versus water stress. Environ. Sci. Pollut. R. 22: 7495-7507.

Baxter A, Mittler R, Suzuki N (2013) ROS as key players in plant stress signaling. J. Exp. Bot. doi:10. 1093/jbx/ert375.

Baptista P, Martins A, Pais MS, Tavares RM, Lino-Neto T (2007) Involvement of reactive oxygen species during early stages of ectomycorrhizal establishment between Castanea sativa and Pisolithus tictorius. Mycorrhiza. 17: 185-193.

Becerra-Castro C, Prieto-Fernández Á, Kidd SP, Weyens N, Rodrígruez-Garrido B, ToucedaGonzález M, Acea MJ, Vangronsveld J (2013) Improving performance of Cytisus striatus on substrates contaminated with hexachlorocyclohexane $(\mathrm{HCH})$ isomers using bacterial inoculants: developing a phytoremediation strategy. Plant Soil. 362: 247-260.

Baud-Grasset F, Baud-Grasset S, Safferman SI (1993) Evaluation of the bioremeriation of a contaminated soil with phytotoxicity tests. Chemosphere. 26: 1365-1374.

Bressano M, Curetti M, Giachero L, Vargas GS, Cabello M, March G, Ducasse DA, Luna MC (2010) Mycorrhizal fungi symbiosis as a strategy against oxidative stress in soybean plants. J. Plant Physiol. 167: 1622-1626.

Buege JA, Aust SD (1978) Microsomal lipid peroxidation. Method. Enzymol. 52: 302-310.

Chance B, Maehly AC (1955) Assay of catalase and peroxidases. Method. Enzymol. 2: 764-755.

Cheeseman JM (2006) Hydrogen peroxide concentration in leaves under natural conditions. J. Exp. Bot. 57: 2435-2444.

Cheema SA, Khan MI, Tang X, Zhang C, Shen C, Zaffar M, Ali S, Yang J, Shen K, Chen X, Chen Y (2009) Enhancement of phenanthrene and pyrene degradation in rhizosphere of tall fescue (Festuca arundinacea). J. Hazard. Mat. 166: 1226-1231.

Cheplick G.P., Clay K. y Marks S (1989) Interactions between infection by endophytic fungi and nutrient limitation in the grasses Lolium perenne and Festuca arundinacea. New Phytologist. 111:89-97.

Chrikishvili DI, Zaalishvili GV, Mitaishvili TI, Lomidze EP (2006) Peptide conjugates of benzene and toluene metabolites in English Ryegrass. Russ. J. Plant Physiol. 53: 511-517. 
Cruz-Hernández A, Tomasini-Campocosio A, Pérez-Flores LJ, Fernández-Perrino FJ, GutiérrezRojas M (2013) Inoculation of seed-borne fungus in the rhizosphere of Festuca arundinacea promotes hydrocarbon removal and pyrene accumulation in roots. Plant Soil. 362: 261-270.

Cuyeu R, Rosso B, Pagano E, Soto G, Fox R, Ayub ND (2013) Genetic diversity in a world germplasm collection of tall fescue. Genet Mol Biol. 36: 237-242.

Cvjetko P, Tolić S, Šikić S, Balen B, Tkalec M, Vidaković-Cifrek Ž, Pavlica M (2010) Effect of copper on the toxicity and genotoxicity of cadmium in duckweed (Lemna minor L.). Arh Hig. Rada. Toksikol. 61: 287-296.

Dakora FD, Phillips DA (2002) Root exudates as mediators of mineral acquisition in low-nutrient environments. Plant Soil. 245: 35-47.

Debiane D, Garçon G, Verdin A, Fontaine J, Durand R, Grandmougin-Fermani A, Shirali P, Sahraoui $\mathrm{AL}$ (2008) In vitro evaluation of the oxidative stress and genotoxic potentials of anthracene on mycorrhizal chicory roots. Environ. Exp. Bot. 64: 120-127.

Debiane D, Garçon G, Verdin A, Fontaine J, Durand R, Shirali P, Grandmougin-Fermani A, Sahraoui $\mathrm{AL}$ (2009) Mycorrhization alleviates benzo[a]pyrene-induced oxidative stress in an in vitro chicory root model. Phytochemistry. 70: 1421-1427.

Dekkers BJW, Schuurmans JAMJ, Smeekens SCM (2004) Glucose delays seed germination in Arabidopsis thaliana. Plant. 218: 579-588.

Dixit P, Mukherjee PK, Sherkhane PD, Kale SP, Eapen S (2011) Enhanced tolerance and remediation of anthracene by transgenic tobacco plants expressing a fungal glutathione transferase gene. J. Hazard. Mat. 192: 270-276.

Dufernez F, Derelle E, Noël C, Sanciu G, Mantini C, Dive D, Soyer-Gobillard M, Capron M, Pierce JR, Wintjens R, Guillebault D, Viscogliosi E (2008) Molecular characterization of iron-containing superoxide dismutase in the heterotrophic dinoflagellate Crypthecodinium cohnii. Protists. 159: 223-238.

Dupont P-Y, Eaton CJ, Wargent JJ, Fechtner S, Solomon P, Schmid J, Day RC, Scott B, Cox MP (2015) Fungal endophyte infection of ryegrass reprograms host metabolism and alters development. New Phytologist. 208: 1227-1240. 
Ferrera-Cerrato R, Rojas-Avelizapa NG, Poggi-Varaldo HM, Alarcón A., Cañizares-Villanueva RO (2006) Procesos de biorremediación de suelo y agua contaminada con hidrocarburos del petróleo y otros compuestos orgánicos. Rev. Latinoam Microbiol. 48: 179-187.

Ferrera-Cerrato R, Alarcón A, Mendoza-López MR, Sangabriel W, Trejo-Aguilar D, Cruz-Sánchez JS, López-Ortiz C, Delgadillo-Martínez J (2007) Phytoremediation of fuel oil-polluted soil with Phaseolus coccineus using organic or inorganic fertilization. Agrociencia. 41: 817-826.

Gao Y, Zhu L (2004) Plant uptake, accumulation and translocation of phenanthrene and pyrene in soils. Chemosphere. 55: 1169-1178.

Gao Y, Li Q, Ling W, Zhu X (2011) Arbuscular mycorrhizal phytoremediation of soil contaminated with phenanthrene and pyrene. J Hazard Mater. 185: 703-709.

Gao Y, Li H, Gong S (2012) Ascorbic acid enhances the accumulation of polycyclic aromatic hydrocarbons (PAHs) in roots of Tall fescue (Festuca arundinacea Schreb.). PLoS ONE 7(11): e 50467.doi:10.1371/journal.pone.0050467.

Gao Y, Zhang Y, Liu J, Kong H (2013) Metabolism and subcellular distribution of anthracene in tall fescue (Festuca arundinacea Schreb.). Plant Soil. 365: 171-182.

Gadd GM (2007) Geomycology: biogeochemical transformations of rocks, minerals, metals and radionuclides by fungi, bioweathering and bioremediation. Mycol. Res. 111: 3-49.

García-Gómez RS, Pandiyan T, Aguilar-Iris V, Ruiz-Figueroa M, Durán-de-Bazúa C (2004) Identificación y cuantificación de hidrocarburos aromáticos policíclicos en suelos usando métodos espectroscópicos. Tecnol. Ciencia Ed. 19: 69-82.

Ghosh M, Singh SP (2005) A review on phytoremediation of heavy metals and utilization of its products. Appl. Ecol. Environ. Res. 3: 1-18.

Glick BR (2010). Using soil bacteria to facilitate phytoremediation. Biotechnol. Adv. 28: 367-374.

Habig WH, Jakoby WB (1981) Assays for differentiation of glutathione S-transferases. En: (Ed). Jacoby W. B. Method. Enzymol. 77: 398-405.

Hadacek F, Kraus FG (2002) Plant root carbohydrates affect growth behavior of endophytic microfungi. FEMS Microbiology Ecology. 41: 161-170. 
Hardegree SP, Van Vactor SS (1999) Predicting germination response of four cool-season range grasses to field-variable temperature regimes. Environ. Exp. Bot. 41: 209-217.

Hawker SJ (1971) Enzymes concerned with sucrose synthesis and transformations in seeds of maize broad bean and castor bean. Photochemistry. 10: 2313-2322.

Hernández-Ortega HA, Alarcón A, Ferrera-Cerrato R, Zavaleta-Mancera HA, López- Delgado HA, Mendoza-López MR (2012) Arbuscular mycorrhizal fungi on growth, nutrient status, and total antioxidant activity of Melilotus albus during phytoremediation of a diesel-contaminated substrate. J. Environ. Manage. 95: S319-S324.

Hu Z, Xie Y, Jin G., Fu J, Li H (2015) Growth responses of two tall fescue cultivars to Pb stress and their metal accumulation characteristics. Ecotoxicology. 24: 563-572.

Huang XD, El-Alawi Y, Gurska J, Glick BR, Greenberg BM (2004) A multi-process phytoremediation system for decontamination of persistent total petroleum hydrocarbons (TPHs) from contaminated soil. Environ. Pollut. 130: 465-476.

Juszczuk IM, Tybura A, Rychter AM (2008) Protein oxidation in the leaves and roots of cucumber plants (Cucumis sativa L.), mutant MSC16 and wild type. J. Plant Physi. 165: 355-365.

Kang K, Chen D, Gao Y, Zhang Y (2010) Distribution of polycyclic aromatic hydrocarbons in subcellular root tissues of ryegrass (Lolium multiflorum Lam.). BMC Plant Biology. 10: 210-216.

Kawaoka A, Matsunaga E, Endo S, Kondo S, Yoshida K, Shinmyo A, Ebinuma H (2003) Ectopic expression of a horseradish peroxidase enhances growth rate and increases oxidative stress resistance in hybrid aspen. J. Plant Physiol. 132: 1177-1185.

Krummenacher JJ, West KN, Schmidt LD (2003) Catalytic partial oxidation of higher hydrocarbons at millisecond contact times: decane, hexadecane, and diesel fuel. J Catalysis. 21: 332-343.

Kwasna H, Bateman GL, Ward E (2008) Determining species diversity of microfungal communities in forest tree roots by pure-culture isolation and DNA sequencing. App/ Soil Ecol. 40: 44-56.

Kwasna H, Ward E, Kosiak B (2006) Lewia ordeicola sp. nov. from barley grain. Mycologia. 98: 662668.

Khalmuratova I, Kim H, Nam Y-J, Oh Y, Jeong M-J, Choi H-R, You Y-H, Choo Y-S, Lee I-J, Shin JH, Yoon H, Kim J-G (2015) Diversity and plant growth promoting capacity of endophytic fungi associated with halophytic plants from the west coast of Korea. Mycobiol 43: 373-383. 
Khan AL, Hamayun M, Kim YH, Kang SM, Lee JH, Lee IJ (2011) Gibberellins producing endophytic Aspergillus fumigatus sp. LH02 influenced endogenous phytohormonal levels, isoflavonoids production and plant growth in salinity stress. Process Biochemistry. 46: 440-447.

Kreslavski VD, Lankin AV, Vasilyeva GK, Luybimov VY, Semenova GN, Schmitt F-J, Friedrich T, Allakhverdiev SI (2014) Effects of polyaromatic hydrocarbons on photosystem II activity in pea leaves. Plant. Physiol. Bioch. 81: 135-142.

Kuldaua G, Bacon C (2008) Clavicioitaceous endophytes: Their ability to enhance resistence of grassesto multiple stresses. Biological Control. 46: 57-71.

Kumar S, Hasan AM, Chkrabrty D, Deo TR, Shanker DR, Kumar TP (2013) Differential expression of rice Lambda class GST gene family members during plant growth, development, and response to stress conditions. Plant. Mol. Biol. Rep. 31: 569-580.

Kvesitadze E, Sadunishvili T, Kvesitadze GK (2009) Mechanisms of organic contaminants uptake and degradation in plants. World Acad Sci Eng Technol 55: 458-468.

Lanfranco L, Novero M, Bonfante P (2005) The mycorrhizal fungus Gigaspora margarita possesses a CuZn superoxide dismutase that is up-regulated during symbiosis with legume host. Plant. Physiol. 137: 1319-1330.

Lee SH, Ahsan N, Lee KW, Kim DH, Lee DG, Kwak SS, Kwon SY (2007) Simultaneous overexpression of both $\mathrm{Cu} / \mathrm{Zn}$ superoxide dismutase and ascorbate peroxidase in transgenic tall fescue plants confers increased tolerance to a wide range of abiotic stress. J. Plant Physiol. 164: 1626-1638.

Lee SH, Lee WS, Lee CH, Kim JG (2008) Degradation of phenanthrene and pyrene in rhizosphere of grasses and legumes. J. Hazard. Mat. 153: 892-898.

Li L, Moore PK (2007) An overview of the biological significance of endogenous gases: new roles for old molecules. Biochem. Soc. Trans. 35: 1138-1141.

Li XM. Chen MJ, Li J, Ma LJ, Bu N, Li YY, Zhang LH (2014) Effect of endophyte infection on chlorophyll a fluorescence in salinity stressed rice. Biologia Plantarum. 58: 589-594.

Lin Q, Mendelssohn IA, Suidan MT, Lee K, Venosa AD (2002) The dose-response relationship between No. 2 fuel oil and the growth of the salt marsh grass, Spartina alterniflora. Mar. Pollut. Bull. 44: 897-902. 
Liu SL, Luo YM, Ho ZH, Wu LH, Ding KQ, Christie P (2004) Degradation of benzo[a]pyrene in soil with arbuscular mycorrhizal alfalfa. Environ. Geochem. Health. 26: 285-293.

Liu H, Weisman D, Ye Y, Cui, Huang Y, Colón-Carmona A, Wang Z (2009) An oxidative stress response to polycyclic aromatic hydrocarbon exposure is rapid and complex in Arabidopsis thaliana. Plant Sci. 176: 375-382.

Liu R, Xiao N, Wei S, Zhao L, An J (2014) Rhizosphere effects of PAH-contaminated soil phytoremediation using special plant named Fire Phoenix. Sci. Total Environ. 473-474: 350-358.

Lowry OH, Rosenberg NJ, Farr AL, Randall RJ (1951) Protein measurement with Folin phenol reagent. J. Biol. Chem. 193: 265-275.

Lucero ME, Barrow JR, Osuna P, Reyes I (2006) Plant-fungal interactions in arid and semi-arid ecosystems: Large-scale impacts from microscale processes. J. Arid Environ. 65: 276-284.

Lucho-Constantino CA, Álvarez-Suárez M, Beltrán-Hernández RI, Prieto-García F, Poggi-Varaldo HM (2005) A multivariate analysis of the accumulation and fractionation of major and trace elements in the agricultural soil in Hidalgo State, Mexico irrigated with raw wastewater. Environ. International. 31: 313-323.

Martí MC, Camejo D, Fernández-García N, Rellán-Álvarez R, Marques S, Sevilla F, Jiménez A (2009) Effect of oil refinery sludges on the growth and antioxidant system of alfalfa plants. J. Hazard. Mat. 171: 879-885.

Martin T, Oswald O, Graham IA (2002) Arabidopsis seedling growth, storage lipid mobilization, and photosynthetic gene expression are regulated by carbon:nitrogen availability. Plant Physiology. 128: $472-481$.

Mei C, Flinn BS (2010) The use of beneficial microbial endophytes for plant biomass and stress tolerance improvement. Recent Pat Biotechnol 4: 81-95.

Mendarte-Alquisira C (2013) Aclimatación de la asociación planta-hongo filamentoso a un suelo contaminado artificialmente con hidrocarburos. Autónoma Metropolitana-Iztapalapa. Posgrado en Biotecnología. Tesis de Maestría en Biotecnología.

Merkl N, Schultze-Kraft R, Infante C (2005) Phytoremediation in the tropics - influence of heavy crude oil on root morphological characteristics of graminoids. Environ. Pollut. 138: 86-91. 
Mhamdi A, Queval G, Chaouch S, Vanderauwera S, Van Breusegem F, Noctor G (2010) Catalase function in plants: a focus on Arabidopsis mutants as stress-mimic models. $J$ Exp. Bot. 61: 41974220.

Mika A, Lüthje S (2002) Properties of guaiacol peroxidase activities isolated from corn root plasma membranes. Plant Physiology. 132: 1489-1498.

Ming Xu X, Lin H, Maple J, Björkblom B, Alves G, Larsen JP, Møller SG (2010) The Arabidopsis DJ1a protein confers stress protection through cytosolic SOD activation. J. Cell Sci. 123: 1644-1651.

Minotti G, Aust SD (1987) The role of iron in the initiation of lipid peroxidation. Chem. Phys. Lipids. 44: 191-208.

Mirzahosseini Z, Shabani L, Sabzalian MR, Sharifi-Tehrani M (2014) Neotyphodium endophytes may increase tolerance to $\mathrm{Ni}$ in tall fescue. Eur. J. Soil Biol. 63: 33-40.

Mirzahosseini Z, Shabani L, Sabzalian MR, Sharifi-Tehrani M (2015) ABC transporter and metallothionein expression affected by $\mathrm{NI}$ and Epichloe endophyte infection in tall fescue. Ecotox Environ Safe 120: 13-19.

Møller IM, Jensen PE, Hansson A (2007) Oxidative modifications to cellular components in plants. Annua. Rev. Plant Biol. 58: 459-481.

Moons A (2005) Regulatory and functional interactions of plant growth regulators and plant glutathione S-transferases (GSTs). Vitam Horm 72:155-202.

Morkunas I, Boker S, Formela M, Ratajczak L (2012) Plant responses to sugar starvation. Chapter 19. pp. $409-438$.

Murashige T, Skoog F (1926) A revised medium for rapid growth and bioassays with tobacco tissue cultures. Plant Physiology. 473-497.

Nanda AK, Andrio E, Marino D, Pauly N, Dunand C (2010) Reactive oxygen species during plantmicroorganism early interactions. J Integr Plant Biol 52: 195-204.

Narro ML, Cerniglia CE, Baalen CV, Gibson DT (1992) Metabolism of phenanthrene by the marine cyanobacterium Agmenellum quadruplicatum PR-6. Appl. Environ. Microbiol. 58: 1351-1359.

Navarro BS, Navarro GG (2003) Química Agrícola. Ediciones Mundi-Prensa Madrid 2ª Edición pp. 15. 
Newsham KK (1999) Phialophora graminicola, a dark septate fungis, is a beneficial associate of the grass Vulpia ciliate ssp. Ambigua. New Phytol. 144: 517-524.

Nicolaï M, Roncato MA, Canoy AS, Rouquié D, Sarda X, Freyssinet G, Robaglia C (2006) Largescale analysis of mRNA translocation states during sucrose starvation and chromatin structure as targets of translational control. Plant Physiol. 141: 663-673.

Pan S, He M, Lei Z, Yuan X (2016) Influence of inoculating earthworm on removal of pyrene in soil growing Festuca arundinacea. Toxicol. Environ. Chem. 98: 601-610.

Pannangpetch P, Laupattarakasem P, Kukongviriyapan V, Kukongiriyapan U, Kongyingyoes B, Aromdee C (2007) Antioxidant activity and protective effect against oxidative hemolysis of Clinacanthus nutans (Burm.f) Lindau. Songklanakarin J. Sci. Technol. 29: 1-9.

Parrish ZD, Banks MK, Schwab AP (2004) Effectiveness of phytoremediation as a secondary treatment for polycyclic aromatic hydrocarbons (PAHs) in composted soil. Int. J. Phytoremediation. 6:119-137.

Petróleos Mexicanos (PEMEX) (2016) Informe anual 2015.

Pilon-Smits E (2005) Phytoremediation. Ann. Rev. Plant Biol. 56: 15-39.

Porra RJ, Thompson WA, Kriedemann PE (1989) Determination of accurate extinction coefficients and simultaneous equations for assaying chlorophylls $a$ and $b$ extracted with four different solvents: verification of the concentration of chlorophyll standards by atomic absorption spectroscopy. Biochim. Biophys. Acta. 975: 385-394.

Porras-Alfaro A, Bayman P (2011) Hidden fungi, emergent properties: Endophytes and microbiomes. Annu. Rev. Phytopathol. 49: 291-315.

Procuraduría Federal de Protección al Ambiente (2015) Informe de actividades 2015. PROFEPA, 2015. pp. 32

Pryor W.A, Castle L (1984) Chemical methods for the detection of lipid hydroperoxides. Method. Enzymol. 105: 293-299.

Pulido P, Llamas E, Rodríguez-Concepción M (2017) Both Hsp 70 chaperone and Clp protease plastidial system are required for protection against oxidative stress. Plant Signaling \& Behavior. doi.org/10.1080/15592324.2017.1290039

Rai MK, Jaiswal VS, Jaiswal U (2008) Effect of ABA and sucrose on germination of encapsulated somatic embryos of guava (Psidium guajava L.). Scientia Horticulturae. 117: 302-305. 
Rasmussen S, Parsons AJ, Bassett S, Christensen MJ, Hume DE, Johonson LJ, Johonson RD, Simpson WR, Stacke C, Voisey CR, Xue H, Newman J (2007) High nitrogen supply and carbohydrate content reduce fungal endophyte and alkaloid concentration in Lolium perenne. New Phytologist. 173: 787-797.

Reynoso-Cuevas L, Gallegos-Martínez ME, Cruz-Sosa F, Gurierrez-Rojas M (2008) In vitro evaluation of germination and growth of five plant species on medium supplemented with hydrocarbons associated with contaminated soils. Bioresour. Technol. 99: 6379-6385

Rodríguez CE, Fukuto JM, Taguchi K, Froines J, Cho AK (2005) The interaction of 9,10phenantrhenequinone with glyceraldehyde-3-phosphate dehydrogenase (GAPDH), a potential site for toxic actions. Chem. Biol. Interact. 155: 97-110.

Rodríguez RJ, White JF, Arnold AE, Redman RS (2009) Fungal endophytes: diversity and functional role. New Phytologist. 182: 314-330.

Rojas-Loria CC, Peralta-Perez MR, Buendia-Gonzalez L, Volke-Sepulveda TL (2011) Effect of a saprophytic fungus on the growth and the lead uptake, translocation and immobilization in Dodonaea viscosa. Int. J. Phytoremediation. 14: 518-529.

Rojas-Loria CC, Favela-Torres E, González-Márquez H, Volke-Sepúlveda TL (2014) Role of glutathione and glutathione S-transferase in lead tolerance and bioaccumulation by Dodonaea viscosa (L.) Jacq. Acta Physiol Plant 36: 2501-2510.

Roy S, Pellinen J, Sen CK, Häenine O (1994) Benzo[a]anthracene and benzo[a]pyrene exposure in the aquatic plant Fontinalis antipyretica: Uptake, elimination and the responses of biotransformation and antioxidant enzymes. Chemosphere. 29: 1301-1311.

Roy S, Sen CK, Hännine O (1996) Monitoring of polycyclic aromatic hydrocarbons using "moss bags". Bioaccumulation and responses of antioxidant enzymes in Fontinalis antipyretica Hedw. Chemosphere. 32: 2305-2315.

Schnoor J, Licht L, McCutcheon S, Wolfe N, Carreira L (1995) Phytoremediation of organic and nutrient contaminants. Environ. Sci. Technol. 29: 318A-323A.

Schulz B, Boyle C, Draeger S, Romert A-K, Krohn K (2002) Endophytic fungi: a source of novel biologically active secondary metabolites. Mycol. Res 106, 996-1004. 
Sherratt JP, Hayes DJ (2001) Enzyme systems that metabolize drugs and other xenobiotics. Reino Unido. Jhon Wiley \& Sons Ltd. pp. 319-352.

SEMARNAT (2013) Informe de la situación del medio ambiente en México. Compendio de estadísticas ambientales. Indicadores clave y de desempeño ambiental. Edición 2012. México.

Shahrtash M (2013) Plant glutathione S-transferases function during environmental stresses: a review article. Rom J Biol. 58: 19-25.

Shin R, Schachtman DP (2004) Hydrogen peroxide mediates plant root cell response to nutrient deprivation. Plant Biology. 101: 8827-8832

Singh VP, Sirvastava PK, Prasad SM (2012) Differential effect of UV-B radiation on growth, oxidative stress and ascorbate-glutathione cycle in two cyanobacteria under copper toxicity. Plant Physiol. Biochem. 61: 61-70.

Soleimani M, Afyni M, Hajabbasi MA, Nourbakhsh F, Sabzalian MR, Christensen JH (2010) Phytoremediation of an aged petroleum contaminated soil using endophyte infected and noninfected grasses. Chemosphere. 81: 1084-1090.

Starkov AA (2008) The role of mitochondria in reactive oxygen species metabolism and signaling. Ann. N. Y. Acad. Sci. 1147: 37-52.

Stiborová M, Anzenbachlr P (1991) What are the principal enzymes oxidizing the xenobiotics in plants: cytochrome P-450 or peroxidase? (A hypothesis). Gen. Physiol. Biophys. 10: 209-216.

Tanaka A, Christensen MJ, Takemoto D, Park P, Scott B (2006) Reactive oxygen species play a role in regulating a fungus-perennial ryegrass mutualistic interaction. Plant Cell. 18: 1052-1066.

Tiwari S, Lata C, Singh CP, Shekhar NC (2016) Pseudomonas putida attunes morphophysiological, biochemical and molecular responses in Cicer arietinum L. during drought stress and recovery. Plant Physiol. Biochem. 99: 108-117.

Tomar RS, Jajoo A (2015) Photomodified fluoranthene exerts more harmful effects as compared to intact fluoranthene by inhibiting growth and photosynthetic processes in wheat. Ecotox. Environ. Safe. 122: 31-36.

Thomas SE, Crozier J, Aime MC, Evans HC, Holmes KA (2008) Molecular characterization of fungal endophytic morphospecies associated with the indigenous forest tree, Theobroma gileri, in Ecuador. Mycol Res. 112(7):852-860. 
Torres MS, White Jr. JF, Zhang X, Hinton DM, Bacon C (2012) Endophyte-mediated adjustments in host morphology and physiology and effects on host fitness traits in grasses. Fungal Ecology. 5: $322-330$

Tripathy BC, Oelmüller R (2012) Reactive oxygen species generating and signaling in plants. Plant Signal Behav. 7: 1621-1633.

Vallentine P, Hung C-Y, Xie J, Hoewyk DV (2014) The ubiquitin-proteasome pathway protects Chlamydomonas reinhardtii against selenite toxicity, but is impaired as reactive oxygen species accumulate. AoB Plants. 6: plu062; doi:10.1093/aobpla/plu062.

Walsh RA (1995). Schenonorus arundinaceaus. In: Fire Effects Information System, (Online). U. S. Department of Agriculture, Forest Service, Rocky Mountain Research Station, Fire Sciences Laboratory (Producer) (http://www.fs.fed.us/database/feis/plants/graminoid/scharu/all.html)

Waqas M, Khan AL, Kamran M, Hamayun M, Kang S-M, Kim Y-H, Lee I-J (2012) Endophytic fungi produce gibberellins and indolacetic acid and promotes host-plant growth during stress. Molecules. 17: 10754-10773.

Wei H, Song S, Tian H, Liu T (2014) Effects of phenanthrene on seed germination and some physiological activities of wheat seedling. C. R. Biol. 337: 95-100.

White Jr JF, Bacon CW, Hinton DH (1997) Modifications of host cells and tissues by the biotrophic endophyte Epichloë amarillans (Clavicipitaceae; Ascomycotina). Canadian Journal of Botany. 75: 1061-1069.

White Jr. JF, Torres SM (2010) Is plant endophyte-mediated defensive mutualism the result of oxidative stress protection? Physiol. Plant. 138:440-446.

Wild E, Dent J, Thomas GO, Jones KC (2006) Visualizing the air-to-leaf transfer and within-leaf movement and distribution of phenanthrene: further studies utilizing tow-photon excitation microscopy. Environ. Sci. Technol. 40: 907-916.

Yang F, Li J, Gan X, Qian Y, Wu X, Yang Q. 2010. Assessing nutritional status of Festuca arundinacea by monitoring photosynthetic pigments from hyperspectral data. Comput. Electron. Agric. 70: 52-59.

Yankova PV, Rasheva TV, Kujumdzieva VA (2002) Catalase enzyme in mitochondria of Saccharomyces cerevisiae. Electronic J. 5: 29-41. 
Yoshimura K, Miyao K, Gaber A, Takeda T, Kanaboshi H, Miyasaka H, Shigeoka S (2004) Enhancement of stress tolerance in transgenic tobacco plants overexpressing Chlamydomonas glutathione peroxidase in chloroplasts or cytosol. Plant J. 37: 21-33.

Zhang X, Fan X, Li C, Nan Z (2010) Effects of cadmium stress and seed germination, seedling growth and antioxidative enzymes in Achnatherum inebrians plants infected with a Neotyphodium endophyte. Plant Growth Regul 60: 91-97.

Zhao S, Jia L, Duo L (2013) The use of a biodegradable chelator for enhanced phytoextraction of heavy metals by $F$. arundinacea from municipal soil waste compost and associated heavy metal leaching. Biores. Technol. 129: 249-255.

Zhuang X, Chen J, Shim H, Bai Z (2007) New advances in plant growth-promoting rhizobacteria for bioremediation. Environ. Int. 33: 406-413. 
ANEXO I 
COMPONENTES DEL MEDIO MURASHIG AND SKOOG

\begin{tabular}{|c|c|}
\hline Componente & $(\mathrm{mg} / \mathrm{L})$ \\
\hline Nitrato de amonio & 1650.0 \\
\hline Ácido bórico & 6.2 \\
\hline Cloruro de calcio (anhidro) & 332.2 \\
\hline Cloruro de cobalto $\bullet 6 \mathrm{H}_{2} \mathrm{O}$ & 0.025 \\
\hline Sulfato cúprico $\bullet 5 \mathrm{H}_{2} \mathrm{O}$ & 0.025 \\
\hline Disodio-EDTA $\cdot 2 \mathrm{H}_{2} \mathrm{O}$ & 37.26 \\
\hline Sulfato ferroso $\cdot 7 \mathrm{H}_{2} \mathrm{O}$ & 27.8 \\
\hline Sulfato de magnesio (anhidro) & 180.7 \\
\hline Sulfato de manganeso $\cdot \mathrm{H}_{2} \mathrm{O}$ & 16.9 \\
\hline Ácido de molibdeno (sodio sal) $\bullet 2 \mathrm{H}_{2} \mathrm{O}$ & 0.25 \\
\hline Ioduro de potasio & 0.83 \\
\hline Nitrato de potasio & 1900.0 \\
\hline Fosfato de potasio monobásico & 170.0 \\
\hline Sulfato de zinc $\cdot 7 \mathrm{H}_{2} \mathrm{O}$ & 8.6 \\
\hline Glicina (base libre) & 2.0 \\
\hline Mio-Inositol & 100.0 \\
\hline Ácido nicotínico (ácido libre) & 0.5 \\
\hline Piridoxina $\bullet \mathrm{HCl}$ & 0.5 \\
\hline Tiamina $\cdot \mathrm{HCl}$ & 0.1 \\
\hline
\end{tabular}


ANEXOII 


\section{PUBLICACIONES}

Plant Soil

DOI I0 1007is III04-0I6-3035-6

REGULAR ARTICLE

\section{Improved growth and control of oxidative stress in plants of Festuca arundinacea exposed to hydrocarbons by the endophytic fungus Lewia sp.}

\section{Caliope Mendarte-Alquisira . \\ Mariano Gutiérrez-Rojas . \\ Humberto Gonzảlez-Märquez . \\ Tania Volke-Sepuilveda}

Received: 17 May 2016/Accepted: 22 Aupust 2016

1. Springer Intemational Publishing Switzerland 2016

\section{Abstract}

Aims The protective role of fungal endophytes in plants under stress by hydrocarbons is yet poorly understood. The influence of the endophytic fungus Lewia sp. on growth and oxidative stress control in plants of Festuca anundinacea exposed to a hydrocarbon mixture (HCM) was evaluated.

Methods Plants of $F$ anundinacea were inoculated or not with Lewia sp. to establish endophytic association. Affer 15 days, the plant growth, oxidative stress, and activity of antioxidant enzymes were analyzed in associated and unassociated plants. Then. both groups of plants were exposed for 7 days to a HCM $(800 \mathrm{mg}$ $\mathrm{kg}^{-1}$ ) in a model soil. The effect of the HCM was

Responsible Editor: Ahin Pierret.

C. Mendarie-Alquisira + M. Guticrezez-Rojas *

I. Volke-Sepúlied $(\triangle)$

Biotechnology Depurtment, Universidad Autčnoma

Mctropolitana-Ltapalapa, San Rafael Atlinco IS6, Col. Vicentina.

Irtapulapa 09340 D.F., Mexico

e-mail: tvs@xanumummx

C. Mendarte-Alquisira

e-mail cma/äxanum uam mx

M. Gutièrrez-Rojas

e-mail: mgraxamum.uam.nx

H. Gonrilez-Mirquez

Health Sciences Department, Universidad Autónoma

Metropolitana-Irtapalapa, San Rafael Atfixco 186, Col. Vicentina.

Iriapulapa 09340 D.F., Mexico

e-mail: hgna ia xamum wam mx assessed in the plants through the same variables as mentioned above.

Results Endophytic association was established after 15 days. The fungus enhanced plant growth, as well as $\mathrm{H}_{2} \mathrm{O}_{2}$ and malondialdehyde concentration, and decreased glutathione S-transferase (GST) activity. Lewia sp. decreased the $\mathrm{H}_{2} \mathrm{O}_{2}$ concentration in plants exposed to the HCM and increased the activity of superoxide dismutase and peroxidases, while significantly decreasing GST activity.

Condusions This study demonstrates the positive role of Levia sp. in promoting growth and alleviating oxidative stress in $F$, anmdinacea exposed to hydrocabons.

Keywords Endophytic association.

Festuca anundinacea - Hydrocarbons - Lewia sp. -

Oxidative stress

\section{Introduction}

Polycyclic aromatic hydrocarbons (PAH) are compounds widely spread in aquatic and terrestrial ecosystems (Liu et al. 2009); among these, phenanthrene, and pyrene are classified as carcinogenic and mutagenic by the U.S. Environmental Protection Agency (Debiane et al. 2009). Plants have defense mechanisms against the adverse effects caused by these compounds, which enables them to survive under such abiotic stress (Kvesitadze et al 2009). In plants under biotic and abiotic stress conditions, reactive oxygen species

으 Springer

Published online: 29 Augast 2016 
(ROS) are produced in excess amounts. These reactive molecules, which comprise radical and non-radical species, react with biomolecules causing chemical changes in proteins, lipids, and even DNA, which results in oxidative stress (Cvjetko et al. 2010). Thus, the intracellular ROS concentration has to be tightly controlled through the antioxidant defense system, which consists of enzymatic - including superoxide dismutase (SOD), catalase (CAT), peroxidases (POD), and glutathione Stransferases (GST) - and nonenzymatic antioxidants, mainly ascorbate and glutathione (GSH) (Debiane et al. 2009). GSH is also a cosubstrate for GSTs, which in plants participate in various functions such as phytohomone homeostasis, hydroxyperoxide detoxification. and apoptosis regulation (Shahrtash 2013), and also have key roles in response to biotic and abiotic stresses (Kumar et al. 2013). Nevertheless, high ROS production is also necessary for plant defense. Currently, the involvement of ROS as signal molecules during cellular growth, plant-pathogen interactions, and stress responses has been demonstrated (Nanda et al. 2010).

A successful plant strategy to adapt to a wide range of stressors is the formation of mutualistic symbiotic associations with microorganisms (Tana ka et al. 2006). Plant-fungi symbiotic associations are ubiquitous in natural plant communities. Besides the well-studied symbiosis with mycorrhizal fungi, mutual relationships among plants and endophytes have had increasing attention (Mci and Flinn 2010). Endophytic microorganisms live within plant tissues without causing symptoms of discase (Porras-Alfaro and Bayman 2011). Several studies have shown that endophytes can benefit plants growing under stress conditions, such as the presence of pollutants - heavy metals (Ahmad et al. 2011) and organochlorines (Becerra-Castro et al. 2013) - or high salt concentrations and drought (Tiwari et al. 2010), by controlling oxidative stress. Plant colonization by endophytes causes biochemical changes during establishment of the association. A common response is an increased production of ROS (oxidative burst), which is tho ught to be required to inactivate the plant's defense response against the fungus, thereby maintaining a mutualistic relationship (Tanaka et al. 2006; Nanda et al. 2010). Most studies have been focused on the association of plants with the arbuscular mycorrhizal fungus Glomus sp. or the endophytic fungus Neoty phodium coenophialum under stress by heavy metals and pesticides (Debiane et al. 2009). Nevertheless, it was recently reported that an endophytic fungus in the genus Leavia increased the tolerance of Festuca arundinacea against a hydrocarbon mixture (CruzHernández et al. 2013). Lewia sp. is an ascomycete fungus in the Pleosporaceae family, which was also identified as an endophyte of halophytic plant species such as Limonium tetragonum and Phragmites australis (Khalmuratova et al. 2015).

Although the coological significance of endophytic fungi has been shown, their role in controlling oxidative stress in plants exposed to hydrocabons is not yet fully understood. To date, the particular mechanisms influencing the tolerance and growth of $F$ anindinacea plants exposed to hydrocarbons in an endophytic association with Lewia sp. have not been reported. This led us to hypothesize that Levia sp. modifies the activity of antioxidant enrymes of $E$ arnendinacea under in vitro conditions, which consequently can improwe growth and control of oxidative stress in plants exposed to a hydrocarbon mixture (HCM). Thus the aim of this study was to cvaluate the effect of Lewia sp. on growth and oxidative stress control in plants of E anumdinacea exposed to a HCM in a model soil.

\section{Materiak and methods}

Plant material

This study was done with plants of tall fescue (Festuca arundinacea Schreb.) produced from seeds obtained in the central food market in Mexico City. Seeds were placed into a filter paper (Whatman 40) and submerged in a commercial detergent solution ( $2 \% w / v)$ for 20 min with agitation, then they were thoroughly washed with tap water. Seeds were then surface-sterilized by soaking in $70 \%$ ethanol ( 30 s), followed by $1.8 \%$ NaClo containing $0.01 \%$ Tween-20 (30 min). Afterwards, seeds were thoroughly rinsed with deionized sterile water.

The treated sceds were aseptically sown in Magenta $^{*}$ boxes (Sigma) containing sterile MurashigeSkoog (MS, Murashige and Skoog 1962) medium (Sigma) with sucrose $\left(10 \mathrm{~g} \mathrm{~L}^{-1}\right.$, Sigma) and Phytagel ( $1.8 \mathrm{~g} \mathrm{~L}^{-1}$, Sigma) added. The $\mathrm{pH}$ of the medium was adjusted to 5.7 beforc autoclaving (121 $\left.{ }^{\circ} \mathrm{C}, 15 \mathrm{~min}\right)$. Sixteen seeds per box were grown for 15 days at $25 \pm 2{ }^{\circ} \mathrm{C}$ under a $16 \mathrm{~h}$ photoperiod (light intensity of $50 \mu \mathrm{mol} \mathrm{m} \mathrm{m}^{-2} \mathrm{~s}^{-1}$ ). 
Fungal inoculum

Lewia sp. was isolated from surface-sterilized seeds of $F$. arundinacea germinated under in vitro conditions (Cruz-Hernández et al. 2013). The strain was identified by comparing the nucleotide sequence (GenBank GU296022, taxid: 708157) with fungal sequences through standard nucleotide-nucleotide BLAST (http:/www.ncbi.nlm nih.zoviblast). The fungus was maintained $\left(4^{\circ} \mathrm{C}\right)$ on potato dextrose agar (PDA) medium after 7 days of growth at $30^{\circ} \mathrm{C}$. The fungal inoculum was prepared by inoculating mycelium discs $(5 \mathrm{~mm})$ on Petri dishes containing MS medium with sucrose ( $10 \mathrm{~g}$ $\mathrm{L}^{-1}$ ) and Phytagel, and incubated at $30^{\circ} \mathrm{C}$ for 15 days. Sixty-five dises of peripheral mycelium were cut and the MS medium adhered was removed from each disk with a sterile scalpel. The free-medium biomass disks obtained were aseptically disaggregated by agitation in tubes containing glass beads $(3 \mathrm{~mm}$ ) and isotonic solution $(0.9 \% \mathrm{NaCl})$. The obtained fungal biomass suspension $\left(10.1 \pm 0.1 \mathrm{mg} \mathrm{mL}^{-1}\right)$ was used as inoculum

\section{Induction of the endophytic association}

In order to establish endophytic association, 15-dayold plants of $F$ arundinacea were inoculated with $2 \mathrm{~mL}$ of the fungal biomass suspension around the roots. Plants inoculated or not were grown for 15 days more at $25 \pm 2{ }^{\circ} \mathrm{C}$ ( $16 \mathrm{~h}$ photoperiod). Then. plants were harvested either for analysis or for their transplant to flasks with model soil added.

The presence of Lewia sp. within root tissues was verified by treating the roots as follows: cubes $\left(1 \mathrm{~cm}^{2}\right)$ of MS medium containing root segments were submerged in $70 \%$ ethanol $(48 \mathrm{~h})$. The gel cubes were washed with deionized water and treated sequentially at $5^{\circ} \mathrm{C}$ by immersion in the following solutions: once in $320 \mathrm{mM}$ sucrose $(48 \mathrm{~h})$, three times in $420 \mathrm{~m} \cdot M$ sucrose $(48 \mathrm{~h}$ ), once in $420 \mathrm{mM}$ sucrose $(24 \mathrm{~h})$. The cubes were stored at $-20^{\circ} \mathrm{C}$ for $24 \mathrm{~h}$ and then defrosted to release the roots. The root was cut into smaller segments, which were placed in a concave microscope slide and stained with Calcofluor White Stain (Sigma) and $10 \% \mathrm{KOH}$ for $7 \mathrm{~min}$. The root images were obtained in a spectral confocal microscopy system (LSM780NLO, Carl Zeiss). The track used was 410-579 bearn splitters.

\section{Culture conditions}

The assay was done in glass flasks (experimental units. EU) containing a model soil polluted or not with $800 \mathrm{mg}$ HCM kg ${ }^{-1}$ of dry model soil. A mixture $\left(1: 1, w^{\prime} v\right)$ of perlite (Dicalite, Mexico) and silica sand was used as model soil. Perlite was sieved $(0.4-2.8 \mathrm{~mm})$ and washed with hot water to remove impurities. Silica sand $(0.4-$ $2.0 \mathrm{~mm}$ ) was treated with $10 \% \mathrm{HCl}(24$ h) to remove organic matter and carbonates, and then thoroughly washed with distilled water. Both materials were dried $\left(60^{\circ} \mathrm{C}, 72 \mathrm{~h}\right)$ and then mixed into EU. Each EU contained $84 \mathrm{~g}$ (dry weight. DW) of model soil, which was moistened with $40 \mathrm{~mL}$ of MS medium with sucrose $\left(16 \mathrm{~g} \mathrm{~kg}^{-1} \mathrm{DW}\right)$ at $\mathrm{pH}$ 5.7. Before sterilization $\left(121^{\circ} \mathrm{C}\right.$, 15 min), the HCM, consisting of hexadecanc, phenanthrene and pyrene (Sigma-Aldrich) in a ratio of $2: 1: 0.5$ ( $(w$ wiv), was added to each flask. The HCM was dissolved in acetone, which was completely evaporated for $24 \mathrm{~h}$.

Twelve 30-day-old plants of $F$ arundinacea, associated or not with Lewia sp., were transferred per EU containing the model soil polluted or not with the HCM. Four treatments were done: (i) $F$. arundinacea (Fa); (ii) $F$. anendinacea exposed to the HCM (Fa+ HCM); (iii) $F$ arundinacea associated with Lewia sp. (Fa-L), (iv) F anandinaced-Lewia sp. with HCM (Fa-L + HCM). EU were incubated for 7 days at $25 \pm 2{ }^{\circ} \mathrm{C}$ under a $16 \mathrm{~h}$ photoperiod. A total of five EU were assayed to obtain 60 plants per treatment. After treatment period, 60 plants were separated into roots and shoots to be destructively analyzed as follows: (i) 12 were used for biomass determination and (ii) 48 were separated into four groups to determine (by triplicate) the content of $\mathrm{H}_{2} \mathrm{O}_{2}$, malondialdehyde (MDA), and oxidized proteins, as well as the enzyme activity in fresh tissues. For analyzes in fresh tissues, a replicate was the biomass obtained from 4 plants. These same analyzes were performed in plants obtained from MS modium.

Plant growth determination

Plant growth was quantified by measuring scparately the biomass of shoots and roots on a DW basis, affer oven-drying $\left(60^{\circ} \mathrm{C}, 48 \mathrm{~h}\right)$.

Preparation of crude extracts

Fresh tissues ( $\sim 100 \mathrm{mg})$ of roots and shoots obtained from each treatment were separately pulverized in liquid 
$\mathrm{N}_{2}$. Tissues were homogenized in cold sodium phosphate buffer $(50 \mathrm{mM}, \mathrm{pH} 7)$ with $1 \%$ polyvinylpyrrolidone and protease inhibitor (P8215, Sigma, $5 \mu \mathrm{L}$ for $100 \mathrm{mg}$ of fresh tissue) added. Homogenates were treated in a cell disruptor (Mikro-Dismembrator U, Sartorius) for $2 \mathrm{~min}$ at $2000 \mathrm{rpm}$ and then centrifuged $\left(4^{\circ} \mathrm{C}, 10 \mathrm{~min}, 10629 \mathrm{~g}\right.$ ). The resultant supernatants (crude extracts, CE) were used to measure the protein content in a microplate spectrophotometer (EL x808, BioTck) by the method of Lowry et al. (1951), using a commercial kit (Bio-Rad) and BSA as standard.

Oxidative stress quantification

Hydrogen peroxide $\left(\mathrm{H}_{2} \mathrm{O}_{3}\right)$

The CE was mixed with $5 \mathrm{mM} \mathrm{KCN}$ to inhibit the CAT and POD activity, and then with a reaction solution containing ammonium ferrous sulfate $(250 \mu \mathrm{M})$, sorbitol $(100 \mu \mathrm{M})$, and xylenol orange $(100 \mu \mathrm{M})$ in $25 \mathrm{mM}$ $\mathrm{H}_{2} \mathrm{SO}_{4}$ and $1 \%$ cthanol. The mixture was incubated at room temperature for $30 \mathrm{~min}$, and the complex formed between $\mathrm{Fe}^{2+}$ and $x y l e n o l$ orange was spectrophotometrically measured at $560 \mathrm{~nm}$ ( 50 Conc, Varian). The standard curve of $\mathrm{H}_{2} \mathrm{O}_{2}$ was prepared in distilled water in a concentration range of 0.5 to $80 \mu M$ (Cheeseman 2006).

\section{Lipid peroxidation}

Lipid peroxidation was quantified by measuring the MDA concentration in the CE, which was prepared by homogenizing fresh tissues in $20 \mathrm{mM}$ Tris - $\mathrm{HCl}$ buffer (pH 7.4) with $10 \mu \mathrm{L}$ of $500 \mathrm{~m} . \mathrm{M}$ butylated bydroxytoluene, and centrifuged $\left(4^{\circ} \mathrm{C}, 15 \mathrm{~min}, 20817 \mathrm{~g}\right)$. The reaction mixture contained $100 \mu \mathrm{L}$. of CE in $200 \mu \mathrm{L}$ of the reaction solution ( $15 \%$ trichloroacetic acid, $0.5 \%$ thiobarbituric acid and $0.25 \mathrm{~N} \mathrm{HCl}$ ). The mixture was incubated at $90^{\circ} \mathrm{C}$ for $25 \mathrm{~min}$. The chromogen produced was measured at $535 \mathrm{~nm}$, and the MDA concentration was estimated with an extinction coefficient $(\varepsilon)$ of $155 \mathrm{m.} \mathrm{cm}^{-1} \mathrm{~cm}^{-1}$ (Buege and Aust 1978).

\section{Oxidized proteins}

The content of oxidized proteins was measured by quantifying the carbonyl ( $\mathrm{CO}$ ) groups in proteins. $\mathrm{CO}$ groups react with 2,4-dinitrophenylhydrazine (DNPH), generating a hydrazone protein conjugate which has a maximum absorbance at $375 \mathrm{~nm}$. The reaction mixture contained the required amount of CE for $20 \mu \mathrm{g}$ of protein and $750 \mu \mathrm{L}$ of $10 \mathrm{mM}$ DNPH in $2 \mathrm{M}$ HCl. The CO group content was estimated with an $\varepsilon-22 \mathrm{~m} M^{-1} \mathrm{~cm}^{-1}$ (Juszczuk et al, 2008).

Enzyme activity

Superoxide dismutase (SOD, EC 1.15.1.1) activity was spectrophotometrically determined at $450 \mathrm{~nm}$ with a commercial kit (19160, Sigma). The assay utilizes a water-soluble tetrazolium salt that produces a formazan dye after reduction by the superoxide $\left(\bullet \mathrm{O}_{2}\right)$ radical. The rate of reduction with $\cdot \mathrm{O}_{2}{ }^{-}$ is linearly related to xanthine oxidase activity, which is inhibited by SOD. The result is compared with a standard curve of SOD. One unit of SOD activity is defined as the amount of enzyme that inhibits in $50 \%$ of the reduction of $\mathrm{O}_{2}{ }^{-}$per minute at $25{ }^{\circ} \mathrm{C}$ and $\mathrm{pH} 7$.

Non-specific peroxidases (POD, EC 1.11.1.7) activity was assayed by measuring the oxidation of guaiacol to tetraguaiacol catalyzed by POD in the presence of $\mathrm{H}_{2} \mathrm{O}_{2}$, which was monitored in a microplate spectrophotometer at $450 \mathrm{~nm}$ for $4 \mathrm{~min}$. The reaction mixture contained $200 \mu \mathrm{L}$ of sodium phosphate buffer $(50 \mathrm{mM}, \mathrm{pH} 7), 10 \mu \mathrm{L}$ of $1 \%$ of guaiacol and $10 \mu \mathrm{L}$. of $\mathrm{CE}$. The activity was calculated from the initial rate of the reaction considering $\varepsilon=26.6 \mathrm{mM}^{-1} \mathrm{~cm}^{-1}$ (Chance and Machly 1955). One unit of POD activity is defined as the amount of enzyme that catalyzes the formation of $1 \mu$ mol of tetraguaiacol per minute at $25^{\circ} \mathrm{C}$ and $\mathrm{pH} 7$.

Glutathione S-transferase (GST, EC 2.5.1.18) activity was measured using a commercial kit (CS0410, Sigma). The conjugation of GSH to 1chloro-2,4-dinitrobenzene (CDNB) catalyzed by GST was monitored at $340 \mathrm{~nm}$ for $4 \mathrm{~min}$. The reaction mixture contained $20 \mu \mathrm{L}$ of $\mathrm{CE}$ and $180 \mu \mathrm{L}$ of reaction solution $(200 \mathrm{mM}$ GSH and $100 \mathrm{~m} M$ CDNB in Dulbecco's buffer at $\mathrm{pH} 7$ ). The activity was calculated with $\varepsilon=9.6 \mathrm{mM} M^{-1} \mathrm{~cm}^{-1}$ (Habig and Jakoby 1981). A GST unit is defined as the amount of enzyme that catalyzes the formation of 1 umol of the GS-DNB conjugate per minute at $25^{\circ} \mathrm{C}$ and $\mathrm{pH} 7$.

In order to assess the effect of either the HCM or Lewia sp. on F. arundinacea, we used the enzyme 
activity obtained in treatments performed in model soil. to obtain four relative enzyme activity indexes.

$$
\begin{aligned}
& \left(\frac{F a-L}{F a}\right)-1 \\
& \left(\frac{F a-L+H C M}{F a+H C M}\right)^{-1} \\
& \left(\frac{F a+H C M}{F a}\right)-1 \\
& \left(\frac{F a-L+H C M}{F a-L}\right)^{-1}
\end{aligned}
$$

Where Eqs. (1) and (2) estimate the effect of Lewia sp. on $F$ anindinacea grown in the absence and presence of the HCM, respectively. Equations (3) and (4) are a measure of the effect of the HCM on $F$. arundinacea grown without or with Lewia sp., respectively.

\section{Statistical analysis}

Treatments were applied in a randomized design with three replicates per analysis, where one EU consisted of 12 plants. A Student's t-test $(\alpha-0.05)$ was used to determine significant differences among inoculated and non-inoculated plants during association induction. Data obtained from assays in the model soil were tested by one-way ANOVA and the means comparison was done using a Tukey-B test $(\alpha-0,05)$. Statistical differences between means are indicated with different letters. Results are expressed as means with their corresponding standard deviation. Analysis was performed using SPSS software, version PASW 18 (IBM SPSS-IBM Corp).

\section{Results}

Plant growth and biochemical responses by induction of endophytic association

It has been demonstrated that some fungi can be established as endophytes in plants by using different methods of inoculation or induction. Endophytic association between $F$. arundinacea and Lewia sp. was established in MS medium, after 15 days of inoculating a suspension of biomass in the roots of 15-day-old plants. The endophytic nature of this association was confirmed by confocal microscopy; we observed fungal hyphac compartmentalized into epidermal root cells (Fig. 1). After 15 days, this particular association significantly enhanced (1.9- and 3.5-fold, respectively) the biomass production of shoots and roots, regarding to endophyte-free plunts (Table 1).

After the period of association induction, increased levels of both $\mathrm{H}_{2} \mathrm{O}_{2}$ (up to 5 -fold) and MDA (up to 3-fold) in roots and shoots of F. arundinacea-Lewia sp. were found compared to control plants (Table 1). The concentration of $\mathrm{CO}$ groups decreased $(\sim 2$ times $)$ in the associated plants compared to those unassociated, while in shoots, association induction did not modify SOD activity, down-regulation ( 1.6 times) was registered in the roots (Table 1). POD activity was found to be $\sim 2$ times higher in roots compared to shoots, particularly in associated plants. Activity in the roots was not significantly modified by the presence of Lewia sp., but the fungus caused a significant decrease (1.5 times) in the shoots. Also, a significant downregulation in GST activity in roots and shoots (7.7

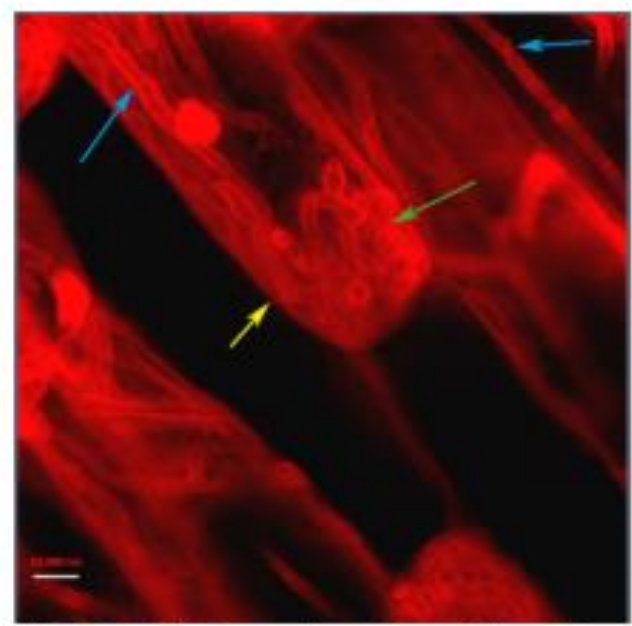

Fie. I Confocal micruscopy image of roots of $F$ anindinuand endophytically associated with $L$ ewia so. afier 15 days of growth in MS medium. Feillow unvw shores cellulose in the cell wall of noos; hiwe arroser show septate hyphac of Lewia sp; grow arrom shows hyphac comparmentalined within cells of the root 
Table 1 Influence of the induction of endophytic association between $F$, arundinacea and Lewia sp. on plant gryath, axidative stress (content of $\mathrm{H}_{2} \mathrm{O}_{2}, \mathrm{MDA}$ and $\mathrm{CO}$ groups), and antioxidant enrymes activity (SOD, POD and GST)*

\begin{tabular}{|c|c|c|c|c|}
\hline \multirow[t]{2}{*}{ Response variable } & \multicolumn{2}{|l|}{ Roots } & \multicolumn{2}{|l|}{ Shoots } \\
\hline & Fa & Fal. & $\mathrm{Fa}$ & Fa-L \\
\hline Growth (mg DW) & $0.96 \pm 0.03^{2}$ & $3.34 \pm 0.12^{b}$ & $7.36 \pm 0.48^{x}$ & $13.87 \pm 0.62^{\mathrm{B}}$ \\
\hline $\mathrm{H}_{2} \mathrm{O}_{2}\left(\mathrm{nmol}_{\mathrm{g}}{ }^{-1} \mathrm{FW}\right)$ & $928 \pm 3.0^{7}$ & $313.8 \pm 13.6^{b}$ & $94.2 \pm 2.9^{4}$ & $466.4 \pm 22.2^{\mathrm{B}}$ \\
\hline MDA (mmol $\mathrm{g}^{-1} \mathrm{FW}$ ) & $11.4 \pm 2.2^{2}$ & $33.9 \pm 0.9^{b}$ & $37.8 \pm 2.8^{4}$ & $46.3=1 . A^{\mathrm{B}}$ \\
\hline $\mathrm{CO}$ (umol g-1 protein) & $461.9 \pm 29^{3}$ & $163.6 \pm 10^{\circ}$ & $349.4 \pm 9^{B}$ & $1932 \pm 11^{4}$ \\
\hline $\operatorname{SOD}\left(\mathrm{U}_{\mathrm{g}}^{-1}\right.$ protain) & $1280 \pm 168^{2}$ & $811 \pm 93^{b}$ & $3990 \pm 271^{4}$ & $3732,0 \pm 572^{\wedge}$ \\
\hline $\operatorname{POD}\left(\mathrm{U}_{\mathrm{g}}^{-1}\right.$ protein) & $1022 \pm 100^{2}$ & $1174 \pm 62^{2}$ & $821=113^{\mathrm{B}}$ & $552.3 \neq 39^{4}$ \\
\hline GST (U $g^{-1}$ protcin) & $84.8 \pm 4.6^{b}$ & $11.0 \pm 1.2^{3}$ & $135.6 \pm 6.25^{\mathrm{b}}$ & $40.2 \pm 3.9^{A}$ \\
\hline
\end{tabular}

-Data with different letter by row indicate significant differences between treatments $(p<0.001$ ). In growth variables, each value is the mean of at least 8 plants. In biochemical parameters, each value cortesponds to the mean of 3 replicates (4 plants per replicate). L.owercase and uppercase indicate independent testing per organ

and 3.4 times, respectively) was registered in response to the endophytic fungus.

Influence of endophytic association in plants exposed to hydrocarbons

\section{Plant growth}

We evaluated the influence of the induced association between Lewia sp. and $F$, anundinacea on plant growth and some biochemical responses during the exposure to a HCM. After 7 days of exposure to the $\mathrm{HCM}$, the fungus significantly stimulated biomass production, particularly in roots (3.8-fold), compared to unassociated plants (Fig. 2).

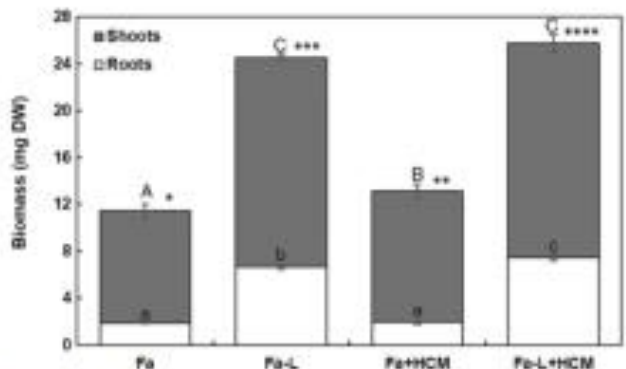

Fig. 2 Biomass production by $F$, arnidinaced $(\mathrm{Fa})$ and E. arusulinacea associated with Levia sp. (Fa-L) exposed or pot to $\$ 00 \mathrm{mg} \mathrm{kg}^{-1}$ of hydrocarbens (HCM) for 7 days in a model soe?. Significant differences are indicaled either with asterisks when compured the botal plant biomass (roots + shoos), or with different letters (lowercase for roots and uppercase for shoots) (P<0.001)
$\mathrm{H}_{2} \mathrm{O}_{2}$ accumulation and oxidative damage

We found a significant increase (1.3-fold) in the $\mathrm{H}_{2} \mathrm{O}_{2}$ content of unassociated roots of $F$. anindinacea by effect of hydrocarbons (Table 2). In contrast, the $\mathrm{H}_{2} \mathrm{O}_{2}$ concentration was not modified in shoots or roots due to exposure to the HCM in associated plants compared to control plants without the $\mathrm{HCM}$. The $\mathrm{H}_{2} \mathrm{O}_{2}$ concentration in the roots of associated plants was lower $(\sim 35 \%)$ that that of unassociated plants, regardless of HCM presence.

MDA in unassociated roots exposed to the HCM was 1.7-fold higher than that recorded in plants grown without the HCM (Table 2). However, the MDA content in the associated roots was not significantly modified by the effect of the HCM compared to the respective control. Regarding the MDA content in shoots exposed to hydrocarbons, a significant reduction ( $53 \%$ ) was registered in associated plants with respect to those unassociated. On the other hand, the concentration of $\mathrm{CO}$ groups in the associated roots exposed to the HCM was significantly lower (2.5-fold) than that in unassociated plants. In contrast, the content of $\mathrm{CO}$ groups in shoots of associated plants significantly increased (3.4fold) in the presence of the HCM compared to unassociated plants (Table 2).

\section{Antioxidant erzyme activity}

SOD and POD activity was stimulated in the roots of associated plants regardless of exposure to the HCM 
Table 2 Biochemical parameters quantified as a measure of oxidative stress in roots and shoots of $F$. arumdinacea (Fa) and endophytic association $F$ anundinacea-Lewia sp. (Fa-L) grown

\begin{tabular}{|c|c|c|c|c|c|c|}
\hline \multirow[t]{2}{*}{ Treatment } & \multicolumn{3}{|l|}{ Roots } & \multicolumn{3}{|l|}{ Shoots } \\
\hline & $\begin{array}{l}\mathrm{H}_{2} \mathrm{O}_{2}\left(\mathrm{nmol} \mathrm{g}^{-1}\right. \\
\mathrm{FW})\end{array}$ & $\begin{array}{l}\mathrm{MDA}\left(\mathrm{nmol} \mathrm{g}^{-1}\right. \\
\mathrm{FW})\end{array}$ & $\begin{array}{l}\mathrm{CO} \text { (umol g-1 } \\
\text { protein) }\end{array}$ & $\begin{array}{l}\mathrm{H}_{2} \mathrm{O}_{2}\left(\mathrm{nmol} \mathrm{g}^{-1}\right. \\
\mathrm{FW})\end{array}$ & $\begin{array}{l}\text { MDA }\left(\mathrm{nmol} \mathrm{g}^{-1}\right. \\
\text { FW) }\end{array}$ & $\begin{array}{l}\mathrm{CO} \text { (umol } \mathrm{g}^{-1} \\
\text { protein) }\end{array}$ \\
\hline $\mathrm{Fa}$ & $450.1 \pm 49.7^{a b}$ & $28.1 \pm 0.3^{b}$ & $157.2=6.8^{2}$ & $480.9 \pm 38.8^{\mathrm{s}}$ & $53.1=3.1^{\mathrm{BC}}$ & $3 y 0.3 \pm 1.1^{c}$ \\
\hline Fa-L & $427.4 \pm 24.7^{a b}$ & $28.3 \pm 0.2^{b}$ & $196.0 \pm 2.4^{2}$ & $308.5 \pm 28.1^{\wedge}$ & $58.2 \pm 10.0^{\mathrm{B}}$ & $265.3 \pm 10.0^{\mathrm{s}}$ \\
\hline $\mathrm{Fa}+\mathrm{HCM}$ & $583.1 \pm 52.3^{c}$ & $48.6 \pm 1 . A^{c}$ & $909.5=21.2^{c}$ & $489.2 \pm 12.3^{\mathrm{b}}$ & $58.6 \pm 2.4^{\mathrm{b}}$ & $167.2 \pm 22.0^{\mathrm{x}}$ \\
\hline $\begin{array}{l}\mathrm{Fa}-\mathrm{L}+ \\
\mathrm{HCM}\end{array}$ & $377.6 \pm 17.4^{a}$ & $25.4 \pm 0.9^{a}$ & $368.1 \pm 14.5^{b}$ & $338.6 \pm 37.5^{\wedge}$ & $27.5 \pm 2.0^{4}$ & $573.3 \pm 13.2^{\mathrm{D}}$ \\
\hline
\end{tabular}

-Data with different letter by column indicate significant differences between treatments $(p<0.001)$. Fach value corresponds to the mean of

3 replicates ( 4 plants per replicate). Lowerease and uppercase indicale independent testing per organ

(Figs. 3 and 4). In the presence of hydrocarbons, the SOD activity in unassociated roots was lower (5.6-fold) than that registered in associated plants (Figs. 3a and 4a). In shoots, SOD activity decreased by effect of the HCM in both unassociated $(50 \%)$ and associated (60\%) plants compared to plants grown without the HCM. In general, GST activity was higher in shoots than in roots of endophyte-free plants (Figs. $3 \mathrm{c}$ and $4 \mathrm{c}$ ). This activity was strongly down-regulated in shoots and roots of associated plants, while in the roots of unassociated plants, GST activity was stimulated $(63 \%)$ in the presence of the HCM; in associated plants it was significantly reduced $(61 \%)$.

\section{Discussion}

Plant growth and biochemical responses by induction of endophytic association

A successful plant-endophyte association requires the colonization of plant cells by the endophyte, which occurs through the physical penetration of hyphae into the cells of the plant host. Similar to our findings, two unknown ascomycetous endophytes were observed compartmentalized into the root cells of Triticum turgidum (Abdellatif et al. 2009). Colonization of the host cells by the endophyte causes modifications that can improve plant growth through mechanisms such as regulation of the production and activity of plant hormones, morphological changes, and increased nutrient capture and solubilization (Mei and Flinn 2010). In fact, enhanced plant growth by endophytes in various plant species has been demonstrated (Bailey et al. 2006). Another way that endophytes can contribute to enhance plant growth is the overproduction and control of ROS such as $\mathrm{H}_{2} \mathrm{O}_{2}$ (White and Torres 2010), which operates as a signaling molecule for growth (Cheeseman 2006).

Thus, the improved growth in plants of F. anundinacea after 15 days of inoculation with Lewia sp. could be attributed to biochemical changes such as increased $\mathrm{H}_{2} \mathrm{O}_{2}$ production. A similar response was registered during the early stages of the symbiosis between Gigaspora margarita and two legumes (Lanfranco et al. 2005), and between Pisolithus tinctorius and Castanea sativa (Baptista et al. 2007). Furthermore, CAT appears to be down-regulated and SOD to be up-regulated during these early stages. This could explain the $\mathrm{H}_{2} \mathrm{O}_{2}$ accumulation, since SOD catalyzes the conversion of $\mathrm{O}_{2}^{-}$to $\mathrm{H}_{2} \mathrm{O}_{2}$, which is then converted to water by CAT and POD (Nanda et al. 2010). The oxidative burst during early stages of symbiotic interactions suggests a key role in the control of the fungus proliferation (Nanda et al. 2010), which could be related to the suppression of plant defense responses against the fungus (Tanaka et al. 2006). This ROS overproduction can also lead to lipid peroxidation and protein oxidation. In fact, the enhanced MDA concentration in tissues of $F$. arundinacea by effect of Lewia sp. indicates that the oxidative burst led to increased lipid peroxidation. In contrast, the decreased level of $\mathrm{CO}$ groups in the associated plants might be explained by the proteolysis of irreparable proteins via lysosome or the ubiquitin-proteasome pathway (Tiwari et al. 2016); one or both of these processes could be improved due to the presence of Lewia sp. 

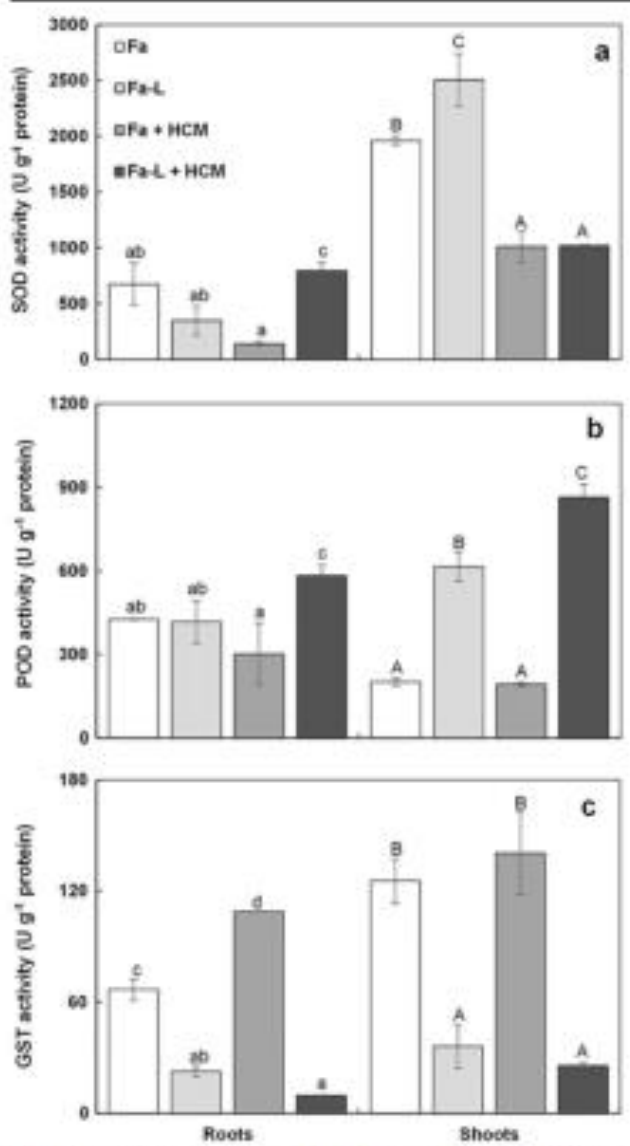

Fig. 3 SOD (a), POD (b) and GST (c) activity in roots and shoots of plants of $F$ arnuminacene grown for 7 drys unassociated (Fa) or associated with Lewria $\$$. ( $\mathrm{Fa}-\mathrm{L}$ ) in a model soil containing $800 \mathrm{mg} \mathrm{kg}^{-1}$ of a hydracarbon mixture (HCM). Different letters indicate significant differences $(P<0.001)$

The significant decrease in SOD activity in roots of $F$. arundinacea after association induction suggests a suppression of the antioxidant defense to form the association (Bailey et al. 2006) with Lewia sp., since roots are the first contact between the organisms. In contrast, the significant down-regulation of POD activity in the shoots by effect of Lewia sp. could be attributed to $\mathrm{H}_{2} \mathrm{O}_{2}$ degradation by catalases (Mhamdi et al. 2010). Meanwhile, plant GST are multifunctional proteins that selectively bind GSH and have key roles in plant development and response to stress conditions (Kumar et al.
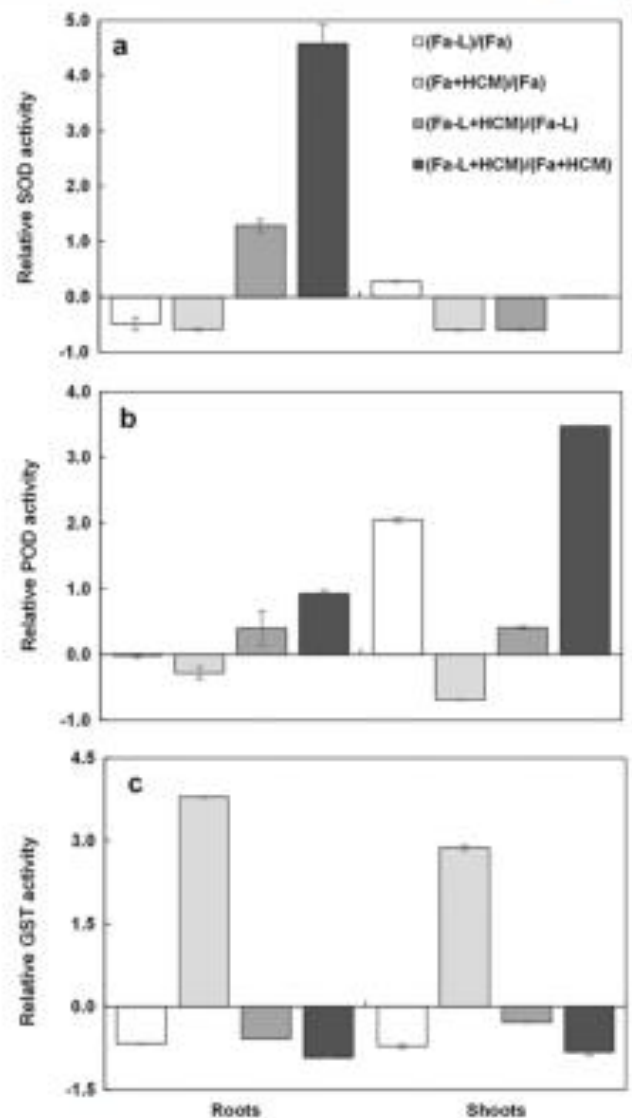

Fig. 4 Relative encyme activity indexes of SOD (a), POD (b) and GST (c) in roots and shoots of plants of $F$. anindinarar gown for 7 days unassociated (Fa) or associated with Levia sp. (Fa-L) in a model soil containing a hydrocarbos mixture (HCM)

2013). Besides their function in the detoxification of xenobiotics and natural products, GST also catalyze GSH-dependent peroxidase reactions that scavenge organic hydroperoxides and protect against oxidative damage. In fact, ROS intermediates are known to be important regulators of GST gene expression (Moons 2005). Expression analysis of the Lambda class GST (particularly sensitive to redox perturbations) gene family in rice suggested that different members of this family are differently expressed during plant growth and development, during biotic and abiotic stress, as well as in response to plant hormones. The gene expression was also found to be dependent on the tolerance 
and susceptibility of seedlings to a hemiparasite fungus (Kumar et al, 2013). It has been found that endophytes can modify the activity of GST (Zhang et al. 2010). which could be a result of changes in intracellular concentrations of plant hormones and/or ROS. The downregulation of GST activity in roots and shoots of $F$ arundinacea in response to the endophytic fungus suggests that this enzyme could be repressed during the establishment and maintenance of this particular association. In contrast, increased GST activity was found in plants of Theobroma cacao endophytically associated with Trichoderma hamatum (Bailey et al, 2000).

This series of results suggests that in order to establish the association with $F$, arundinacea, Lewia sp. promotes increased ROS production, besides a reduction in the activity of enzymes involved in antioxidant defense, at least under in vitro conditions. Several biochemical factors, besides ROS production and the antioxidant system, are involved in stress signaling (Baxter et al. 2013) and can facilitate plant-endophyte interaction at a biochemical level (Tanaka et al, 2006). Indeed, it has been reported that biochemical changes due to the formation of an association can contribute to greater tolerance and growth in plants exposed to stressors such as PAH (Debiane et al. 2009), heavy metals (Ahmad et al. 2011) and drought (Tiwari et al. 2016).

Influence of the endophytic association in plants exposed to hydrocarbons

Plant growth

Endophytic microorganisms can enhance plant growth and the antioxidant system response in plants exposed to several stressors (Soleimani et al. 2010). Our results confirm that the endophytic association between F anendinacea and Lewia sp. stimulates plant growth even under the abiotic stress generated by the HCM. Plant biomass is a response variable usually used as an indicator of growth performance in plants exposed to xenobiotics such as PAH (Soleimani et al. 2010). Increased biomass production was also registered in plants of $F$. arundinacea exposed to hydrocarbons when grown in the presence of the endophytes Neatyphodium coenophialum (Soleimani et al. 2010) and Lewia sp. (Cruz-Hemández et al. 2013). Endophytic fungi may increase the growth of grasses through mechanisms such as the production of plant hormones and morphological changes, as well as by enhanoed solubilization and uptake of nutrients (Porras-Alfaro and Bayman 2011).

\section{$\mathrm{H}_{2} \mathrm{O}_{2}$ accumulation and oxidative damage}

An increased level of $\mathrm{H}_{2} \mathrm{O}_{2}$ is a common response in plants grown under abiotic stress conditions such as the presence of PAH, such as phenanthrene (Alkio et al. 2005; Kreslavski et al. 2014). The fact that the HCM caused an increased $\mathrm{H}_{2} \mathrm{O}_{2}$ content in the roots of unassociated plants, while its content was reduced by effect of the fungus, indicates that Lewia sp. bas a role in ROS control when a stressor such as the HCM is present. Similar to our results, a reduction $(10 \%)$ in the $\mathrm{H}_{2} \mathrm{O}_{2}$, concentration in plants of $F$ arundinucea associated with Epichloë coenophiala exposed to nickel (180 mg $\mathrm{kg}^{-t}$ ) was registered compared to the level in endophyte-free plants (Mirzahosseini et al. 2015).

If $\mathrm{H}_{2} \mathrm{O}_{2}$ is not controlled, it can be transformed into the hydroxyl radical and oxidize proteins and unsaturated membrane phospholipids, leading to increased content of $\mathrm{CO}$ groups and MDA, respectively (Kreslavski et al. 2014; Hu et al. 2015). However, it has been shown that both mycorthizal (Debiane et al. 2009) and endophytic fungi (Mirzahosscini et al. 2014, 2015), can alleviate the oxidative damage produced by ROS aceumulation in cells of plants such as $F$. arundinacea. In fact, we registered an increased MDA coatent, particularly in the roots of plants exposed to the HCM, which was significantly reduced in both shoots and roots by effect of Levia sp. This response might be the result of decreased lipid peroxidation due to an increase in POD activity by effect of Lewia sp. Peroxidases are enzymes responsible for degrading lipid hydroperoxides, by utilizing GSH and/or other reducing equivalents, thus preventing their accumulation (Pryor and Castle 1984). Another consequence of the ROS overproduction generated by abiotic stress is protein oxidation (Cvjetko et al. 2010). However, in the roots of $F$ arundinacea exposed to the HCM, the concentration of oxidized proteins was significantly reduced in the presence of Levia sp. It has been demonstrated that tolerant organisms are able to increase the activity of antioxidant enzymes in order to alleviate or attenuate ROS overproduction by the accumulation of hydrocarbons (Balasubramanlyam et al. 2015), which could result in decreased concentrations of the two oxidative stress markers here studied. 
Antioxidant enzyme activity

Down-regulated SOD and POD activity has been observed in plants of Arabidopsis thatiana (Liu ct al, 2009) and Triticum aestivum (Tomar and Jajoo 2015) during exposure to PAH. This decrease was related to increased ROS production that exceeded the plant antioxidant capacity (Cvjetko et al. 2010). The down-regulation of SOD activity in shoots and roots of unassociated plants of $F$ anindinacera could be considered as indirect evidence of the increased accumulation of ${ }^{\mathrm{O}_{2}}-$ in response to the HCM (Debiane et al. 2008). Compared with controls, the higher SOD activity in the roots of associated plants indicates that Lewia sp. helps to control the $\mathrm{O}_{2}^{-}$concentration in the presence of hydrocarbons. Various studies have shown that the activity of antioxidant enzymes such as SOD is commonly higher in plants exposed to pollutants when they are associated with endophytes (Becerra-Castro et al. 2013).

The up-regulation in POD activity, particularly in shoots of associated plants regardless of the HCM presence (Figs. 3b and 4b), indicates that Lewia sp. plays a role in stimulating the plant oxidative defense by controlling the $\mathrm{H}_{2} \mathrm{O}_{2}$ level. Indeed, a reduced $\mathrm{H}_{2} \mathrm{O}_{2}$ concentration was registered in the associated plants, particularly in those exposed to hydrocarbons (Table 2). Furthemore, in these same plants, a decreased content of MDA was also registered (Table 2). Peroxidases reduce hydroperoxides to the corresponding alcohol, thus preventing the accumulation $\mathrm{H}_{2} \mathrm{O}_{2}$ and lipid hydroperoxides (Pryor and Custle 1984). In fact, it was found that POD activity plays a role in the growth of $F$ anendinacea through the modification of functions such as the control of senescence hormone production (Kawaoka et al 2003). The up-regulation of SOD and POD in the associated roots of $F$ arnendinacea grown with the HCM suggests that Lewia sp. improves the control of ROS overproduction induced by the presence of the HCM. These results are confimed by the fact that the content of MDA and $C O$ was significantly reduced by the effect of Lewia sp. The above facts could consequently contribute to the enhanced plant growth registered.

Otherwise, the down-regulation in GST activity in associated plants of $F$, anindinacea exposed to the HCM could be attributed to changes in the plant hormone levels by effect of Lewia sp, since it has been shown that the activity of this enzyme is modulated by these compounds (Kumar et al. 2013). This fact may also contribute to the improved plant growth registered in associated plants. Until now, most studies related to GST in plants have focused on responses to the presence of heavy metals (Mirzahosscini et al. 2014; Rojas-Lona et al. 2014). Similar to our results, GST activity was enhanced in shoots of $F$ anudinacea exposed to low concentrations ( $30 \mathrm{mg} \mathrm{kg}^{-1}$ ) of nickel. However, $\mathrm{re}$ duced activity was recorded in plants associated with Neotyphodium coenophialum (Mirzahosseini et al. 2014).

Relative enzyme activity (Fig 4) helps to clearly distinguish the effect of either hydrocarbons or the fungus in the plant SOD, POD, and GST activity. The down-regulation of SOD and POD activity and upregulation of GST by effect of the HCM in unassociated plants of $F$ arundinacea suggest that plant GST are related to hydrocarbon detoxification, while SOD and POD appear not to be involved in such a process. On the contrary, in the associated plants exposed to the HCM, the up-regulation of SOD and POD activity, particularly in roots, indicates the involvement of both enzymes in improving the plant defense system against ROS accumulation under hydrocarbon stress, which was stimulated by Lewia sp. Meanwhile, the down-regulation of GST activity by influence of Lewia sp., even in the presence of hydrocarbons, suggests that these enzymes could be related to maintenance of the endophytic association. These results demonstrate that the plant's defense mechanisms against the adverse effect of hydrocarbons are influenced by the endophytic association with Lewia sp.

\section{Conclusions}

To our knowledge, this is the first study analyzing the influence of the endophytic association between $F$ arum dinocea and Lewia sp. on oxidative stress and antioxidant response in the presence of a HCM. The endophytic association between the organisms could be established affer 15 days under in vitro conditions, and Lewia sp. significantly impooved plant growth. Establishment of the association caused a significant increase in the production of $\mathrm{H}_{2} \mathrm{O}_{2}$ and lipid peroxides as well as a reduction of oxidized proteins and GST activity. After 7 days of exposure to hydrocarbons in a model soil, Lewia sp. improved plant growth by controlling the content of $\mathrm{H}_{2} \mathrm{O}_{2}$ and MDA. which was in turn related to an increase in antioxidant enryme activity. This study demonstrates the positive role 
of Lewia sp. in promoting growth and alleviating oxidative stress in $E$ anumdinacea exposed to a HCM. Although more research is still required to examine the relationship between the detoxification and degradation of hydrocarbons by this specific endophytic association. it could potentially be used in remediation of hydrocarbonscontaminated soils.

Acknewledgments. This work was partially supported by Conscjo Nacional de Ciencia y Teconologia (CONACyT), Mexico. The authors ackaowledge Dr. David M. Dazz-Pontones for the support in confocal microscopy analysis. C. Mendarte-Alquisina thanks CONACyT for the financial sumpont (grant number 15330).

\section{Compliance with ethical standards}

Conflict of interest The authors declare no conflict of interest

\section{References}

Abdellatif L, Bouzid S, Kaminskyj S, Vujanovic V (2009) Endophytic hyphal conpartmentaliontion is required for suecessful symbiotic Ascomycota association with root cells. Mycol Res 113:782-791

Ahmad P, Nabi G, Ashraf M (2011) Cadnium-induced oxidative dumage in mustard [Bruscicu junceu (L.) Cnem. \& Coss.] plants can be alleviated by salicylic acid. S Afr J Bot 77:3644

Alkio M, Tabuchi TM. Wang X, Col n-Camona A (2005) Stress responses to polycyclic aromatic hydrocarbons in Arabidoper inclade gromth inhibition and hypersensitive response-like synuptoms. J Exp Bot 56-2983-2994

Bailey BA, Bac H. Stran MD, Roberts DP. Thomas SE, Crorier I. Samuels GJ, Choi I-Y, Holmes KA (2006) Fungal and plant gene expression during the colanization of cacae seedlingts by endophytic isolates of four Trichoderma species. Planta 224:1449-1464

Balasubramanlyam $A$, Chapman MM, Harvey JP (2015) Responses of tall fescue (Festuca anmedinacea) to growth in maphthalene-contaminated sand: xenobiotic stress versess water stress. Ensinun Sci Pollat Res 22:7495-7507

Baptista P, Martins A, Pais MS, Tavares RM, Lino-Neto T (2007) Involvaraent of reactive oxygen species during early stages of ecionsycothizal establishment between Cosfancer sativu and Pisolithus tictorius. Myoornhina 17:185-193

Baxter A, Mittler R, Sunuki N (2013) ROS as key players in plant stress signaling J Exp Bot. dock10.1093 J bx/ert375

Becerra-Castro C, Pricto-Fernindez A. Kidd SP, Weyens N, Rodrigruez-Giarrido B. Touceda-Gonzilez M, Acea MJ, Vangronsveld J (2013) Improwing performunce of Cyfisus striatus on substrates contaminated with hexachlorocyclebexane (HCH) iscmers using bacterial inoculants: developing a pbyzotemediation strategy. Plant Soil 362:247-260
Buege JA. Aust SD (1978) Microsomal lipid peroxidation. Methods Enyymol 52:302-310

Chance B, Machly AC (1955) Assay of catalases and peroxidases. Methods Enzymol 2:764-775

Chesseman JM (2006) Hydrugen peroxide concentration in leaves under natural conditions. J Exp Bot 57:2435-2444

Cruz-Herninder A. Tomasini-Campocosis A. Pérez-Fleres U, Fernàndez-Perrino F). Gutiérrez-Rojas M (2013) Inoculation of seed-bome fungus in the rhizosphere of Fectuca anundimorex promoles bydrocarbon removal and pyrene accumulation in roots. Plant Soil 362-261-270

Cvjetko P, Tolic S, Sikic S, Balen B, Tkalex M, VidakoviC-Cifruk: 之. Pavlica M (2010) Effect of eopper on the toxicity and genotosicity of cadmium in duckweed (Lamna minor L.). Arth Hig Rads Toksikol 61:287-296

Debiane D, Garçon G. Verdin A. Fontaine J, Durand R. Grandmougin-Feriani A. Shirali P. Sahraoui ALH (2008) In vitm evaluation of the oxidative stress and genotoric potentials of anthracene on mycornhizal chicory roots. Envirsen Exp Bot 64:120-127

Debiane D, Garçon G, Veruin A, Fontaine J, Durand R, Shirali P. Grandmougin-Ferjani A, Sahraoti AL-H (2009) Myourhization alleviates benmo[a]pvrene-induced oxidative stress in an in vion chicory noot model. Phytochemistry 70 1421-1427

Habig WH, Jakuby WB (198I) Assays for defferentiation of glutathione S-transferases. In: Jacoby WB (ed) Method Enzymal 77: 398-405

Ha Z, Xe Y, Jin G, Fu J, LiH (2015) Growth responses of two tall fescue cultivars to $\mathrm{Pb}$ stress and their metal accumulation characteristics. Econoxicology 24:563-572

Jusnzauk IM. Tybura A. Rychter AM (2008) Protein oxidation in leaves and roots of cucumber plants (Cincumis sutives L) mutant MSCI6 and wild type. J Plant Physiol 165:355-365

Kawaoka A. Matsunaza E, Endo S. Kondo S, Yoshida K. Shinmyo A. Fbinuma H (2003) Ectopic expression of a borseradish percoxidase enhunces growth rate and increases oxidative stress resistance in hybrid aspen. Plant Physiol 132 $1177-1185$

Khalmuratova L, Kim H, Nam Y.J, Oh Y, Jeong M.J, Choi H.R. You Y-H, Choo Y-S, Lee 1-J, Shin J-H, Yoon H, Kim J-C (2015) Diversity and plant growth pronsoting capacity of endophlytic fungi associated with halophytic plants from the west coust of Korca. Mycobiology 43:373-383

Kreslavski VD, Lankin AV. Vasilyeva GK, Luybimor VY, Semenova GN, Schmitt F-J, Friedrich I, Allaktherdiev Si (2014) Effects of polyarounatic bydrocarbons on photosystem II activity in pea leaves. Plant Physiol Biochem 81:135-142

Kumar S, Hasen AM. Chknabrty D, Deo TR, Shanker DR, Kumur TP (2013) Differcatial expression of rice Lambda class GST gene family mambers during plant guouth, develeyment, and response to stress conditions. Plint Mol Bool Report 31:569-580

Kvesitadne E, Sadunishvili T, Kvesitadre GK (2009) Mechanisms of orranic contaminants uptake and degradation in plants. World Acad Sci Eing Tectunol 55:458-468

Lanfranco L. Novero M, Bonfante P (2005) The mycorrhizal funges Gigospeva margariala pessesses a CuZn superoxide dismutase that is up-regulated during symbiosis with legume bost. Plant Physiol 137:1319-1330

Lia H, Weisman D, Ye Y, Cui B, Huang Y, Colón-Carmona A, Wang $\mathbf{Z}(2009)$ An oxidative stress respense to polycyclic 
aromatic hydrocarbon exposure is rapid and complex in Anathidogsis thadiuma. Plant Sci 176:375-382

Lowry OH, Rosebrhough NJ, Farr AL, Randall RJ (1951) Protein measurement with the Folin phenol reagent. I Biol Chem 193:265-273

Mei C, Flinn BS (2010) The use of beneficial mictobial endophytes for plamt biomuss and stress tolerance improvernent. Recent Pat Biotechnol 4-81-95

Mhamdi A, Queval G, Chaouch S, Vanderatrwera S, Van Breusegem F, Noctor G $(2010)$ Cataleve function in plants: a focus on .Arabilopsis mutants as stress-mimic models. I Exp Bot 61:4197-4220

Mirzahosseini Z Stubani L. Sabzalian MR. Sharifi-Tehrani M (2014) Neonphoutium endophytes may increase tolerance to Ni in tall fescue. Eur J Soil Biol 63:33-40

Mirzahosseini Z Shabani L. Sabralian MR. Sharifi-Tehrani M. 2015) ABC transporter and metallothioncin expressicen affected by NI and Ejxichloc endophyte infection in tall fescue. Ecotoxicol Environ Saf 120:13-19

Moons A (2005) Regulatory and functional interactions of plant growth regulators and plant glutathione S-transferases (GSTs). Vitam Houm 72:155-202

Murashize T, Sloovg F (1962) A revisod medium for rapid erouth and bioassays with tobacco tissue cultures. Physiol Plant 15 : 473-497

Nanda AK, Andrio E. Marino D, Parly N, Dumand C (2010) Reactive oxygen species during plant-microorganism early interactions. I Integr Phant Biol 52-195-204

Porras-Alfaro A. Bayman P (2011) Hidden fungi emergent properties: endophyies and microbiones. Annu Rev Phytopatbol 49:291-315
Pryor WA. Castle L (1984) Chemical mathods for the detection of lipid hydroperoxides, Methods Enrymol 105:293-299

Rojas-Loria CC, Favela-Torres E, Gonzallez-Marquez H, VolikeSepuilveda TL (2014) Rok of ghutathione and glunthione Sransferase in lead wlerance and biococumulation by Dedenas viecasa (L.) Jacy Acta Ptysial Plart 16x2501-2510

Shahrtash M (2013) Punt ghatrthione S-unnsferase function during emvinumental stresses a revicw atticle Roan J Biol 58:19-25

Solcimuni M, Afyuni M, Hajabbasi MAA, Nourbakhsh F. Sabzalian MR. Christensen JH (2010) Phyzoremediation of an aged petroleum contaminated soel using endophyte infected and non-infected grasses. Chemsosphere 81:1084-1090

Tanaka A. Christensen MJ. Takemsoto D. Park P. Scott B (2006) Reactive oxygen species play a role in regulating a fungusperennial ryegrass mutualistic interaction. Plant Cell 18 $1052-1066$

Trwari S, Lata C. Singh CP. Shedhar NC (2016) Psendomomas putitia attunes norpboptysiological, biochemical and molocular responses in Cicer aridinum L. during druaptu stress and recovery. Pant Physiol Biochem 99:108-117

Tomar RS, Jajoo A (2015) Photemodified fluoramthene exerts more harmful effects as compared to intact fluoranthene by inhibiting growth and photosynthetic processes in wheat. Ecotoxical Environ Saf 122-31-36

While JF Jr, Torres SM (2010) Ls plant endophyte-mediatad defensive mutualisin the result of oxidative stress protection? Physiol Plant 138:440-446

Thang X. Fan X, Li C, Nan Z (2010) Effects of cadmium stress and seed sermination, secdling growth and antioxidative enrymes in Adthatherum iashrians plants infected with a Neatypivadiran endophlytc. Plant Cinowth Regul 60-91-97 
ANEXO III 
PARTICIPACIONES

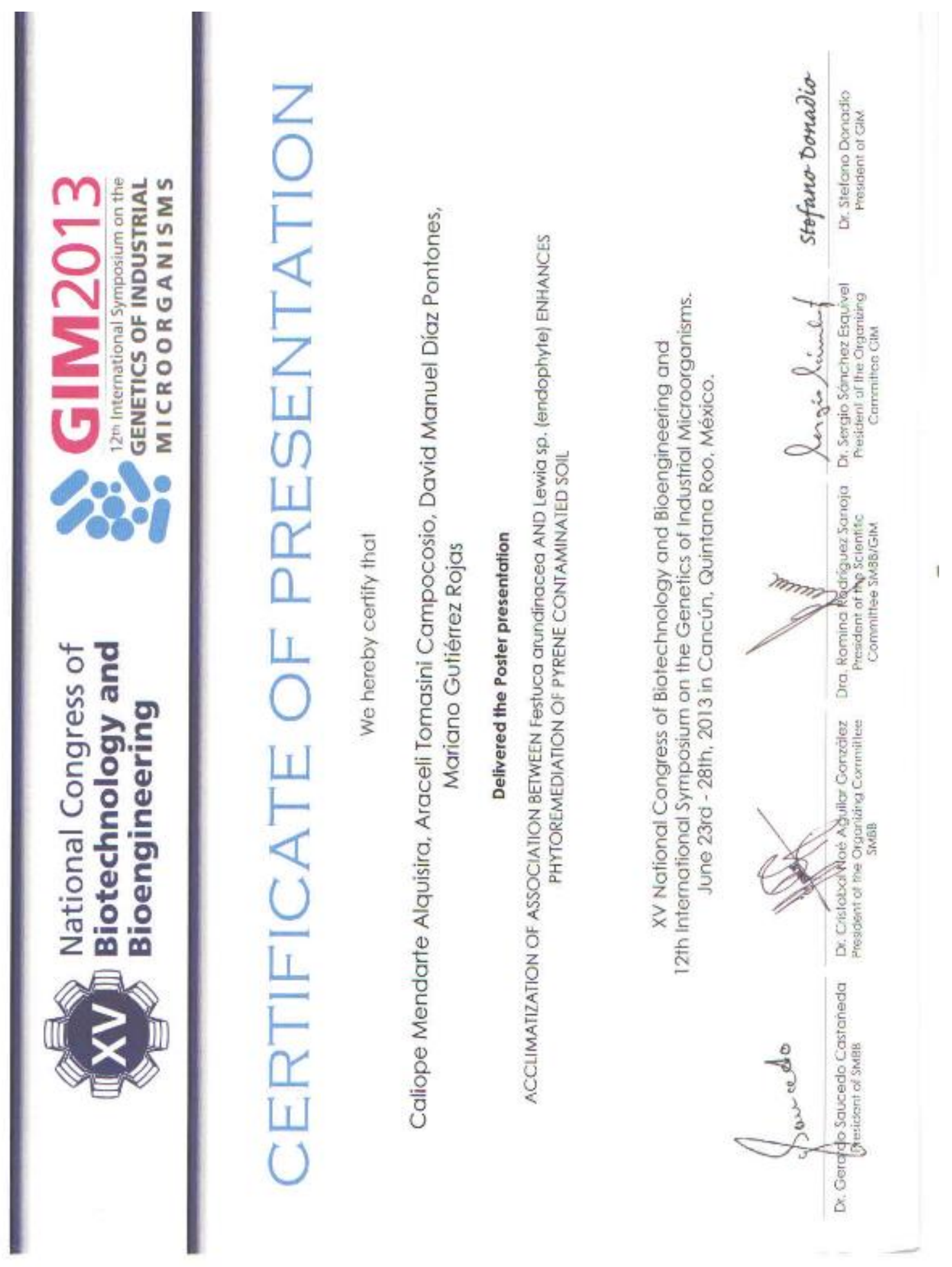



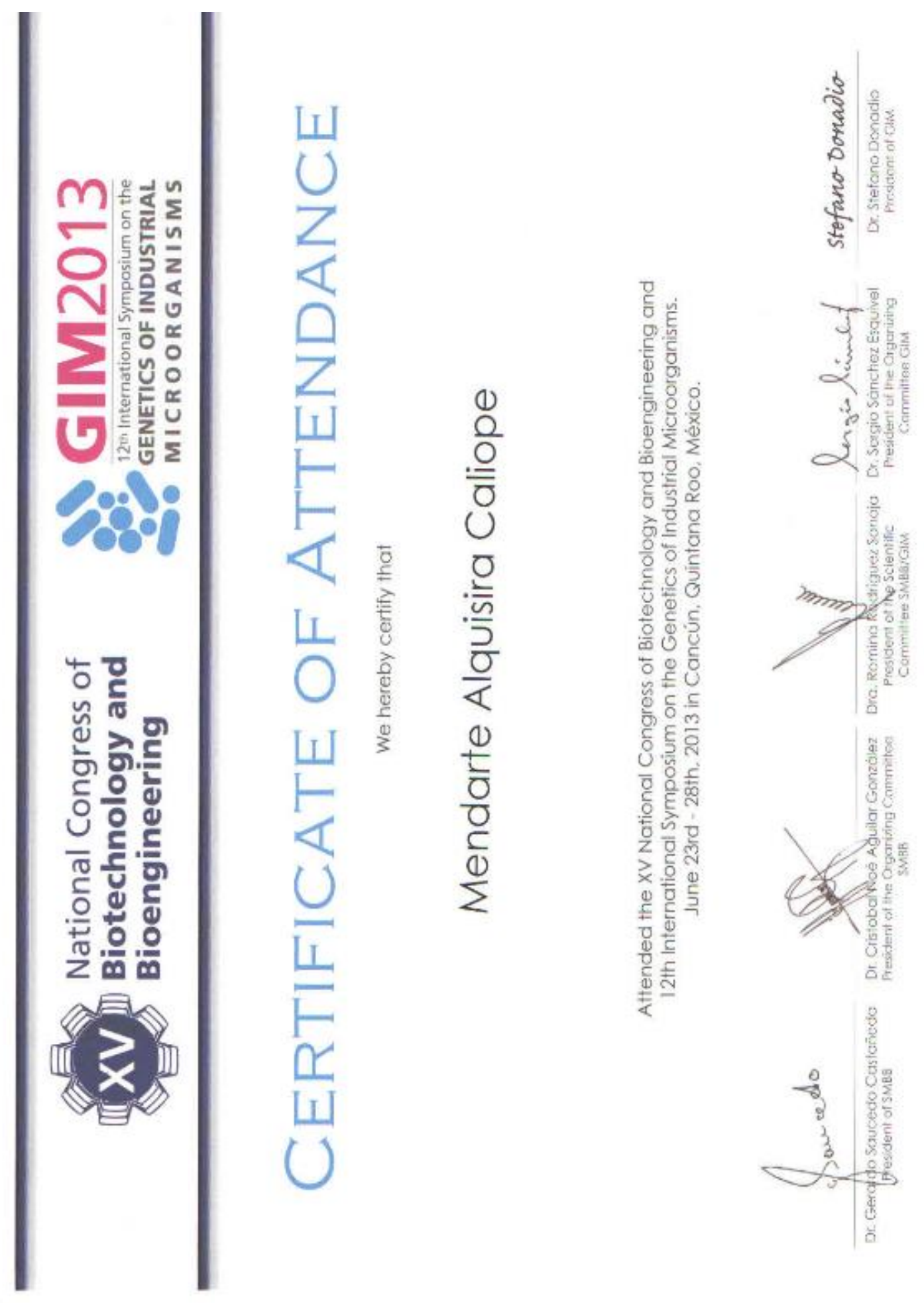


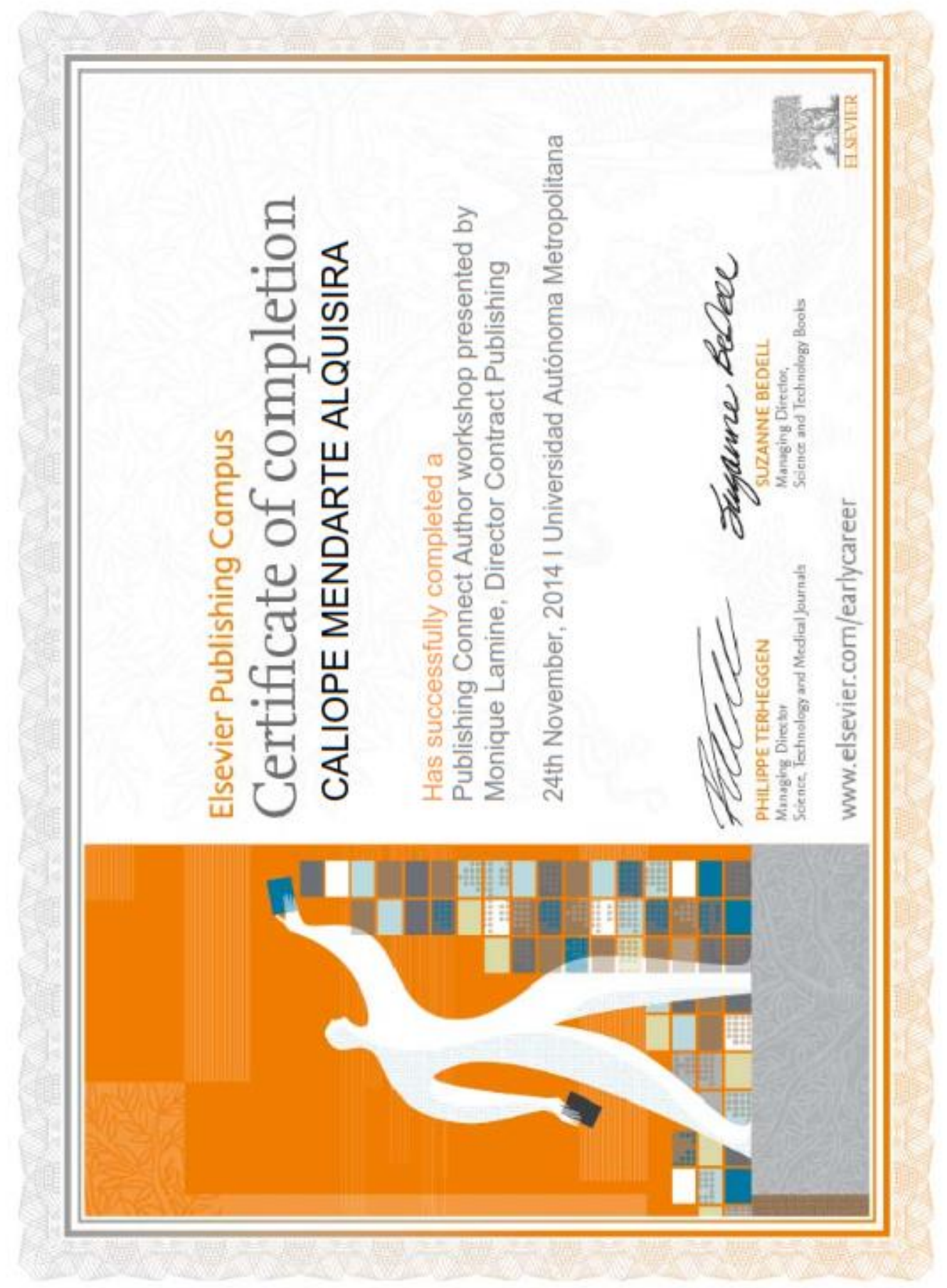




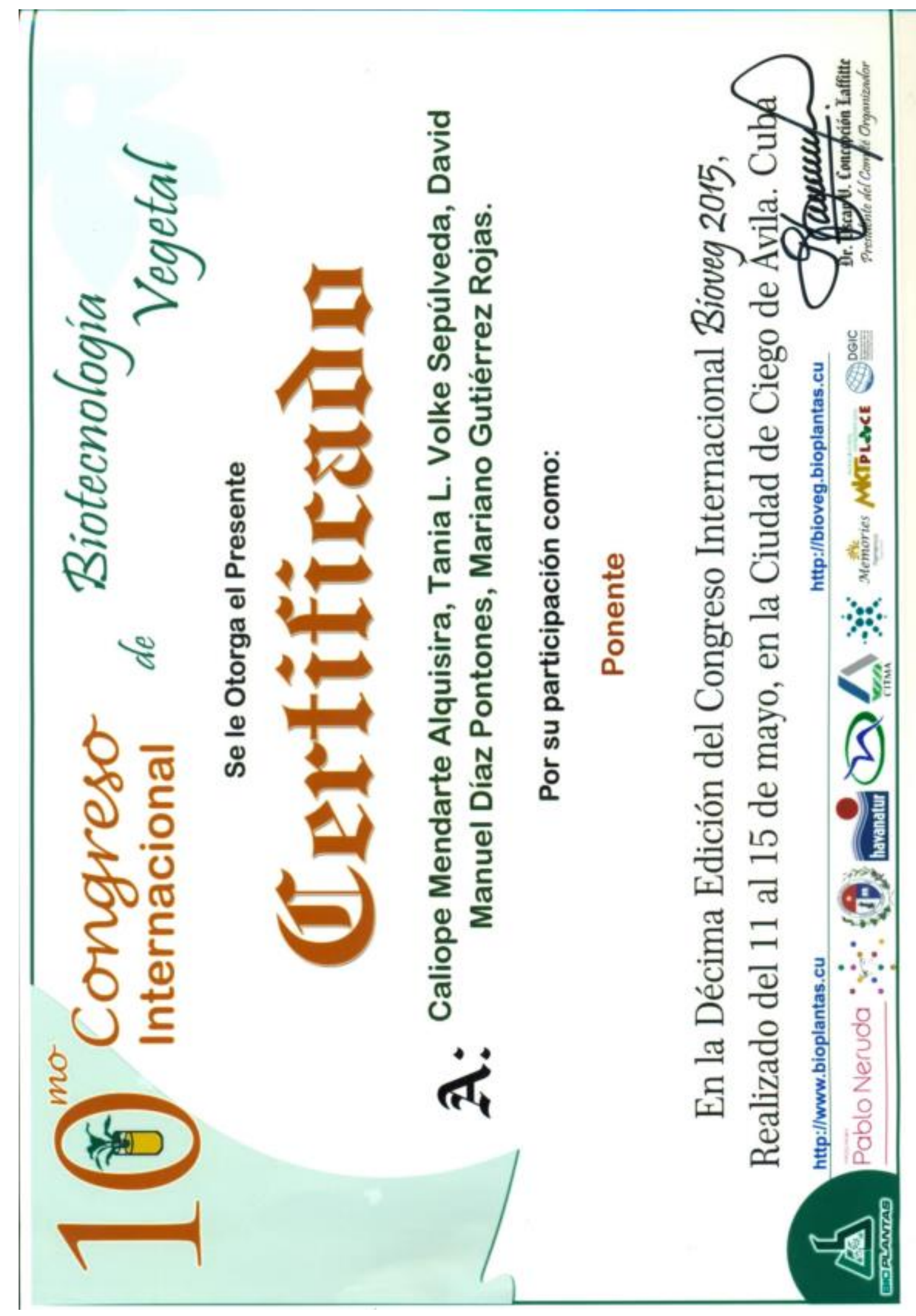



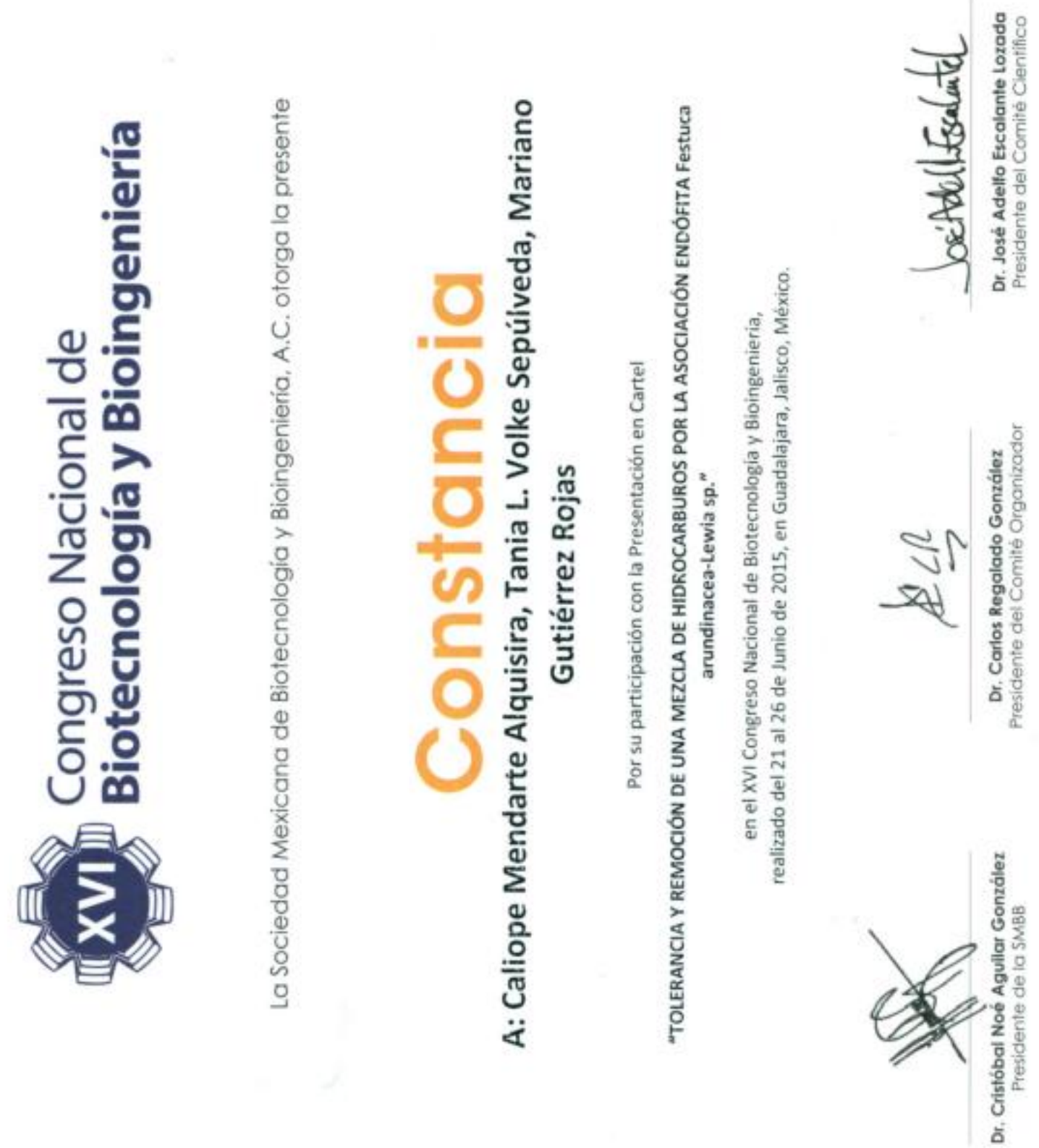